Portland State University

PDXScholar

1996

\title{
Characteristics of Administrators' Leadership Style in Quality Child Care Centers
}

Katherine Ann Bobula

Portland State University

Follow this and additional works at: https://pdxscholar.library.pdx.edu/open_access_etds

Part of the Urban Studies and Planning Commons

Let us know how access to this document benefits you.

\section{Recommended Citation}

Bobula, Katherine Ann, "Characteristics of Administrators' Leadership Style in Quality Child Care Centers" (1996). Dissertations and Theses. Paper 1327.

https://doi.org/10.15760/etd.1326

This Dissertation is brought to you for free and open access. It has been accepted for inclusion in Dissertations and Theses by an authorized administrator of PDXScholar. Please contact us if we can make this document more accessible: pdxscholar@pdx.edu. 
CHARACTERISTICS OF ADMINISTRATORS' LEADERSHIP STYLE

IN QUALITY CHILD CARE CENTERS

by

KATHERINE ANN BOBULA

A dissertation submitted in partial fulfillment of the requirements for the degree of

DOCTOR OF PHILOSOPHY

in

URBAN STUDIES

Portland State University

1996 
DISSERTATION APPROVAL

The abstract and dissertation of Katherine Ann Bobula for the Doctor of Philosophy in Urban Studies were presented May 8, 1996 and accepted by the dissertation committee and the doctoral program.

APPROVALS:
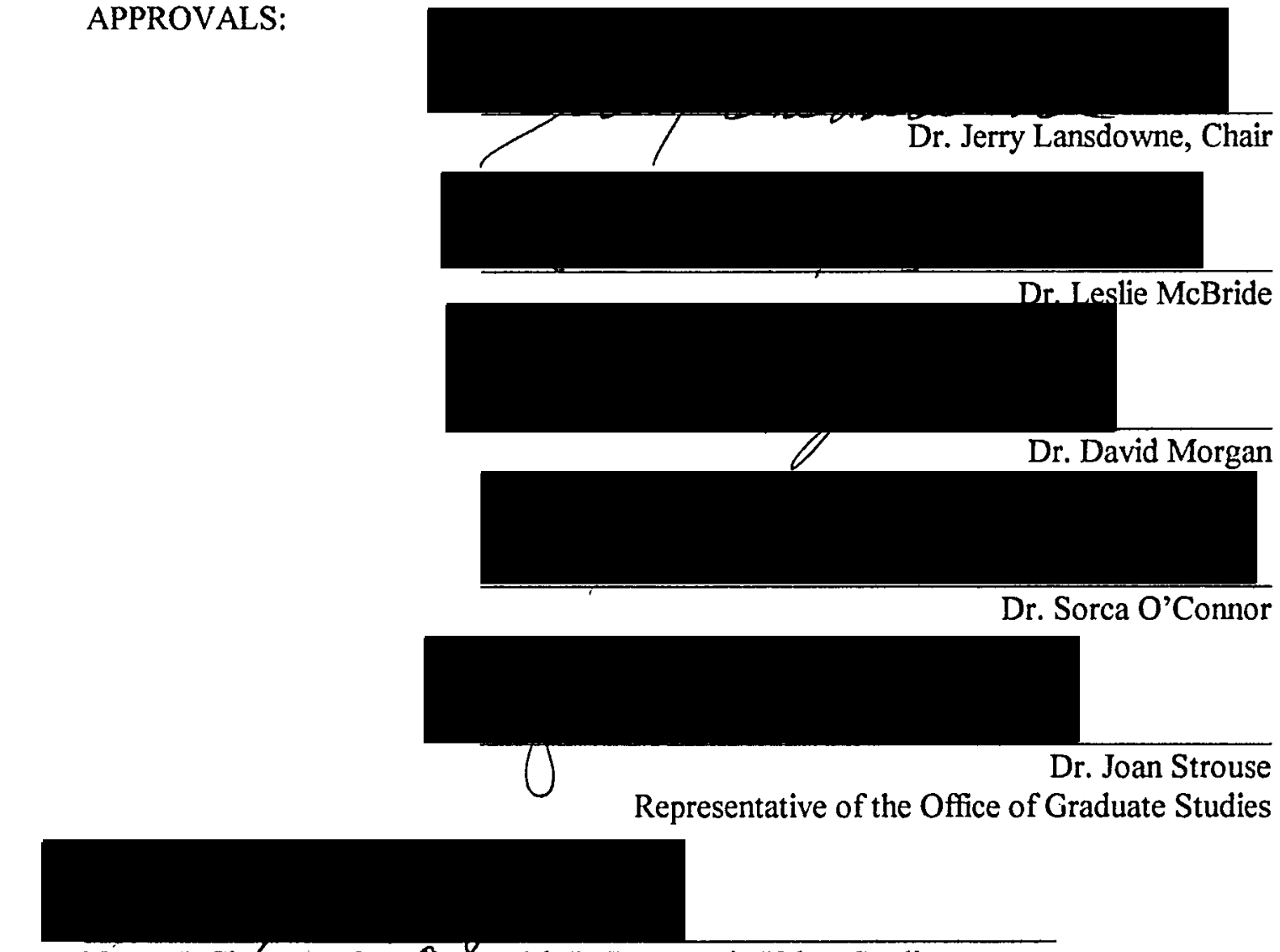

Nancy J. Chrpman, Coopfinator, Ph.D. Program in Urban Studies

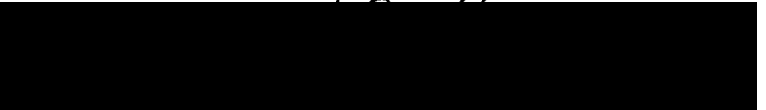

Nonad A. Toulan, Dean, Schostef Urban and Public Affairs

************************************************************

ACCEPTED FGR PORTLAND STATE UNIVERSITY LIBRARY

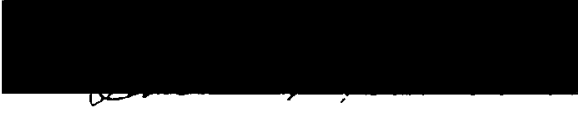

on 152 2een 1996 


\begin{abstract}
An abstract of the dissertation of Katherine Ann Bobula for the Doctor of Philosophy in Urban Studies presented May 8, 1996.
\end{abstract}

Title: Characteristics of Administrators' Leadership Style in Quality Child Care Centers

The utilization of center-based child care services by working and student parents has increased dramatically over the last two decades, and has been accompanied by an equally strong interest, among the public and researchers alike, in the establishment and maintenance of quality caregiving in center-based care. This study addresses the leadership characteristics of administrators of quality child care centers. The intent of the study is to add to the existing knowledge concerning the role that the child care center administrator has in maintaining the delivery of high quality child care by the teaching-caregiving staff. Two factors were investigated: the leadership style of the administrator; and the organizational climate of the center, which is both directly and indirectly influenced by the administrator.

Four child care centers were selected as the cases to be examined. The information about leadership style and organization climate was gathered through the use of semi-structured interviews with the administrators, the Leadership Style Assessment Tool, the Early Childhood Work Environment Survey, and SYMLOG Group Average Field Diagrams. 
From this study, the leadership characteristics that the administrators of high quality child care centers shared in common were that they employed a balanced leadership style that utilized different approaches depending on the situation. The administrators in this study chose a mostly female approach to their job which seemed to create very healthy, responsive, and supportive work environments for the teachercaregivers. The work environments that these leaders have created tend to unify the staff members who work there in a positive direction. These high quality child care centers are, in one word, friendly. The leaders of these provide staff with strong supervisor support, opportunities for professional growth, and an appropriate physical setting in which to do their work. These factors are strongly related to findings about high quality early childhood education in the research, and this study has provided additional support for these findings. 
PAGE

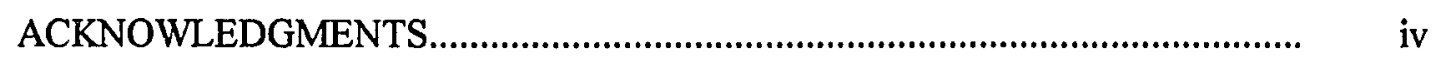

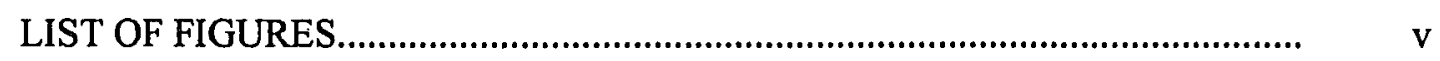

\section{CHAPTER}

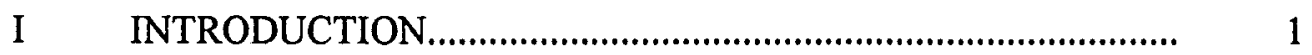

II DEFINITION OF TERMS......................................................

III LITERATURE REVIEW.........................................................

Theoretical Framework................................................................. 15

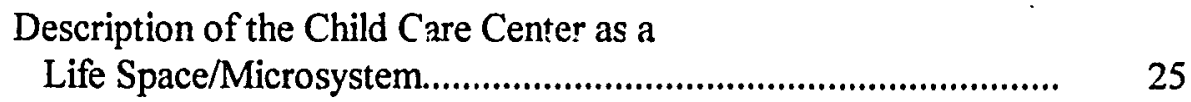

Leadership Style and Maintenance of Quality

Caregiving.

VI RESEARCH DESIGN........................................................

Statement of the Question...........................................................

Sample Selection..................................................................

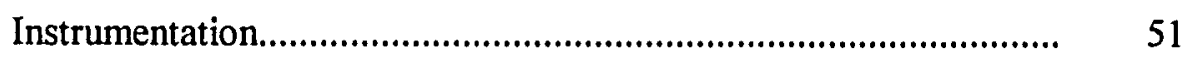

Inter-instrument Consistency...................................................... 56

The Development of the Interview Questions................................... 59

Additional Information and Feedback............................................... 


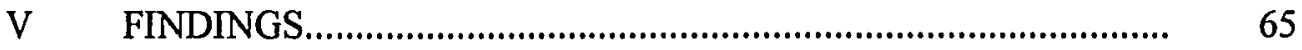

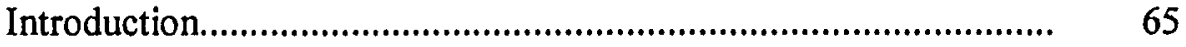

Center B.1: Observation, Interview, and Findings.......................... 67

Center A.2: Observation, Interview, and Findings........................... 97

Center A.1: Observation, Interview, and Findings.......................... 135

Center B.2: Observation, Interview, and Findings.......................... 159

Analysis of the Findings............................................................... 183

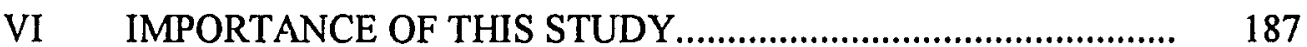

Context for this Research.......................................................... 188

Reflections on the Findings in Context......................................... 189

Implications of Quality Child Care on

Worker Productivity.............................................................. 190

Implications for Further Research............................................ 196

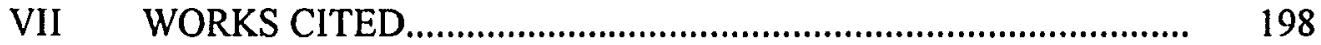

VIII APPENDIX

Letter to Informants for Center Sample

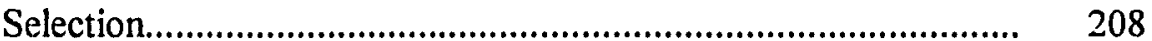

Rating Form for Center Sample Selection....................................... $\quad 210$

Letter of Introduction of the Study to

Participants.............................................................................. 211

Informed Consent Forms for Adults........................................... 212 
Interview Questions for Administrator........................................ 214

SYMLOG Specific Behavior Descriptions.................................... 216

Leadership Style Assessment Tool.............................................. 217

Classroom Pradtices Inventory................................................ 220 


\section{ACKNOWLEDGMENTS}

I would like to acknowledge and thank Silas N.T. Crowfoot for his many hours of work on the dozens of SYMLOG forms that needed to be recorded. In addition, I thank my father, Edward M. Bobula (1915-1995), for his financial support of my research. 


\section{LIST OF FIGURES}

1. Kurt Lewin's Life Space............................................................... 20

2. A Conceptualization of Urie Bronfenbrenner's Nested Systems Model... 


\section{CHAPTER I}

\section{INTRODUCTION}

This study addresses the leadership characteristics of administrators of quality child care centers. The intent of the study is to add to the existing knowledge concerning the role that the child care center administrator has in maintaining the delivery of high quality child care by the teaching-caregiving staff. It has been reported that teacher-caregiver education is a key determinant of quality in child care, specifically college level, early childhood education (Whitebook et al. 1989). However, teacher-caregivers do not work in a vacuum, but in a real environment that may be more or less supportive on both a physical level ( room size and arrangement, staff-child ratio, wages, amount and type of equipment, etc.) and on a psychosocial level (supervisor support, peer interaction, etc.). Whitebook et al., in their report of the National Child Care Staffing Study, found that "the education of child care teaching staff and the arrangement of their work environment are essential determinants of the quality of services children receive" $(1989,44)$.

Administrators of child care centers impact the quality of child care by having control of the organization's budget and by establishing a work environment or organizational climate in which the service of child care is delivered.

The specific question being asked in this research is; What characterizes the leadership style of the administrators of quality child care centers? To answer this question, this investigator looked in depth at a few high quality child care centers in order to examine (1.) the leadership characteristics of the child care center administrator(s) and 
(2.) the organizational climate, within which the teacher-caregivers work.

There are two assumptions on which the question of this research is based. The first is that the qualitative level of caregiving by child care center staff is, in fact, influenced by their perception of the quality of the work environment. The second assumption is that the leadership style of the administrator influences (both directly and indirectly) this perception.

In a study by Jorde-Bloom and Sheerer (1992), twenty-two child care center directors took part in a sixteen month leadership training program. There were three statistically significant outcomes as a result of the training: the directors' perceived level of knowledge increased; classroom teaching practices of the teacher-caregivers improved (compared to a control group); and the organizational climate of the center improved. Maxcy (1991), in his book on educational leadership, points out that researchers have provided "statistical support for the view that the behavior of the school leader, as perceived by the teachers, is related to school 'productivity' as well as teacher morale" (34). These findings lend support to this study's assumptions that the behavior of the administrator of a child care center influences teacher-caregiver behavior via organizational climate and leadership style, which, in turn, impact the quality of caregiving delivered by staff.

In a discussion of directions for future research in this area, Jorde-Bloom suggests that research directed at finding out which "organizational characteristics are associated with positive organizational climates will provide clues as to what administrators and teachers can do to promote more conducive work conditions" $(1991,170)$. The goal of 
this study, consistent with Jorde-Bloom's advice, was to learn something about the characteristics of the administrators who direct quality child care centers. The method utilized for gaining this information was to go directly to the staff and the administrator and ask them to describe the leadership characteristics and organizational climate of their center through the use of three tools. The first tool, SYMLOG, is a generic measure of group process, based on the group members' subjective perceptions of each ather's behavior. SYMLOG provides a diagram of the group's average perception of each member's behavior and their positions relative to each other. The second tool, The Early Childhood Work Environment Survey, is a field specific, subjective measure of the organizational climate of child care centers. It gives an indirect perspective of the leadership behavior of the administrator, as she or he is primarily responsible for policies, procedures, and budgetary decisions that strongly impact the work climate of the center. The third tool is the Leadership Style Assessment Tool by Jorde-Bloom, who is also the author of the Early Childhood Work Environment Survey. This is also a field specific tool that was developed from several generic assessments of leadership style. 


\section{CHAPTER II}

\section{DEFINITION OF TERMS}

\section{Accreditation}

The National Academy of Early Childhood Programs or NAECP (an arm of the National Association for the Education of Young Children (or NAEYC) has designed an accreditation system with two major goals:

1. to help early childhood program personnel become involved in a process that will facilitate real and lasting improvements in the quality of the program serving young children, and 2 . to evaluate the quality of the program for the purpose of accrediting those programs that substantially comply with the Criteria for high quality programs. (NAEYC 1991, 1)

The criteria for accreditation are based on developmentally appropriate practices as well as research on early childhood programs.

\section{Administrator}

The person who is clearly in charge of the child care center and is responsible for budgeting, enrollment, staff supervision, licensing, facility maintenance, children's program, parent relations, board relations (if applicable), and public relations. This person may own the facility (often referred to as an owner-operator), or she may have been hired by the owner (for profit) or board of directors (nonprofit). 
Child Care Center (Day Care, Day Nursery, and Center-Based Care)

Child care centers are full or part day programs where children are cared for in a group in a nonresidential facility. Centers may serve infants ( 0 to 12 months), toddlers (12 to 30-35 months), preschool children (30-35 months to 5 years), and/or school age children ( 5 to 11 years). Most child care centers are required to be certified (e.g., Oregon) or licensed (e.g., Washington) by a state authority, (e.g., Children's Services Division and Department of Social and Health Services, respectively).

Child care centers can be further categorized by tax status (for profit or nonprofit); by relationship to other organizations (sponsored, independent, or member of a chain); and by auspices for nonprofit, sponsored programs (Head Start, public school, etc.) (Willer et al. 1991; Oregon Child Care Resource and Referral Network, n.d.).

\section{Developmentally Appropriate Practice (DAP)}

The National Association for the Education of Young Children (NAEYC) has produced a statement of developmentally appropriate practices for work with children from birth to 8 years of age. This "represents the early childhood profession's consensus definition of developmentally appropriate practice in early childhood programs..., [including] the thoughtful suggestions and careful review of hundreds of early childhood professionals" (Bredekamp 1987, iv). This concept (DAP) matches the practice to the developmental level of the child and includes two dimensions: (1) age appropriateness which is based on the "universal, predictable sequences of growth and change that occur in children during the first 9 years of life" and upon which "teachers prepare the learning 
environment and plan appropriate experiences" (Bredekamp 1987, 2); and, (2) individual appropriateness wherein "both the curriculum and adults' interactions with children should be responsive to individual differences" (Bredekamp 1987, 2).

Play is basic to developmentally appropriate practice as "a primary vehicle for and indicator of [children's] mental growth" and it "enables children to progress along the developmental sequence" of the cognitive stages of development (Bredekamp 1987, 3). Play also helps children develop physically, socially, and emotionally. "Therefore, childinitiated, child-directed, teacher-supported play is an essential component of developmentally appropriate practice" (Bredekamp 1987, 3).

Family Child Care (Family or Home Day Care)

Family child care is care provided for a small group of children in the home of the person who gives the care. Family child care may be regulated by child care licensing, or nonregulated but with an optional registration. "Nonregulated care includes providers who are not licensed or registered whether or not they are subject to regulation" (Willer 1991, 3).

\section{Group Size (Total Group Size)}

This is the maximum number of children allowed (by regulation or policy) in a group at any given point in time. A typical group size for preschoolers is 20 . 
In-Home Care (Nanny or Babysitter)

In-Home Care is provided in the child's home by a non-relative.

Leadership

Leadership is difficult to define in a manner that allows one to measure it in a systematic way, as it is situational behavior that occurs in the dynamic setting of an organization or group. Leadership is also frequently confused with the concept of management. However, "leadership and management are not synonymous terms. One can be a leader without being a manager.... Conversely, one can manage without leading" (Schon 1986, 36). However, "we generally expect managers to lead, and criticize them if they fail to do so" (Schon 1986, 36).

Maxcy $(1991,7)$ states that "despite the large number of empirical studies conducted on leadership, there is still an enormous conccptual confusion regarding the meanings and bearing of the term." Thus, though volumes have been written on "leadership," there is no consensus on a definition of the word. "Leaders face issues of fact, strategy, budget, and system" (Maxcy 1991, 83); but, in addition to these managerial tasks, they also are concerned with the value of what their program is doing. "Leadership seems to imply some bond between leader and followers that does not hinge entirely on either expertise or compliance" (Maxcy 1991, 7). Leaders have "symbolic, inspirational, educational and normative functions"; they represent that for which an organization stands (Schon 1986, 36).

Jones (1993) presents a constructivist approach to staff development in early 
childhood programs. She contends that an effective leader will find a balance and complementarity in using both a human-relations model and a power model of leadership. She states that the important part is to "choose the one more appropriate at a given time (Jones 1993, xv). For example, a more facilitative, collegial approach is appropriate for teacher-caregivers to develop their teaching style; whereas a power model is appropriate for maintaining minimum state requirements for health and safety.

Maxcy feels that Robert K. Merton provides insight into the meaning of leadership when he states that it "does not, indeed cannot, result merely from individual traits or leaders; it must also involve attributes of the transactions between those who lead and those who follow.... Leadership is, then, some sort of social transaction" (Maxcy 1991, 35).

For this study, the leadership characteristics of the administrator will be determined from four sources: the Leadership Style Assessment Tool; SYMLOG Field Diagrams; the Early Childhood Work Environment Survey; and the individual interview with the administrator of each center in the study.

\section{Manager}

In contrast to leaders, "managers are interested in the strategies needed to accomplish the ends of the institution or business. The manager deals with facts" (Maxcy 1991, 83-4). Managers, according to Schon (1986), "monitor and control organizational activities, make decisions, and allocate resources" (36). 
Mixed-age Grouping

In child care centers, this is a situation where the ages of the children in a given room or group span more than one year. A typical mixed-age preschool group is $2 \frac{1}{2}$ to 5 years of age.

No Supplemental Care (Parental care)

This is a situation where parents provide for all the care needed and use nonparental care occasionally, but not on a regular basis.

\section{Office Staff}

These are the people who work on administrative tasks under the supervision of the Administrator. Their duties include general secretarial and bookkeeping activities, ordering and purchasing of supplies, and may include scheduling of staff, enrolling children, and helping in a classroom in an emergency.

\section{Organizational Climate}

Tagiuri (1968) defines organizational climate as "a relatively enduring quality of the internal environment of an organization that (a) is experienced by its members, (b) influences their behavior, and can be described in terms of the values of a particular set of characteristics (or attributes) of the organization" (27).

Jorde-Bloom expands this definition by adding that organizational climate is a "composite of the personalities that come together and the leadership that guides them.... 
It is influenced both by the structural components of the organization and the interactions between the individuals who work in the environment" $(1989,3)$.

For this study, organizational climate will be measured by the Early Childhood Work Environment Survey and the SYMLOG Field Diagram. The Early Childhood Work Environment Survey is based upon the phenomenological premise that "before we can understand human behavior in organizations, we must know how people perceive the environment in which they work" (Jorde-Bloom 1989, 5-6). SYMLOG, in a similar fashion, provides information on how all members of the organization subjectively perceive themselves, how they perceive each of the others in the group, and how they view the relationship of each member to the others.

\section{Parent Involvement}

Parent involvement is an attitude as well as a wide variety of activities. The goal that early childhood education, as a field, has for parent involvement is to create open communication between the parent(s) and the center staff, particularly their child's teacher-caregiver(s). According to Weikart $(1989,15)$, "involvement of parents has been a basic part of American early education programs since the mid-1960s." Parent involvement activities include, but are not limited to, daily informal conversations between teacher-caregivers and parents, daily charts or logs of what each child did that day, parentstaff conferences, parent meetings, family activity nights, children's programs for parents, parent participation in the classroom, parent participation on a Parent Advisory Board, 
parent assistance on field trips, etc.

Quality

Quality in child care centers is determined by multiple measures. These include:

group size; ratios of children to adults; training of staff; salaries of staff; type of curriculum; and design of the space. Research has found that early care and education programs of good quality have positive effects on children. Children have significantly better test scores and behave in observably different ways. They achieve more in their lives and cost society less in the long run. Low quality programs, however, fail to have these positive effects and have been found to harm children. (Oregon Child Care Resource and Referral Network n.d., 3)

According to Weikart $(1989,18)$ the concept of a high quality program is dynamic,

it is not a matter of teacher education degrees or even of resources; rather it consists in steadily focusing on the most efficient use of staff skills within a curriculum. The results depend upon the process by which the curriculum is implemented. Thus, programs can be successful in many different settings and with a variety of curricula.... The key remains excellent supervision preferably within a child development curriculum model.

In Weikart's discussion of quality, the administrator's role is central as is a child development curriculum model, which "features child-initiated activities... [and] ...accepts children at whatever developmental level they are on. A child development (or DAP) curriculum model provides ample opportunity for children to solve problems independently, to initiate meaningful conversations with peers and adults, and to explore materials and interests on their own" $(1989,18)$.

The National Academy of Early Childhood Programs has developed a set of Criteria for High Quality Early Childhood Programs, based on developmentally 
appropriate practices, which represent "the consensus of the early childhood profession regarding the definition of a good early childhood program for young children" (NAEYC 1991, 11). A high quality program is "one that meets the needs of and promotes the physical, social, emotional, and cognitive development of the children and adults -parents, staff, and administrators -- who are involved in the program. Each day of a child's life is viewed as leading toward growth and development of a healthy, intelligent, and contributing member of society" (NAEYC 1991, 11).

Burts et al. (1990) did a related study that lends support to the argument that developmentally appropriate practices have a desirable impact on children's development and well-being. They compared stress behaviors of kindergarten aged children in developmentally appropriate and inappropriate classrooms. They found that "children in the developmentally inappropriate classroom exhibited significantly more stress behaviors than children in the appropriate classroom" (407).

In a 1992 follow-up to the 1988 National Child Care Staffing Study, the centers in the study that were accredited, in comparison to those that were not, had "better educated and trained staff, lower rates of turnover, and provided higher quality services to children"; thus, "the study concluded that accreditation enhances center quality" (WAEYC 1993, 1).

Accredited centers fulfill two of the criteria that Vaill (1986) lists as indicators of high-performing systems. "They are judged qualitatively by informed observers to be doing substantially better than other comparable systems," and, "they are perceived as exemplars of the way to do what they do" (86). 
For this study, quality will be determined in three ways: (1) the center must be accredited or in the process of accreditation or reaccreditation by the National Academy of Early Childhood Programs; (2) the program for the preschool children must be developmentally appropriate as measured by the Classroom Practices Inventory, based on the National Academy's criteria; and (3) the center must be recognized, by reputation, as a quality center by experts in the local Early Childhood Education community (college and university teachers in early childhood education or related field, state licensing officials, information and referral staff, early childhood teacher trainers).

\section{Relative Care}

Relative care occurs either in the child's home or in the caregiver's home, when the caregiver is a relative.

\section{Single-age Grouping}

In child care centers, this is a situation where the children are grouped by age in years with each room having an age span of approximately one year. Centers with singleage grouping typically have a room or class for 2-year-olds, 3-year-olds, and 4-year-olds.

\section{Staff-Child Ratio (Ratios)}

This is the number of teachers relative to the number of children in any group. Staff-child ratios are a commonly regulated component of child care. A typical ratio for preschoolers is $1: 10$. 


\section{Support Staff}

The support staff includes people in job categories such as cook, janitor, housekeeper, bus or van driver, and maintenance.

Teacher-assistant (Teacher's Aide, Assistant Teacher, Aide)

Teacher-assistants are the child care center staff who deliver direct care to the children under the supervision of the teacher-caregiver. The teacher-assistant helps to carry out curriculum activities and interacts with the children. The teacher-assistant may be responsible for some additional housekeeping tasks, particularly in regard to meals.

\section{Teacher-caregiver}

Teacher-caregivers are the child care center staff who deliver direct care to the children and who are responsible for curriculum planning and child guidance. They can include staff with a variety of titles (teacher, child care provider, early childhood specialist, etc.), as well as staff with various levels of early childhood education training (ranging from no formal training to graduate training). 


\section{CHAPTER III}

\section{LITERATURE REVIEW}

\section{Theoretical Framework}

The overall theoretical framework for this research is phenomenological in nature. According to Immanuel Kant, there is a "fundamental distinction between two different kinds of worlds: the noumenal and the phenomenal. The noumenal world consists of things or objects in and of themselves; the phenomenal world consists of things or objects as we experience them" (Hillner 1984, 85). Phenomenology's basic assumption is that a person's own definition or perspective of a situation is, in fact, all that he or she knows. According to Hillner, when applying phenomenology to research in the field of psychology, one or both of the following assumptions must be involved:

(1) the conscious experience of the organism constitutes the canonical, or most meaningful, aspect of man for psychology to study, and (2) the externalization of the content of consciousness, as given, via the use of the vernacular language, amounts to a reliable/valid psychological process or experimental technique $(1984,257)$.

Elaborating on these assumptions, humanist psychologists, embracing the phenomenological approach, assume that "one has to appreciate individuals' personal, subjective experiences to truly understand their behavior" (Weiten 1995, 489). Thus, when studying how an organization works, one must ask the participants to tell how they 
think it works in addition to utilizing more objective measures. This study asked staff to say how they thought people behave and interact with one another in their child care setting and how the work environment is characterized. SYMLOG and the Early Childhood Work Environment Survey are both tools that measure or capture a person's subjective perception. In order to analyze the overall work environment, the investigator collects information from these instruments and aggregates it into group averages, because "in phenomenal description the categories of descriptive self-report are subject derived; and it is possible for two different observers to disagree when faced by essentially the same objective situation" (Hillner 1984, 83).

The basic principle of Gestalt Psychology, which is also phenomenologically based, is "that Gestalten exist or the whole is different from the sum of the parts" (Hillner 1984, 97). Taking this principle into account when looking at an organization, one cannot, then, simply look at the components in an additive or list-like fashion for analysis. When looking at people, one realizes that the interactions that take place within the organization create sornething new -- something more than or different from the simple sum of the component parts. In a similar vein, quality in child care cannot be determined solely by checking the requirements listed in a book or in licensing statutes. Quality child care is the result of the interactions of the child care staff (including the administrators) with each other, the interactions of the teacher-caregivers with the children and their parents, and the interactions of the teacher-caregivers with the physical environment.

Kurt Lewin, as described by Bronfenbrenner, states that one of the major tasks of psychological science is "to discover empirically how situations are perceived by the 
people who participate in them" $(1979,24)$. Field Theory, as presented by Lewin, takes a phenomenological approach to group dynamics. Behavior is assumed to be and is viewed as a function of the person's or subject's representation of both the physical and social influences in his or her environment. In child care, one must look at more than the physical facility or program structure factors to understand what really makes quality care happen. The caregivers' experience of working in this setting (how they feel) impacts what they do and how they interact with the children, thus influencing the quality of care. Both SYMLOG and the Early Childhood Work Environment Survey are based, in part, on Lewin's Field Theory.

The last theoretical framework employed in this study is that of taking an ecological orientation (Bronfenbrenner 1979) to methodology which "asserts that behavior evolves as a function of the interplay between the person and the environment, expressed symbolically in Kurt Lewin's classic equation: $B=f(P E)$ " (16). Bronfenbrenner points out in his work The Ecology of Human Development that although psychology accepts this basic principle, in reality its application has been uneven, with "a hypertrophy of theory and research focusing on the properties of the person and only the most rudimentary conception and characterization of the environment in which the person is found...; [and,] as a result, interpretations of environmental effects are often... 'explained' simply as attributes of the setting in question," such as comparing child care in America to child care in France (1979, 16-17). In addition, and as Bronfenbrenner states "perhaps ironically," studies that include environmental factors as variables are frequently conducted by removing the subjects from the setting in question and studying them in a 
laboratory without taking the laboratory environment into account. ${ }^{1}$ The rigor often leads to research being conducted in such artificial circumstances that it is not generalizable.

The reaction to this problem led to people doing more socially relevant research, but "often with indifference to or open rejection of rigor" $(1979,19)$. Most often this "antirigor" sentiment is expressed in an emphasis on the use of naturalistic observations, but without the guidance of theory or hypotheses conceived in advance, i.e. the observations must be "uncontaminated by highly structured experimental designs imposed prior to data collection" (Bronfenbrenner 1979, 19). Bronfenbrenner, through his ecological orientation, "rejects both the implied dichotomy between rigor and relevance and the assumed incompatibility between the requirements of research in natural situations and the applicability of structured experiments at an early stage in the scientific process" (1979, 20). He goes on to argue:

The understanding of human development demands more than the direct observation of behavior on the part of one or two persons in the same place; it requires examination of multiperson systems of interaction not limited to a single setting and must take into account aspects of the environment beyond the immediate situation containing the subject. In the absence of such a broadened perspective, much of contemporary research can be characterized as the study of development-out-of-context. (21)

This orientation supports doing interdisciplinary case studies of several centers and

'This observation gave rise to the classic quote from Bronfenbrenner commenting that "much of developmental psychology, as it now exists, is the science of the strange behavior of children in strange situations with strange adults for the bricfest possible periods of time" $(1979,19)$. 
allows for taking account of each center's complexity and unique qualities. The Work Environment Survey, SYMLOG and the Classroom Practices Inventory, as instruments are each both valid and reliable, supplying rigor. In addition, an ecological methodology also directs the researcher to go to the subjects in situ and to approach the project as a collaborative enterprise. Thus, all work was done on site and the subjects were informed of the purpose of the study. The subjects were told their ideas were valuable -- because this is the information needed for the research. This subjective approach brings relevance to the work. Studying subjects in their own unique situation also supports the use of field specific tools, such as the Early Childhood Work Environment Survey and the Leadership Style Assessment Tool, which were designed for use specifically in early childhood settings.

The topic being investigated in this study is how leaders create an organizational climate that motivates employees to do their best work in spite of multiple constraints inherent in the job of child care. Kurt Lewin presented his field theory in a diagram (see figure 1) or topological form, where: the field is the "...totality of a situation to be investigated..." (Maus 1971, 147-8), or the life space ${ }^{2}$; the person is located within their psychological environment or social space and is seen as moving about in that space in response to social and psychological pressures or forces (Pearman and Rotz 1981, 127); and the foreign hull represents those experiences not incorporated into the life space, but

\footnotetext{
${ }^{2}$ The life space includes a person or group of people and "everything that exists for them at that moment" (Yanoff and Bryan 1986, 171).
} 


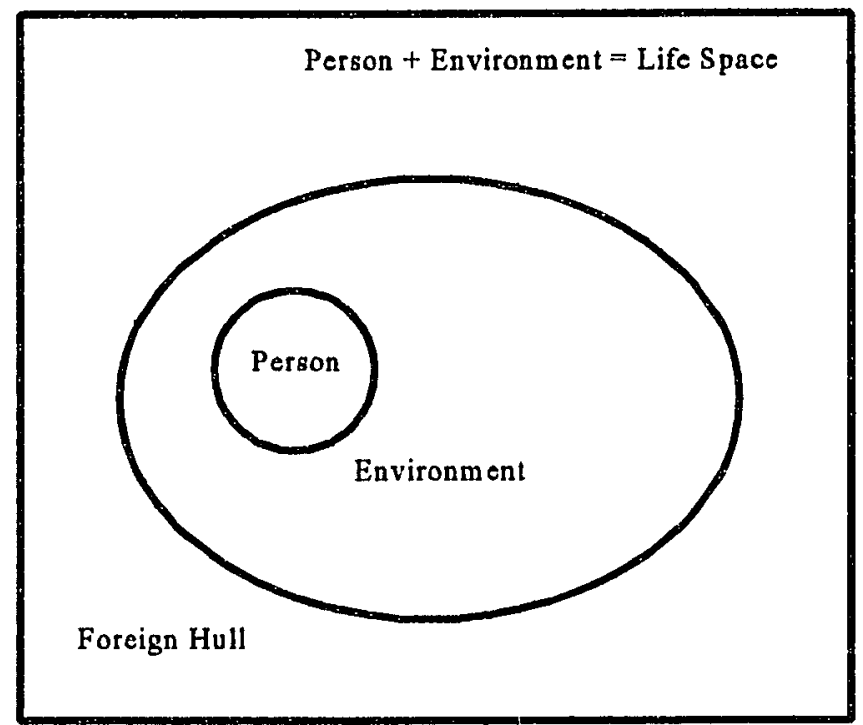

Figure 1. Kurt Lewin's Life Space (Gifford 1987, 80)

which can influence it (Gifford 1987).

Lewin's social-psychological theory (upon which the SYMLOG method of group observation is based) is a dynamic one that sees individuals moving about in their life space, being influenced by their own history and future aspirations as well as by other people, events, and situations -- loth from within their life space and outside of it. The life space that I have chosen to study is the child care center, a truly dynamic organization which is influenced by five opposing forces that Lewin describes:

These forces set up tension systems within the life space and function to cause action to reduce tension and achieve equilibrium. Thus, change can be produced by increasing the tension in some region and forcing movement with greater tension or by decreasing the tension in some region and achieving equilibrium by tension 
reduction. The former leads to dissatisfaction whereas the latter approach achieves some satisfaction with the change (Yanoff and Bryan 1986, 172).

The parents or other primary caregivers of the child (foster parents, grandparents, etc.) are primarily driving forces ${ }^{3}$ as they move in and out of the child care center life space on a regular and predictable basis, carrying an expectation of some level of influence on the behavior of the child care staff (Galinsky 1990; Halpern 1987). From farther outside the life space of the child care center are various forces that can be driving and/or restraining forces ${ }^{4}$, such as state child care center licensing officials, fire and sanitation inspectors, legislative branches of the government, and the various child care/early childhood education professional communities (local, state, national, and international). More impersonal forces ${ }^{5}$ are the various perceptions of child care held by mass media and the public (Goetz et al. 1984; Gould 1983), as well as broad social influences (such as the state of the economy, the number of women with young children who are employed outside of the home, the number of single parents, etc).

Contained within the life space of the child care center are three groups of people: the children; the caregiving-teaching staff; and the administrative, support and office

${ }^{3}$ Driving forces "push toward or away from current behavior and lead to movement" (Yanoff and Bryan 1986, 171).

"Restraining forces are "actually obstacles or barriers to movement" (Yanoff and Bryan 1986, 171).

s Impersonal forces are representative of social norms" (Yanoff and Bryan 1986, 172). 
personnel. These three groups have the potential, at any given time, to function as any of Lewin's five forces: driving, restraining, induced ${ }^{6}$, impersonal, and personal $^{7}$. For this study, I plan to look at what behaviors and/or characteristics of the administrator create an organizational climate that (1) discourages any of the caregiving-teaching staff from being restraining forces, thus resisting change in the way they work with children and each other; (2) encourages them to examine the personal values and societal norms they bring with them into the caregiving environment, so as to reduce egocentric and ethnocentric judgments about children and parents; (3) supports them to be driving forces that are open to change; (4) supports them to be sensitive to the wishes of others within the life space thus respecting diversity and individual differences, and (5) supports them to be realistic and communicative about their own needs so as to reduce the potential of burnout.

"Lewin demonstrated that resistance increases if change is pushed or mandated. However, if resistance is reduced and diminished, change and growth are possible" (Yanoff and Bryan 1986, 175).

According to Glossop (1988), Urie Bronfenbrenner "most particularly... builds on the phenomenological concepts of the 'life space' and the 'psychological field' as incorporated into the systematic theory of Kurt Lewin" (10). Bronfenbrenner (see figure

\footnotetext{
"Induced forces are those that represent the "wishes of others in our life space" (Yanoff and Bryan 1986, 172).

${ }^{7}$ Personal forces are those which "represent one's own needs" (Yanoff and Bryan 1986 172).
} 
2) used a "nested systems" (Pence 1988, xxii) model, or a socio-ecological map where (1) Microsystems are immediate experiences that people are having; (2) Mesosystems are groupings of two or more microsystems and are embedded in an Exosystem; (3) an Exosystem is an area of non-immediate social contact, similar to Lewin's foreign hull; and (4) a Macrosystem is the outer shell which contains socio-cultural mores, values, and laws.

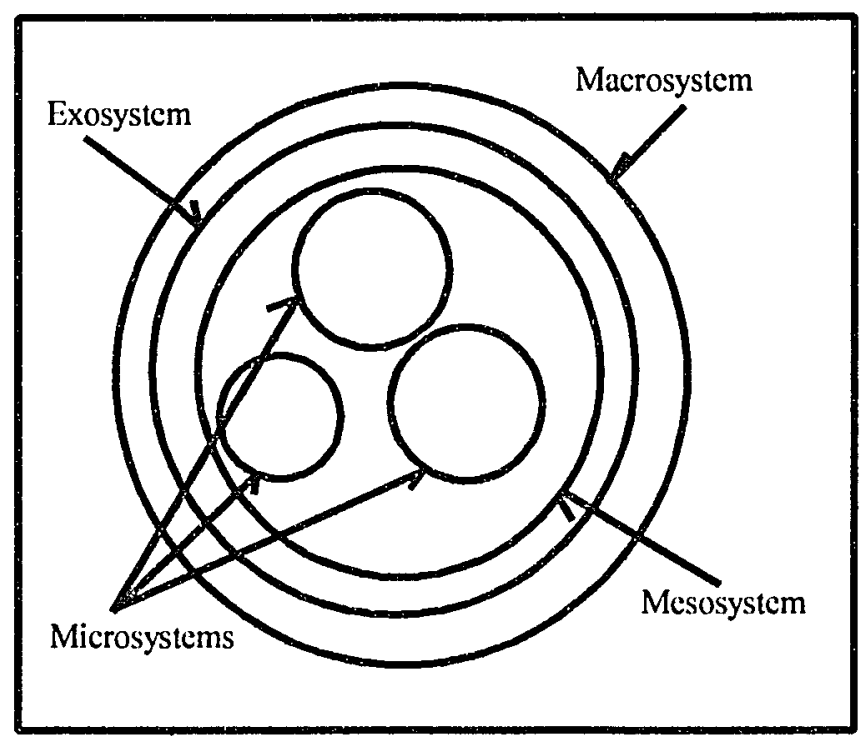

Figure 2. A Conceptualization of Urie Bronfenbrenner's Nested System's Model (Bobula, 1996)

According to Bronfenbrenner, "the social context of individual interactions and experiences determines the degree to which individuals can develop their abilities and realize their potentials" (Berns 1993, 14). The child care center as a microsystem contains numerous people with whom the child (as the central focus of child care) interacts and 
who interact with each other.

Berns, in her discussion of Bronfenbrenner's approach, notes that the child is affected by relationships with others, for example, in his or her family. She states further that the child is also affected "by interactions between members of the particular microsystem", such as the father and mother's relationship, which in turn affects each parent's treatment of the child $(1993,16)$. In the case of the microsystem of the child care center, the child is affected not only by his or her own direct interaction with the teachercaregivers, but by the way that the teacher-caregiver interacts with the other staff members of the child care center, and most particularly with administrators who directly impact the teacher-caregiver's work environment. Bronfenbrenner's ecological approach looks at the "reciprocal relations between the multiple environments within which any person develops" (Glossop 1988, 1):

It is Bronfenbrenner's emphasis on the "immediate settings" and the "larger contexts" in which the immediate settings and the developing person are embedded that is almost universally acknowledged as the cornerstone of the ecological frame of reference (Glossop 1988, 5).

At the end of this paper, in the analysis and implications, I will relate these findings to parental work behavior using the ecological perspective, wherein child care could be viewed as a microsystem along with the family and the parental workplace. The implications of the interaction of the family-child care mesosystem and the family-parental work place mesosystem will be discussed, linking high quality child care to reduced strain between work and family roles and the accompanying increase in worker productivity. 
Description of the Child Care Center as a Life Space/Microsystem

\section{Patterns of Use of Child Care Centers}

I have chosen to study leadership in the context of child care centers, because center based child care, in particular, has "experienced a $400 \%$ growth rate in the past two decades. Not only has center care grown in sheer numbers, it has also grown faster than all other forms of care" (Neugebauer 1992, 14). Child care centers care for more children than any other form of care besides parental care (no supplemental care). In fact, in 1990 , care by parents and care by centers each accounted for $28 \%$ of the child care for the youngest preschool child in families with employed mothers (Willer et al. 1991, 44).

Use of child care centers peaks when children are 3-4 years old (Willer et al. 1991, 9). For parents with infants and toddlers, family child care and care by relatives are preferred (Neugebauer 1992, 15). Assessing the use of various forms of child care is difficult. Usage rates vary according to the source. Care for a child in the child's own home has shown the most significant decrease in use, from $15 \%$ in 1965 to $3-7.5 \%$ in 1990-1. Center-based care, on the other hand, increased from $6 \%$ in 1965 to $28-32.3 \%$ in 1990-1. Family child care usage remained relatively unchanged during this same period, accounting for $20-25 \%$ of the care, which is in the range of care by relatives estimated to be between 19-32.9\% (Neugebauer 1992, 14-15; Children's Defense Fund 1996, 27).

\section{Constraints in Child Care}

Center based child care is replete with constraints which potentially impact the 
maintenance of quality in child care. This is due to what Willer (1987) calls the "child care trilemma," which is composed of three (seemingly mutually exclusive) issues of affordability of care for the parents; quality of care which is determined largely by the caregiving staff's behavior; and, compensation of the staff, which includes both wages and benefits. Since child care is a labor-intensive service industry, a significant percentage of the cost of care is for the teacher-caregivers (Howes et al. 1987). The rate of pay, or compensation, of child care teacher-caregivers tends to be very low and benefits, from health insurance to in-service training, are few (Howes et al. 1987; Willer 1987; JordeBloom 1988; Whitebook et al. 1989; NAEYC 1990). In fact, contends Willer, "for years, early childhood staff have subsidized the provision of early childhood programs by accepting compensation far below the value of their work" $(1987,42)$. In spite of this "subsidy" or foregone wages ${ }^{8}$, many parents still cannot afford the cost of their current child care arrangements or the ones they would prefer (Willer 1987, 42). Even with the recent federal child care block grants, which allocated the first direct federal dollars for child care since the Lanham Act in 1942, the child care trilemma persists.

There is a high rate of staff turnover in child care as well as a general shortage of trained teacher-caregivers (Galinsky 1989; Sheerer and Jorde-Bloom 1990; Whitebook 1986). Galinsky (1989) lists six causes for the staffing crisis in child care: (1) There is a

\footnotetext{
8 "Foregone wages refer to the difference between the wage a staff person could earn in another occupation (based on the person's education, gender, age, race, and marital status) and the person's wages as a child care worker;" they are estimated to equal $\$ .54$ out of the $\$ 2.83$ average full cost per child per hour. (Cost, Quality, and Outcomes Study Team 1995, 41-2).
} 
labor shortage in the country. "The number of people in the 18-24-year-old range is estimated to [have decreased] ...by approximately five million between 1980 and 1990", (2) Salaries are very low for child care workers and the turnover rate is $35.2 \%$ (compared to public school prekindergarten and kindergarten teachers who have almost twice the salary and have a separation rate of only $17.8 \%$ ); (3) Benefits in child care are few. "Centers are most likely to provide paid sick days and holidays and least likely to provide health, dental, or retirement funds" (Galinsky 1989, 2); (4) Child care as a career has low status and lacks societal respect; (5) Opportunities for advancement or significant pay increases are few; (6) Working conditions are related to retention of staff and quality of the program. Galinsky found that job autonomy or the ability to make decisions about one's work were related to less turnover in staff(Galinsky 1989, 3). These constraints make consistent delivery of quality care difficult (Whitebook and Granger 1989).

The National Child Care Staffing Study, upon which Galinsky's above remarks were based, was conducted first in 1988. In 1992, the study was updated and revealed "no major changes in compensation and benefits or turnover" (WAEYC 1993, 1).

Teaching staff continue to earn exceptionally low wages, according to the study. The wages paid to the highest paid teachers, rose $8 \%$ to only $\$ 8.85 /$ hour. Relatively few staff are in this group. The real wage paid to the lowest paid teaching assistants (also the fastest growing group in the child care work force) declined between 1988 and 1992. In addition, the 1992 data confirmed the 1988 finding that wages in for-profit centers are significantly lower than those in nonprofit centers (WAEYC 1993, 1).

In terms of benefits, "only $27 \%$ of centers provided fully paid health insurance for teaching staff, and $32 \%$ of those provided that coverage for teachers only, not teaching assistants" 
(WAEYC 1993, 1). Health insurance for employees as well as dependents is limited and, since 1988, has been reduced or eliminated in many situations.

Child care work is both physically and emotionally demanding (Townley et al. 1986; Whitebook and Ginsburg 1983). Many teacher-caregivers experience daily burnout. Townley, Thornburg, and Wise $(1986,31)$ describe burnout as having "three major components: emotional and/or physical exhaustion, lowered job productivity, and overdepersonalization." These characteristics of burnout might result in changes in teachercaregiver behaviors, such as reduced focus on individual children and an increase in whole group focus, reduced effort in curriculum planning and gathering of materials, and reduced abil!cy to do problem solving with children along with a concurrent increase in an authoritarian or laissez-faire style of guidance. In child care there are numerous factors related to this type of work that "can contribute to child care staff burnout: high staff-child ratio; long working hours; few breaks; lack of space; [and] little input in designing policies and structure of program" (Townley, Thornburg, and Wise 1986, 31). Lack of knowledge about child development and early childhood education often leads to teacher-caregivers developing inappropriate behavior patterns and practices (Roupp et al. 1979; Snider and Fu 1990). Working with a group of young children can be overwhelming, especially when the untrained teacher-caregiver is expected to simply "keep them busy" and is given no meaningful support.

The very nature of center based child care presents a dilemma for the teachercaregiver which can be summed up in the question, Who does the teacher-caregiver serve? Should the teacher-caregiver's behavior be based on what the parents expect, on what the 
children appear to want, on what the organization demands, on what she/he as the caregiver prefers, or on what the early childhood profession recommends? Whose needs come first? What happens if these needs are in conflict? How do the teacher-caregivers balance meeting the expectations and demands of others, meet their own needs, and assure quality caregiving, all at the same time?

\section{Determinants of Quality in Child Care}

In spite of all of these constraints in caregiving, there are child care centers that $d o$ provide consistent, developmentally appropriate child care. A broad range of research has been conducted around the general question, What determines quality child care?

Structural factors, staff characteristics, program components, curricular approaches, and classroom materials that correlate with desirable outcomes in children's development and behavior have been delineated.

The literature on determinants of quality in center based child care includes studies on the physical environment and space (Phyfe-Perkins 1980; Fagot 1977); proprietary versus non-profit status (Kagan and Newton 1989); staff-child ratio (Ruopp et al. 1979); total group size (Ruopp et al. 1979); single versus mixed age grouping (Katz et al. 1990); teacher training (Ruopp et al. 1979); staff wages (Whitebook et al. 1989); and teaching style and educational philosophy (Schweinhart et al. 1986). From this research as well as from the experience of classroom teachers, the National Association for the Education of Young Children has constructed a list of Developmentally Appropriate Practices or DAP (Bredekamp 1987) for work with young children in child care and preschool settings. 
They have also developed a set of standards for programs to meet for the purpose of voluntary accreditation by the National Academy of Early Childhood Programs or NAECP (NAEYC 1991).

Implementation and maintenance of these standards and guidelines for practice are two separate processes. A small percentage of all child care centers in the United States are accredited. For those that are, the program staff have been able to implement the more rigorous standards and practices necessary for the accreditation process. In a first year follow-up study on the initial group of programs (full day and half day) that became accredited, Bredekamp and Berby (1987) found that the program staff were maintaining the standards and in some cases were improving them. The authors noted, however, that all the programs in the follow-up study had the same director who had implemented the accreditation, and they wondered if this quality maintenance would be true with a change in director, as informed observers have noted that quality of care is lost when the director who was there when accreditation took place leaves.

Research on the physical environment of the early childhood classroom and its relationship to quality is highlighted by the work of Prescott and Jones (1972; Jones and Prescott 1978) at Pacific Oaks College for Teachers. They have developed an analysis of classroom environments for the care of young children. From this and other research, the Early Childhood Environment Rating Scale (Harms and Clifford 1980) was developed and was one of the first tools available to measure program quality. It has frequently been used in early childhood education research on quality programming and care.

Concerning the specific influence of the amount of space, studies have been done 
comparing the varying degrees of spatial and social density on young children's behavior.

Elizabeth Phyfe-Perkins (1980), in a review of research on the physical environment,

looked at the factor of the number of square feet per child, and concluded the following:

It seems that broad generalizations are not warranted about space variation per se, except for a possible bottom threshold of 25 to 15 square feet per child for increased aggression, lower social interaction, and increased noninvolvement. When social density increased and/or when the competition for equipment increases, then there are more apparent effects (97).

Regarding teacher behavior and the amount of physical space per child, there are two studies of interest. Fagot (1977), in a study she did concerning the impact of density on task and social behaviors of preschool children, found no significant effects, but in her concluding remarks she stated:

Although higher density does not necessarily produce negative behavior in young children, it would be a mistake to conclude that differences in density have no effect. Crowding in the classroom forced teachers to adopt different strategies from what they might choose in less crowded situations. Teachers in the more crowded schools appeared to have planned the day's activities more carefully and to be more directive with the children. In fact, in the very crowded Dutch classrooms, the children were assigned to areas of the room, and free choice of play as seen in most American preschools was not possible. In addition, lack of space ruled out some large motor activities indoors. The teachers were careful to provide outdoor periods for motor activities, but indoors these children's lives were more regulated. Differing densities may force different social organization upon children (166-7).

The second study, by Perry (Phyfe-Perkins 1980), was directed specifically at space and teacher behavior. Perry found that teachers in classrooms which had less than 30 square feet per child exhibited more controlling behavior $(46.7 \%)$ than did teachers in rooms of over 49 square feet per child, who displayed less controlling behavior (16.2\%). 
In addition, the high spatial density seemed to cause teachers to restrict free play to manipulation of toys at the table, as "opposed to the use of blocks, wheel toys, and doll corner" that are seen in the larger classrooms (Phyfe-Perkins 1980, 96), and which involve more active play and small group interaction.

Kagan and Newton (1989) conducted research on the similarities and differences between for profit and nonprofit child care centers. They defined quality as being represented by: three "regulatable variables that are related to positive child outcomes 1 . group size, 2. teacher training in child-related areas, [and] 3. ratios; " and three nonregulatable variables " 4 . the nature of the interaction between the caregiver and the child, 5. the nature of the environment, [and] 6. the nature of the interaction between the caregiver and parent" (Kagan and Newton 1989,6). Kagan and Newton's findings were that nonprofit centers (as compared to for profit centers) had better (smaller) ratios; more services were offered to children (such as referrals, library visits, field trips, etc.); more services were offered to parents; the environment was more child-sensitive; there were more materials available to the children; and there were more materials that stimulated creativity $(1989,7)$. "While the formal education and experience of caregiver staff varied greatly among center types, director education and experience did not" (Kagan and Newton 1989, 8). In other words, the directors of for profit and nonprofit centers were equally trained or untrained, thus removing director training per se as a key variable to quality.

Studies have been conducted on group size and group composition. Research on mixed-age grouping of young children compared to single-age grouping, "though 
incomplete, indicates that social development can be enhanced" in a mixed-age group (Katz, Evangelou, and Hartman 1990, v). Both leadership and prosocial behaviors have been observed to increase when a mixed-age grouping was initiated (Katz, Evangelou, and Hartman 1990, v).

The National Day Care Study (Ruopp et al. 1979) was the first major research to separate out specific factors of child care centers which were significantly correlated to positive outcomes for the children enrolled. "The study's most important findings bear on the composition of the day care class (group size and caregiver/child ratio) and the qualifications of caregivers (education, experience and training)" (Smith 1979, 2).

The National Day Care Study found that with classroom composition, "across all study sites, smaller groups are consistently associated with better care, more socially active children and higher gains on two developmental tests" -- the Preschool Inventory (PSI) and the revised Peabody Picture Vocabulary Test (PPVT) (Smith 1979, 2). Concerning caregiver/child ratio, those that range between 1:5 and 1:10 show "some relationships to measures of caregiver and child behavior, although the results are not strong or consistent. Ratio is not related to child test score gains" (Smith 1979, 3). However, caregivers with training or education that relates to young children" ${ }^{9}$ deliver better care with somewhat superior developmental effects for children" in spite of the fact that they "do not receive higher wages than other caregivers" (Smith 1979, 3). Another

9 This would include specific training in child growth and development and early childhood education. 
finding (that surely surprised some child care practitioners) was that "neither total years of day care experience, total years of formal education, nor degrees or certificates unrelated to child care were systematically associated with caregiver [behavior], ...child behavior, or child test score gains" (Smith 1979, 3).

Snider and Fu's study (1990) supported the National Day Care Study's findings about training of teacher-caregivers. They found that participants in their study who had "degrees in $\mathrm{CD} / \mathrm{ECE}$ [child development/early childhood education] scored significantly higher than those with academic degrees in other fields of study" (Snider and Fu 1990, 75) on a test of their knowledge of developmentally appropriate practice.

The Cost, Quality, and Child Outcomes in Child Care Centers study of 1993 had findings about quality that were consistent with previous research and found that quality was related to specific variables: "higher staff-child ratios, staff education, and administrator's prior experience. In addition, certain characteristics distinguish poor, mediocre, and good-quality centers, the most important of which are teacher wages, education, and specialized training" (Cost, Quality, and Outcomes Study Team 1995, 41). Whitebook et al. (1989) reported on the findings of the National Child Care Staffing Study which "explored how teachers and their working conditions affect the caliber of center-based child care available in the United States today" (41). They found that the "...most important predictor of the quality of child care children receive...is staff wages" (Whitebook et al. 1989, 44), which have an indirect relationship with the turnover rate. Concerning the quality of the 227 randomly selected centers in their study, they were "rated as barely adequate [in general]. The better quality centers had: higher wages, better 
adult work environments, lower teaching staff turnover; [and] ... were more likely: to be operated on a nonprofit basis, to be accredited..., to be located in states with higher quality standards, to meet adult-child ratios, group size, and staff training provisions contained in the 1980 Federal Interagency Day Care Requirements"10 (Whitebook et al. $1989,44)$.

Schweinhart and Weikart (1996) reported on the findings at the twenty-fifth year of a longitudinal study that compared academic and social outcomes for 123 individuals who were divided into two groups: one that attended the High/Scope Perry Preschool (a high quality program) and the other that received no preschool program. All participants (now age 27) were African-American and, as preschoolers at the beginning of the study, were from families with low incomes. In comparison with the no-program group, the program group had significantly higher earnings per month; higher percentages of owning a home and a second car; higher level of formal education completed; "lower percentage receiving social services at some time in the previous 10 years"; and, "fewer arrests by age $27 . .$. , including significantly fewer arrests for crimes of drug making or dealing" (339). The preschool model used for the program group had the following "four aspects of high quality: a developmentally appropriate, active learning curriculum; an organized system of inservice training and systematic, ongoing curriculum supervision; an efficient, workable

${ }^{10}$ The Federal Interagency Day Care Requirements, or FIDCR, were standards developed for child care centers that received Title XX funds from the federal government. These standards were considered to be high and were never really enforced. The FIDCR were similar to those advocated by NAEYC. 
method of parent involvement; good administration, including a valid and reliable, developmentally appropriate assessment procedure, a monitoring system, and a reasonable adult-child ratio" (342).

In terms of specific classroom curricular approaches that are related to positive child outcomes, Weikart (1989) has reported on a longitudinal study (Schweinhart et. al. 1986) that compared a direct instruction approach (DISTAR which is based on the behaviorist psychological theory of B.F. Skinner) with two open framework approaches (High/Scope which is based on cognitive developmental theories of Jean Piaget, and the traditional nursery school approach based on the psychoanalytic theory of Sigmund Freud). This study found that low income children made similar later academic gains by attending preschools using any of these three curricular approaches. However, at age 15, the children attending the direct instruction preschool

engaged in twice as many delinquent acts as did the other two groups, including five times as many acts of violence against property. The direct instruction group also reported relatively poor relations with their families, less participation in sports, fewer after-school jobs and less reaching out to others for help with personal problems (Weikart 1989, 15).

The open framework approaches that were related to the long-term positive social outcomes are, in general, consistent with developmentally appropriate teaching practices. The Classroom Practices Inventory measures quality of care based on developmentally appropriate practices and the standards for NAECP accreditation. 


\section{Leadership Style and Maintenance of Quality Caregiving}

In spite of the constraints inherent in the child care system, some programs $d o$ maintain high standards and appropriate practices a majority of the time. Studies of leadership in public education have historically come out of three "theoretical constellations" (Maxcy 1991, 2). Leadership has been viewed as a function of the psychological character traits of the leader, the leader's behavior or style, and the school or organizational climate. Research on character traits has had mixed results as there is disagreement on how to define "trait" as well as how to categorize different traits. The number of traits identified became too large and too complex and "the search for some set of universal traits or abilities failed" (Maxcy 1991, 31). Much of the current writing in the field of organizational development (concerning private business and industry) points to the style of management used by the managers or administrator(s) as a key determinant of quality performance by workers (Drucker 1989; Helgesen 1990; Stivers and Wheeler 1986). However, the literature on style of leadership actually developed many years ago when researchers began to examine the specific behaviors of leaders, i.e., what they did.

\section{History of Research on Leadership}

In particular, the work of Kurt Lewin was important in the development of the literature on leadership style. In his Iowa Childhood Studies that he started in 1938, Lewin "sought to create different climates and test them relative to leadership" in school settings (Maxcy 1991, 31). In his work, he identified three styles of leadership in teachers: 
democratic, laissez-faire, and authoritarian:

Lewin and his graduate students found that in an autocratic environment the children appeared discontented, aggressive, and without initiative; in a laissez-faire climate children lacked direction, failed to finish tasks, and appeared frustrated; while in the democratically led groups the children appeared productive and socially satisfied, demonstrated more originality and independence, and were less hostile (Maxcy 1991, 31-2).

Lewin (1951) specifically took a look at the impact of leadership style on the behavior of workers when he analyzed the experiments by Lippitt and Lippitt and White where they "compared the amount of intermember aggression of the same group of boys in democratic and autocratic atmospheres" (207). According to Lewin, "since the personalities and types of activities were kept constant, the change [observed] can be attributed to the different social climate or form of leadership" $(1951,207)$. Lewin's analysis pointed out that people's behavior changed as the social atmosphere changed. When a democratic leadership approach was introduced into a work situation, there was a corresponding decrease in aggressive acting out by workers; and, likewise, when an autocratic leadership approach was introduced, aggressive acting out increased. Lewin concluded that "a sufficiently large change of the level of equilibrium leads to a basic change in the character of the total situation" $(1951,213)$. Lewin continued:

It is of great practical importance for any type of social management that production levels are quasi-stationary equilibria which can be changed either by adding forces in the desired direction or by diminishing opposing forces" $(1951,217)$.

When forces are added, tension is increased; and, when forces are diminished, tension is decreased.

Since increase of tension above a certain degree goes parallel with greater 
fatigue, higher aggressiveness, higher emotionality, and lower constructiveness it is clear that as a rule... [diminishing opposing forces] will be preferred to the high-pressure method [of adding forces] (217).

Yanoff and Bryan (1986) state that increasing the "number or intensity of the driving/pushing forces..." has drawbacks since this tends to "increase tension, instability and brittleness in the institution" (178). However, removing or decreasing the intensity of restraining forces will reduce "flight behavior" and increase "problem solving and decisionmaking" (Yanoff and Bryan 1986, 178). Thus, in a child care center, the administrator's leadership style, according to Lewin, ought to be one that results in reducing opposing forces, in this case child care constraints, through changing the work environment itself or the teacher-caregiver's perceptions of the work environment.

Research in the area of leadership style was also influenced by the "human relations movement." This influence brought together the literature on democratic leadership (inspired by John Dewey) and that on "behavioral science and industrial studies pioneered by the work of Elton Mayo and Kurt Lewin" (Maxcy 1991, 32). This research looked at both what the leader did to the group and what the group did to the leader, and found that morale and communications seemed to be important to a well functioning group. Decentralized authority and expanded involvement in decision making communicated to workers that their supervisor was interested in them and cared about what they were doing. Leaders who were considerate to the workers and who initiated organization or structuring of the work tended to be successful (Maxcy 1991, 33).

In a study of the characteristics of the "actions of leaders of high-performing systems," Vaill (1986) found that regardless of the leader's style, there were three 
consistent components. Leaders of high-performing systems: (1) "put in extraordinary amounts of time," (2) "have very strong feelings about the attainment of the system's purposes," and, (3) "focus on key issues and variables" (Vaill 1986, 93-4).

Style research has had some problems, one being that ieadership style was seen as a causal factor and the composition of the work group was not taken into consideration. Also, various style surveys were developed and yielded different results. According to Maxcy, "traits and behaviors research has yielded inconsistencies, prompting researchers to look at some other factor to account for leadership besides consideration and initiating structure" (1991, 33).

\section{Women and Leadership}

In looking at the leadership characteristics of child care center directors, one cannot help but note that the vast majority of people in this position are female. Literature on women in leadership positions (Helgesen 1990; Kanter 1977; Lunneborg 1990; Lenz and Myerhoff 1985), as well as literature on the ways that women think (Belenky et al. 1986; Gilligan 1982; Ruddick 1989), add a further dimension to this study. In their chapter "Humanizing the Workplace," Lenz and Myerhoff note that "the mass movement of women into the workplace has been hailed by social scientists and historians as a social change of momentous proportions, comparable to the industrial revolution or the waves of immigration in the last century" $(1985,80)$. Women are gradually feminizing the workplace as they try to integrate work and home:

As these attributes of feminine culture are brought into the workplace, they 
are providing a much-needed balance to what has been a predominantly male environment, and slowly but steadily they are eroding some of the obsolete practices and prejudices that have dehumanized work and the work environment (Lenz and Myerhoff 1985, 81).

Child care, as a service industry, has typically been a female-dominated environment. In fact, women, overall, have developed the whole field of Early Childhood Education and Development, which includes child care, preschool, Head Start, etc. (Hymes 1978a, 1978b, 1979). In light of this, one might expect child care center administrators to display a management style that includes the (so-called) "feminine" characteristics of helpfulness, nurturance, balance and complexity as described by Lunneborg in her book, Women Changing Work (1990) as well as a cooperative, caring value orientation similar to that described by authors such as Belenky et al. (1986), Gilligan (1982), Lenz and Myerhoff (1985), and Ruddick (1989). The questions developed for the interviews with administrators were based in part on these qualities or "feminine" characteristics.

\section{Humanism, Context, and Relationships}

Researchers, according to Maxcy, grew weary of simply looking at leadership style, and "switched to the notion that leadership was always context specific" $(1991,34)$, thus arriving at a more ecological approach. Work on "settings in which leading took place" (Maxcy 1991, 33) brought the literature on leadership to a place where researchers were looking for and isolating "specific situational variables determining leadership," such as structural properties of the organization, organizational climate or work environment, characteristics of each position or role in the organization, and characteristics of the 
workers themselves (Maxcy 1991, 34).

Jones (1993), looking at leadership in the context of the child care environment, advises child care administrators to adopt an approach that incorporates both a power model and a more humanistic one. The human relations model of leadership has come to be viewed as the preferred model for education (with the more authoritarian or power model being rejected) (Maxcy 1991). Jones, however, posits that the human-relations and power models of leadership are both needed and are complementary, rather than contradictory. The power model is called for in meeting all child care licensing regulations and in maintaining appropriate standards regarding sanitation, safety, and health on a consistent basis. The humanistic model is more appropriate for working with staff as they do planning and problem solving. "Finding an appropriate balance between initiative and power" is the challenge that administrators must meet in working with the program staff (Jones 1993, xvi). Jorde-Bloom's Leadership Style assessment tool measures both task orientation (compatible with the power model) and people orientation (compatible with the humanistic model).

Numerous theories of organizational effectiveness have been posited, often as pairs of opposite concepts: open/closed; robust/non-robust; input/output; needs/press; and, coherent/non-coherent (Maxcy 1991, 35). In addition, self-help books of lists have sprung up, which tell the administrator how to lead in "three easy steps." This trend toward viewing educational leadership in a mechanistic manner has given way to a new "thrust in the direction of 'humane leadership,' or 'empowerment leadership' (stressing the redirection of dictation of power, focusing upon feeling over facts, and in other ways reframing the 
leadership concept)" (Maxcy 1991, 50). In support of this shift in focus, Wheatley (1992), in Leadership and the New Science, brings to the study of leadership the new concepts coming from physics, biology, and chemistry as well as from the interdisciplinary theories of evolution and chaos. She states:

Scientists in many different disciplines are questioning whether we can adequately explain how the world works by using the machine imagery created in the seventeenth century, most notably by Sir Isaac Newton. In the machine model one must understand parts. Things can be taken apart, dissected literally or representationally (as we have done with business functions and academic disciplines), and then put back together without any significant loss. The assumption is that by comprehending the workings of each piece, the whole can be understood. The Newtonian model of the world is characterized by materialism and reductionism -- a focus on things rather than relationships (8-9).

Humane leadership is one of empowerment and teaching, facilitating and learning. It is the interaction between the leader (or administrator) and the followers (or teachers) rather than either the leader or the follower alone that influences the work environment or climate in which the caregiving/education occurs. According to Jones, the humane leadership or human relations model is "based on faith in self-fulfilling prophecies -- faith that ordinary teachers, viewed as interesting and competent by colleagues worthy of respect, will become more thoughtful about their work, will continue to seek input from others, and will thereby become increasingly empowered as critical thinkers and problem solvers" (1993, xiv).

Wheatley (1992) elaborates on the changes that are occurring in the study of leadership by pointing out that leadership is now being examined for its "relational" aspects as "more and more studies focus on followership, empowerment, and leader 
accessibility" (12). Wheatley contends that "in new science, the underlying currents are a movement toward holism, toward understanding the system as a system and giving primary value to the relationships that exist among seemingly discrete parts" (9). She goes on: "The quantum mechanical view of reality strikes against most of our notions of reality.... It is a world where relationship is the key determiner of what is observed and of how particles manifest themselves. Particles come into being and are observed only in relation to something else. They do not exist as independent 'things"' (9-10). Consisterit with the phenomenological approach, Wheatley points out how the new physics has cogently explained "that there is no objective reality out there waiting to reveal its secrets" (7). Thus, she "no longer believe[s] that organizations can be changed by imposing a model developed elsewhere...[as] so little transfers to, or even inspires, those trying to work at change in their own organization" (7). Instead, the focus must be on processes being applied and, moreover, fine-tuned to individual situations. 


\section{CHAPTER IV}

\section{RESEARCH DESIGN}

\section{Statement of the Question}

The question posed for this research is as follows: What characterizes the leadership style of the administrators of quality child care centers? I completed case studies of four child care centers that deliver quality child care. These centers were analyzed for three factors: administrative style, group interaction, and work environment thus enhancing the study's generalizability through triangulation (Marshall and Rossman 1989, 146).

\section{Sample Selection}

The choice of child care centers was patterned on an approach used by Larson and LaFasto (1989) in their study of teams and teamwork, that of purposive sampling. They rejected using a traditional random or representative sampling approach, because complex concepts such as teamwork, creativity, or in this case, leadership, are best investigated by studying many cases of individuals or groups of people who display this quality. Thei"strategy was to handpick teams -- in a sense because of their nonrepresentativeness " which, in the case of teamwork, would provide the authors with the "greatest theoretical insight into what characterizes effectively functioning teams" (Larson and LaFasto 1989, 
20). They used an informant to make up the first list of teams. As they interviewed this first group, they came up with a set of qualities that stood out. This led to the researchers looking for more teams that might have these qualities. In addition, they got leads on additional teams from individuals who had already been interviewed.

Helegsen also elected to use this purposive sampling approach in her study of women's ways of leadership (Helgesen 1990). She wanted to get a picture of the details of how they function, (the nuances in approach, the small things they do, their point of view, etc.), so she selected four outstanding women leaders to study in depth.

\section{Method for Selecting This Sample}

Centers that were included in this study were ones that initially met an established criteria for delivering quality care and, in addition, were reputed by early childhood education professionals to be excellent or exemplary centers. Centers were selected in the following manner. To begin, I limited the study geographically to two cities, City A and City B. These two cities function as a larger metropolitan area with many people working in one city and living in the other, however they are in two different states. In terms of child care, the two states have many similar rules and regulations, with a notable difference. In child care centers, the staff/child ratio for infants (0-12 mo.) is 1:8 in City A's state and 1:4 in City B's state. As it ended up, I studied two centers in each city.

Next, I created a sampling frame (in the form of a list) from which I selected the four centers for the case studies. In creating this sampling frame of centers known for their excellence, I utilized two sources. The first source was an up-to-date list of the 
NAECP accredited centers in these two states from which I extracted the names of all the accredited centers that were located within the geographical boundaries I had set for myself. Personal informants were the second source for creating a list. I contacted two personal informants, one in each city, who are professionals in the area of child care information and referral, and are quite familiar with the child care centers in these communities. When I spoke with each of them by telephone, I described to them the nature of my research and asked if they would serve as informants, explaining that their remarks would be held in complete confidence, i.e., their names would never be written down nor connected with this research in any way. They both agreed to participate. I read to them each the list of quality factors that were included in the Sample Selection Questionaire': program for children; quality and effectiveness of the staff; leadership qualities of the administrator; physical environment and equipment; parent relations and involvement; and organizational climate or work environment. Next, I read the list of NAECP accredited centers in their respective communities and asked them to tell me what they knew about these centers, using the above factors as a guide. In addition, I asked each one if there were other centers which were not on the list of accredited centers but which they felt were very good. Both informants gave me additional names. One informant felt that, on the whole, the centers that he/she suggested were the ones that he/she felt were the best and only one was an accredited center. Using the information I

'The Sample Selection Questionaire was developed by the author as a tool to facilitate the responses of the field informants on the quality of the centers in the sampling frame. A copy of the questionaire is included in the appendix. 
obtained from these two sources, I constructed the following sampling frame: eleven centers in City A and six centers in City B for a total of seventeen centers.

After completing the sampling frame, I then developed a list of professionals in the early childhood education/child care field whom I would contactfor assistance in selecting the four centers to be included in the study. This list was generated both from my own personal knowledge as an early childhood professional and from a resource list I obtained on May 20, 1993, at a presentation by the Human Services Standing Committee of the City Club of City A and City A's state Child Care Resource and Referral Network entitled, "How we can meet our child care needs in an era of limited resources". I mailed a set of sample selection questionaires to each individual on this list of professionals in the field of child care - one questionaire for each center from my list which was in their community and one blank form so they could add a center to the list. I asked them to rate each of these centers based on their personal knowledge and/or the center's reputation for program quality. The cover letter accompanying the questionaires assured confidentiality for the raters by referring to each using a numerical code (e.g., Rater \#7) and by keeping records that linked their names to their answers separate from the actual data collected.

The return of the sample selection questionaires was slow because it coincided with summer vacations. I mailed out questionaires to fifteen people in all, nine sets or $60 \%$ were returned. Of the 15 sets, 12 were sent to people in City A, 3 in City B. Seven of the twelve from City A were returned (58\%), with one of the seven declining to complete the questionaires. For City B, two of the three sent were returned (66\%). 
Five centers clustered at the top of the ratings. I These centers, in rank order, were: (1) a relatively new, on-site, employer sponsored child care center; (2) a center which is one of a larger corporate group of child care centers in the U.S. and is located in a rapidly growing area (Site B.1); (3) a non-profit child care center receiving community charitable funds, that is also the only unionized child care center in the immediate area (Site A.2); (4) a campus child care center and teacher training site, serving student, state employee, and community parents (Site B.2); and (5) another campus child care center serving students and staff (Site A.1). To select four out of the five centers, I decided to contact them in rank order, highest score first, planning to take the first four that accepted.

In June 1994, I began contacting the directors of the centers with the highest ratings to see if they would be interested in participating in the study. I mailed a letter of introduction with a brief summary of the research project and the estimated time committment required for staff and directors. I followed the letters with a phone call to discuss the directors' interest in participation and, if there was an interest, to set up a time for an introductory meeting between the director and me.

The following are the results of contacting the directors. The director of the employer sponsored center declined to participate in the project as the staff had been involved for the previous year in a rather large research project, and the director had promised the staff that the next year would be spent on their own work within the program.

The director of Site B.1 was very interested and I met with her on July 25, 1994. After discussing the project, she agreed to participate. The center observation and 
director interview was scheduled for Monday, August 15, 1994.

The director of Site A.1 was hesitant at first (stating concern about time committment and the tension of being "scrutinized") but then agreed to meet with me. We met on July 17, 1994 and had a successful visit. After I explained the project and its intent more thoroughly, she was very interested in participating but needed to talk with staff and her administrative team. During our discussion of the project, she also requested that I consider her and the two program coordinators as "the director" of the center, and I agreed. I met with the two program coordinators and the director on July 27 to explain the project to the program coordinators. Following this visit, they agreed to participate.

I contacted the director of Site B.2, explained the project, and she agreed to participate. Since I work with this person, I spoke with her at work about the nature of the project.

I sent a letter to the director of Site A.2. I followed up with a phone call on July 28. The director said she was very interested in participating in the project and we set up a meeting for August 3, 1994.

In meeting with each of the directors, I found that I would have to individualize the mechanics of obtaining the data. For example, at Site B.1, I instructed the staff on filling out the instruments during a twenty minute presentation at the monthly staff meeting. They filled them out at home and returned them to the center. At Site A.1, which has a large staff, I found I had to meet with various groups of staff members on several days from 2:10 to 3:00 in the afternoon until the intruments were completed. In addition, at site A.1 I analyzed the leadership styles of the three member administrative 
team rather than of the director alone. At Sites A.2 and B.2 I met with staff at weekly staff meetings which the core or permanent staff attend.

\section{Instrumentation}

The tools that I employed to complete these case studies include both field specific (the field being early childhood education) and non-field specific tools. The field specific tools provide more sensitive measuements than non-field specific ones because they are fine-tuned to the specific setting in which the subjects are found and are being measured, thus making them ecologically based. The non-field specific tool utilized in this study provides a way to check the field specific tools' coherence with a more robust tool that also measures the behaviors in question.

\section{General or Non-Field Specific Tools}

The tool for analysis of group interaction to be used was SYMLOG (A System for the Multiple Level Observation of Groups) developed by Robert Bales and Stephen Cohen (1979). This adjective rating method measures people's perceptions of group communication and can be used in any setting. Keyton and Springston (1990) describe SYMLOG in the following way:

SYMLOG is a theoretical and methodological system that accounts for and measures group communication behavior on three theoretically orthogonal dimensions: (a) dominant $(U=$ upward) to submissive ( $D=$ downward); (b) friendly ( $\mathrm{P}=$ positive) to unfriendly $(\mathrm{N}=$ negative); and (c) instrumentally controlled $(\mathrm{F}=$ forward $)$ to emotionally expressive $(\mathrm{B}=$ backward $)$. The 
SYMLOG method allows members to rate their perceptions of their own interaction behavior and that of other group members on the three dimensions. The group members' ratings are averaged across the group to enable a visual image of the group to be plotted in the three-dimensional SYMLOG space (group average field diagram) (235)..

Twenty-six adjective phrases represent the single dimensions and combinations of two or three of them, and "subjects respond to the adjective phrases using a 3-point scale $(0=$ never or seldom, 1 = sometimes, and 2 = often or always)" (Keyton and Springston 1990, 235). Examples of the SYMLOG Adjective Rating forms are found in the Appendix.

In terms of the validity of the adjectives used and the reliability of the instrument, Bales and Cohen (1979) state:

the three orthogonal factors which account for a large percentage of the variance [approximately $85 \%$ ]...[found in a factor analysis of the] ...adjective rating items chosen to measure the twenty-six SYMLOG vectors... [were] oriented approximately on the theoretical reference dimensions U-D, P-N, and F-B.... (296) When the six scales $[\mathrm{U}, \mathrm{D}, \mathrm{P}, \mathrm{N}, \mathrm{F}, \mathrm{B}]$ are added together into the three dimensional scales actually used for most measurement, U-D, P-N, and F-B, the [reliability (r)] coefficients are all .98 or .99(298).

In addition, Bales and Cohen (1979) point out that "an important finding for practical use is the estimate derived from the data that one can reach satisfactory levels of reliability using the results of comparatively small groups [3-7] of raters" (298).

The administrator(s), support/office staff, and teaching staff did: SYMLOG ratings of themselves and each other, using the Specific Behavior, General Behavior and Value Description Forms (Bales 1980). All the individual ratings will be added together and averaged. A SYMLOG Group Average Field Diagram will be constructed for each center and will be analyzed in terms of the placement of the administrator in relation to the 
teaching-caregiving staff, and the cohesion of the group.

\section{Field-Specific Tools}

The other tools used in this study come directly from the field of early childhood education (which includes child care). When one is trying to study how well an organization works, "effectiveness is in the eyes of the beholder" (Heffron 1989, 340). Heffron points out that:

No single, operational definition of organizational effectiveness exists.... Although dictionaries define effective as producing the intended or expected result, there is no agreement on what the intended result of organizations is or should be.... The world of organizations, private, public, and nonprofit, is too rich and diverse for any universal criteria to be appropriate (323-4).

Thus, I have chosen to use tools that are based on the collective criteria developed by the child care profession as being essential for an effective child care center.

Instruments to assess climate have been developed both for business and industry and elementary and secondary schools. However, as Jorde-Bloom points out, "the funding structure, decision-making hierarchy, methods of supervision, delineation of roles, and the nature of the work in preschool and child care programs are quite different than other work environments. This has diminished the practical utility of using other organizational climate instruments to monitor and change the early childhood work setting" $(1989,5)$.

To describe organizational climate, I had all staff complete the Early Childhood Work Environment Survey (Jorde-Bloom 1989), which is an instrument designed to "both 
describe and differentiate settings along several dimensions... [and to] serve as a useful tool for the profession to monitor and improve work settings" (Jorde-Bloom. 1988, 25). According to Jorde-Bloom (1988):

Items on the survey were drawn from interview data collected during early exploratory research and from several other organizational climate scales.... [It] analyzes the professional environment of a center.... The responses of individuals are compiled into one center profile that reflects group perceptions of current organizational practices (25-6).

In addition, the center profile is compared to the average profile based on Jorde-Bloom's collective responses gathered from all the centers that have used the survey to date.

The ten dimensions of organizational climate include collegiality, professional growth, supervisor support, clarity, reward system, decision-making, goal consensus, task orientation, physical setting and innovativeness. "One-way ANOVA was performed on each scale with school membership as the main effect" and the results showed that "all ten subscales significantly discriminated among centers ( $\mathrm{p}<.001)$ " (Jorde-Bloom 1989, 57). The internal consistency of each subscale was determined through "computation of Cronbach's alpha coefficient on a subset of each sample" (Jorde-Bloom 1989, 61). The total scale alpha coefficients for two samples were .93 and .95 (Jorde-Bloom 1989, 61).

In addition to the ten subscales which measure the ten dimensions of organizational climate, there are additional subscales to measure: "workers' commitment to the center, their perceived congruence between existing and ideal conditions, the valance or degree of importance attached to each of the organizational climate dimensions, the perceived degree of existing decision-making influence, their desired decision-making influence, and their priority ranking of six different educational goals and objectives" 
(Jorde-Bloom 1989, 40).

For describing leadership style, I had all staff members complete the Leadership Style Assessment tool (Jorde-Bloom et al. 1991) which was adapted from the work of several authors (Blake and Mouton 1969; Getzels and Guba 1957; Giammatteo 1975; Hersey and Blanchard 1982). "It assess three different leadership styles: the task-oriented style emphasizing organizational needs; the people-oriented style focusing on people and their individual needs; and the transactional style stressing an appropriate emphasis on both the center's needs and the individual worker's needs depending on the situation" (12). For eight categories of administrative behavior, the subjects have a forced choice response between three descriptions that relate to the three different leadership styles. According to the authors:

The research in this area suggests that the most effective organizations tend to be those that apply a transactional leadership style - an ability to adjust their style to the demands of each situation so that both organizational needs and individual needs are met (Jorde-Bloom et al. 1991,12).

An example of this instrument is included in the Appendix.

In addition, I conducted a semi-structured interview with each administrator about her management style. I developed a set of open-ended questions that pertain both to child care center functioning and to findings from authors who have studied (1) women's thinking style, such as Belenky et al. (1986), Gilligan (1982), and Ruddick (1989); (2) women in leadership, such as Helgesen (1990), and Kanter and Fassel (1977), Lenz and Myerhoff (1985), Lunneborg (1990); and (3) ways to improve organizational functioning, such as Heffron (1989), and Schaef and Fassel (1988). The questions were pre-tested 
with an administrator of a half-day preschool to see if her answers were what I was trying to elicit. Questions were adjusted accordingly.

Confirming Classroom Quality

For measuring developmentally appropriate practice (program quality), I used the Classroom Practices Inventory (Hyson et al. 1990). This tool is a "26-item rating scale tapping the curricular emphasis and emotional climate of programs for 4- and 5-year old children [and is] ...based on NAEYC's Guidelines for Developmentally Appropriate Practices for 4- and 5-year-old children" (475). This tool was used only in observing the preschool classrooms (excluding any classrooms for infants, toddlers, and school-agers) as a simple measure of the center's quality. The authors state that in their research, "the measure demonstrated excellent internal consistency and good levels of interobserver reliability, even when observers were not present at exactly the same times" (Hyson et al. $1990,488)$.

\section{Inter-instrument Consistency}

SYMLOG is a tool that can be applied to written material that describes behavior. To see how the field-specific tools I was using compared to the SYMLOG rating, I completed a SYMLOG rating on the descriptions of behavior in the Work Environment and Leadership Style Surveys. 
Comparison of the Early Childhood Woirk Environment Survey and SYMLQG

Jorde-Bloom (1989) provides a discussion of the ten dimensions of organizational climate and the research related to each. I went through these descriptions and did a SYMLOG rating of the adjectives that she uses to describe each of the ten dimensions, treating the survey as a whole. Each adjective used in her descriptions was given a score of 2 (out of $0,1,2$ ) to expand the diagram as much as possible. If an adjective was repeted within a dimension description, it was scored only once. However, if an adjective was used in more than one dimension, each case was given a score. I prepared a directional profile and field diagram for the survey. The directional profile resulted in the following rating: $6 \mathrm{U}, 16 \mathrm{P}, 2 \mathrm{~F}$. This rating is described as representing the values of social solidarity and progress and the behavior of a purposeful, democratic task leader (Bales 1980 , n.p.).

\section{Comparison of the Leadership Style Assessment Tool and SYMLOG}

The Leadership Style Assessment Tool separates leadership style into three styles: task-oriented, people-oriented, and transactional (or more balanced). Subjects are asked to choose one out of three sets of descriptions that relate to each style in response to six aspects of leadership style. I did a SYMLOG rating on this tool, rating each of the 18 descriptions. As done previously, I assigned a rating of 2 (out of $0,1,2$ ) to each SYMLOG descriptor to achieve an expanded result. With this tool, I treated each of the three styles separately in the directional profile. The Task-oriented Style (14U, 8N, 16F) describes values of law and order or powerful authority and behavior that is authoritarian, 
controlling and disapproving. The People Oriented Style (14U, 14P, 14B) describes behavior that is entertaining, sociable, smiling, and warm and values such as making others feel happy. The Transactional Style (12U, 16P, 16F) is described in SYMLOG as a purposeful, democratic leadership style with values of social solidarity and progress.

For both the Leadership Style Assessment Tool and the Early Childhood Work Environment Survey, the preferred style and climate are located in the SYMLOG dimension of UPF, i.e., behaving as a purposeful democratic task leader (behavior description) or belief in social solidarity and progress (value description). The UPF dimension describes behavior that seems dominant, friendly, and instrumentally contolled. For example, a person rated as being UPF "takes the initiative in persuading or offering to help the group on a task of confronting the group as a whole, offers democratic leadership, or tries to smooth out conflicts between group members by mediating, conciliating, or moderating so as to get ahead with the tasks of the group" (Bales and Cohen 1979, 357).

A high rating on the Early Childhood Work Environment Survey translates into a UPF (though not terribly high on F) location on the SYMLOG field diagram. The Transactional style on the Leadership Style Assessment Tool is clearly in the UPF location. If the directors in this study are rated as having a Transactional Style and if the center receives relatively high ratings on the Work Environment Survey, Part A: Organizational Climate, and if the directors are rated as displaying UPF behavior using SYMLOG, then the compatability among the three measurment tools used can be assumed. This study, in fact, did find the above described conditions, confirming that the 
tools were indeed compatible for describing leadership style and organizational climate.

\section{The Development of the Interview Quiestions}

Each of the questions, its purpose, and supporting documentation from the literature follow.

\section{Describe your style of administration.}

\section{PURPOSE: TO HEAR WHAT WORDS THE ADMINISTRATOR SELF- SELECTS TO DESCRIBE HER APPROACH TO MANAGEMENT.}

Schaef and Fassel (1988): To be healthy, "leadership in organizations would be diffused and situational;" and "the concept that every person has a leadership role and responsibility (the ability and necessity to respond) would be integral to the structure and process of the organization" (221).

Belenky et al. (1986): In a discussion on women as teachers ${ }^{2}$, the authors comment that the role of being a "connected" teacher "does not entail power over the students; however it does carry authority, an authority based not on subordination but on cooperation" (227)

Gilligan (1982): In a discussion on perceptions of power, she states that "while men represent powerful activity as assertion and aggression, women in contrast portray acts of nurturance as acts of strength" (167-8).

Lunneborg (1990): She found that women in her study had "an attraction to managing others using power differently than men did."

Heffron (1989): Karl Weick suggests that in effective organizations, people talk a lot (339); thus, there should be a focus on face-to-face communication among staff.

Helgesen (1990): In her interviews of four women leaders, she found that women "focused on the ecology of leadership" (25) and "saw their identities as complex and

2 "If research on leadership reveals anything it tells us that all leadership must involve teaching and learning" (Maxcy 1991, 50). Thus, documentation on how women teach can be applied to the analysis of women in leadership positions. 
multifaceted" (26). They were process-oriented and emphasized relationships with people. They saw people and work as ends in themselves, rather than as means to another end (29).

2. Tell me how decisions are made, regarding:

staffing and scheduling

budgeting

children's program

physical facility

\section{PURPOSE: TO DETERMINE THE EXTENT OF PARTICIPATION BY THE} STAFF IN DECISION MAKING.

Kanter and Fassel (1977): In their small observational study of all-female groups and organizations, they found that those women who were most successful and effective were "interested in empowering subordinates (sharing power with them)...[and] ...the most collaborative and humane" (302). "They have political connections in the wider system, and they know how to make subordinates feel powerful in their own right" (303).

Heffron (1989): Karl Weick states that the people in effective organizations do not adapt to change too easily; yet they are not always rational for, in spite of resistance to change, to be effective, one "avoids overreliance on past experiences and the know'edge derived from it, which is not necessarily valid in changed circumstances" (339). Making significant changes, especially in the children's program is frequently resisted by staff in child care centers.

Belenky et al. (1986): In a discussion of the teacher as a "midwife" to her students, the authors describe the teacher as one "who would help [the students] articulate and expand their latent knowledge" (217).

Gilligan (1982): "Women...are ideally situated to observe the potential in human connection both for care and for oppression.... In relationships of temporary inequality, such as parent and child or teacher and student, power ideally is used to foster the development that removes the initial disparity" (168). 


\title{
3. How do you organize your time and responsibilities? What are your priorities?
}

\author{
PURPOSE: TO DETERMINE HOW WELL SHE BALANCES THE \\ MANY FUNCTIONS OF A CHILD CARE DIRECTOR AND TO FIND \\ OUT WHAT HER VALUES ARE BY LOOKING AT HOW SHE \\ PRIORITIZES HER WORK.
}

Gilligan (1982): "When women construct the adult domain, the world of relationships emerges and becomes the focus of attention and concern" (167). Gilligan states that women develop in a different way; "women find order where others saw chaos.... These discoveries required new modes of analysis and a more ethnographic approachl in order to derive constructs that could give order and meaning to the adult life they saw" during their development (169). Thus, the organization and maintenance of relationships would be expected to be a priority.

Helgesen (1990): In her interviews with four successful women in leadership, she found that the women: "worked at a steady pace, but with small breaks scheduled throughout the day" (19); "did not view unscheduled tasks and encounters as interruptions" (19); "made time for activities not directly related to their work" (22); "preferred live action encounters, but scheduled time to attend to mail" (24); and "scheduled time for sharing information" (27).

\section{How do you maintain quality caregiving by the staff?}

\section{PURPOSE: TO DETERMINE IF THE ADMINISTRATOR IS AWARE OF THE IMPACT OF ORGANIZATIONAL CLIMATE AND MANAGEMENT STYLE ON THE QUALITY OF CAREGIVING. TO FIND OUT WHAT THE ADMINISTRATOR THINKS ARE THE KEY DETERMINANTS OF QUALITY.}

Heffron (1989): "Unfortunately, organizations suffering from decreased resource availability are not going to be able to avoid serious employee morale and satisfaction problems. Reality and fairness indicate that a new set of criteria for measuring treatment of employees be derived for organizations experiencing decline [of resources compared to need]" (342).

Lenz and Myerhoff (1985): "A service/information economy does not lend itself to massive bureaucratic organization" (82). I would expect to find few levels of bureaucracy in child care center organizations.

Heffron (1989): "Schools' efficiency is frequently measured by cost per student, but students are not really their outputs -- they are in fact one of the inputs" (341-2). I would 
expect administrators to measure success in holistic ways, in context, and to value processes over end products.

Belenky et al. (1986): In their discussion of teachers as midwives, they discuss the process that women engage in which is a "cycle... of confirmation -- evocation -- confirmation" (219), whereby the teacher [or administrator] encourages the student [or staff member] to start with their own learning or knowledge and to confirm that which is true. Then the teacher through presentation of more information or a question evokes the student to come up with yet more knowledge which the teacher and student can then confirm again.

Heffron (1989): Karl Weick states that effective organizations have "grouchy" members who complain a lot and are "never satisfied"; this is the sign of a healthy organization and of healthy people, as a lack of complaints is "dangerous in a dynamic environment" (340). I would expect the administrators to welcome complaints and constructive criticism and to build in a time for staff to air problems.

5. How do you balance your job here in the child care center and your life outside of the center?

PURPOSE: TO DETERMINE IF THE ADMINISTRATOR

INTEGRATES HOME AND WORK OR IF SHE MAINTAINS A

CLEAR SEPARATION BETWEEN THE TWO. TO DETERMINE IF

THE ADMINISTRATOR ALLOWS WORK TO INTERFERE WITH HER PERSONAL/FAMILY LIFE OR VISA VERSA.

\section{EXPECT THIS TO BE AN AREA OF CONCERN AND STRUGGLE FOR ADMINISTRATORS.}

Lunneborg (1990): In her book Women Changing Work, she found that one of the "four major, dominant, higher order themes" was that of "an insistence upon a balanced lifestyle" (xviii).

Gilligan (1982): In her discussion of men and women's languages of rights vs. responsibilities, she states that ".hese languages articulate with one another in critical ways. Just as the language of responsibilities provides a weblike imagery of relationships to replace a hierarchical ordering that dissolves with the coming of equality, so the language of rights underlines the importance of including in the network of care not only the other but also the self" (173). This implies that the ideal situation would be to find a balance between connectedness and preservation of one's individuality.

Lenz and Myerhoff(1985): These authors state that the feminization of the workplace is providing a needed balance to this traditionally male dominated environment. "Much of 
this change is linked to women's deeply rooted need to integrate love and work. The work-home division grates against the feminine sensibility" (81). The implication here is that women bring a point of view and a purpose from the "home" into the workplace.

Helgesen (1990): This author found that the women she interviewed "maintained a complex network of relationships with people outside their organizations" (24).

6. What about the personal lives of staff members - what are your expectataions for how much of the personal can come into the workplace or into your awareness?

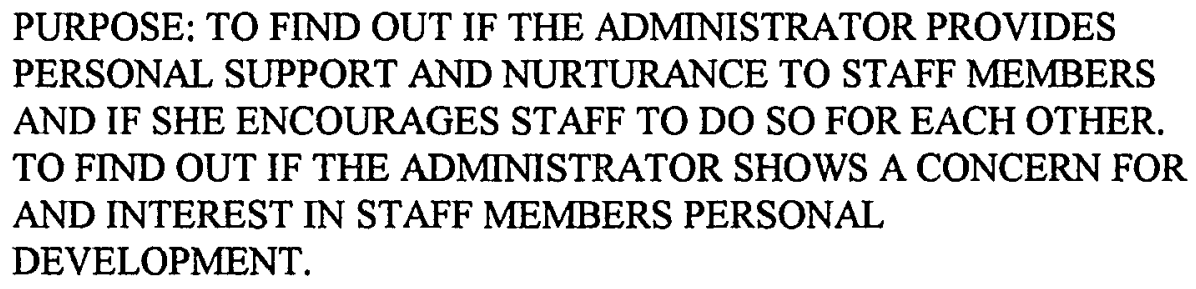

Gilligan (1982): She notes that women "define their identity through relationships of intimacy and care..., and attachment is supported by an ethic of care" (169).

Lunneborg (1990): One of the "four major, dominant, higher order themes" that she found was "a nurturant approach to coworkers" (xviii).

Schaef and Fassel (1988): In their work The Addictive Organization, the authors state that in a healthy organization, "There would be awareness that the structure and the system, that is, the way of organizing the work, are integral to the company's mission and must support and facilitate the work of the organization" (219). In other words, organizations that heal should promote health in the people who work there; and, likewise, organizations that provide caregiving should care for their employees.

Gilligan (1982): Attachment and affiliation are key in women's development.

7. How do you work with parents? How do you expect staff members to work/interact with parent?

PURPOSE: TO DETERMINE THE ADMINISTRATOR'S APPROACH

AND ATTITUDE TOWARD "CLIENTS" OR "CUSTOMERS." TO

DETERMINE THE LEVEL OF PARENT INVOLVEMENT THAT THE ADMINISTRATOR EXPECTS OR ENCOURAGES.

Gilligan (1982): She states that women use an "ethic of resporsibility" which "relies on the 
concept of equity, the recognition of differences in need" (164).

Lunneborg (1990): One of the "four major, dominant, higher order themes" that was found about women was that they had a "service orientation to clients" (xviii).

\section{Additional Information and Feedback}

Finally, I collected additional data on the program structure and the staff that relate to prior research on determinants of quality, that is, I noted staff/child ratio, total group size, staff qualifications, type of curriculum, teacher training, longevity of employment, rate of pay and benefits provided, and arrangement of materials and equipment in the classroom.

After observing and collecting data from each of the centers in the study, I met with each director to report the findings and arrange for the feedback session. The individual feedback session with the staff of each center were very well received. 


\section{CHAPTER V}

\section{FINDINGS}

\section{Introduction}

The four cases in this study are presented in the order in which they were done. For each of these child care centers, the following information was collected and is presented in this section a description of the center, the administrator's replies to the interview questions, the group averages of the Leadership Style Assessments of the administrator(s), the aggregated results from the Work Environment Profile, and the group average SYMLOG field diagram. As the findings are presented, references to supportive information from the literature review and the research design chapters have been inserted to begin the analysis.

At the end of each center's section is a summary of the findings relating to the administrator(s) leadership characteristics and the work environment, with an overall summary following the fourth center. In an effort to make the various research tools more accessible to the reader, the first case will have a more comprehensive explanation of the findings, and the subsequent three cases will make reference to this material. This chapter ends with the overall summary and analysis wherein the centers are compared to each other in a manner that highlights both their similarities and their differences. Significantly different characteristics of any individual case will be noted and discussed. In the chapter that follows, the implications of this study are discussed which set these findings into their 
larger context.

The four centers that ultimately comprised the sample provide a diverse picture of child care. They vary in size, staff structure and composition, ages served, populations served, organizational structure, tax status (for- or not-for-profit), source of income, location of facility, characteristics of facility, and level of pay. One thing that they all have in common, though, is that the leadership positions are occupied by women. The interviews with the directors were designed to see if, in fact, any or all of them employed a female style of leadership. Through an analysis of their answers (as indicated in footnotes throughout the interviews), a female style was confirmed for all of the directors and the two program coordinators.

The quality of the children's program of the centers was confirmed through on-site observations using the Classroom Practices Inventory. The results of the observations supported the evaluations, made by the informants who participated in the sample selection, which indicated that all the centers provide high quality, developmentally appropriate programming for young children. All programs met or exceeded their state's licensing standards for adult-child ratio and group size. The children's classrooms all had ample, appropriate equipment and rooms were arranged using interest or activity centers. Materials were on low shelves and available for the children to use freely. The children's programs all appeared to be philosophically child-centered and based in active exploration and play. All of these characteristics have been found to be related to high quality programming (Schweinhart and Weikart 1996; and Weikart 1989). 


\section{Center B, 1: Observation, Interview, and Findings}

The observation of this center and interview with the director (herein referred to as

Director B.1) occurred on September 22, 1994.

\section{The Setting}

Center B. 1 is one of a number of child care centers that are part of a for-profit corporation'. Managers in the corporation select the directors for each of their sites. Each center building is designed in a similar manner, but it is up to each director to decorate, furnish, and arrange the various rooms and areas. Center B.1 was opened 10 years ago in an empty field. Today the surrounding area is filled with residential and commercial buildings as it is located in a rapidly expanding area of City $\mathrm{B}$. The area is populated primarily by middle and upper-middle income families. The vast majority of the children observed in the center appeared to be of European-American origin. The staff of the center were all female, and appeared to be of European-American origin.

Center B.1 is housed in a single story structure which was designed to be a child care facility. In front of the building is a lawn area with several mid-size trees and low bushes which are all well maintained making the entrance inviting. The children's outdoor

\footnotetext{
${ }^{1}$ The Cost, Quality, and Outcomes Study Team (1995) reported quality differences between non-profit and for-profit centers in areas such as: staff-child ratios; specialized and formal teacher training; prior experience; wages; and, staff-turnover. However, Center B.1 does not fit in this pattern, except in the case of wages (43).
} 
play space is located in a fenced area behind the building and an employee parking area is to the right of the building.

The entry way to the center is glass allowing the visitor to see into the center before entering. The reception area is decorated with a contemporary "country" theme, large green plants, and a wicker couch with colorful cushions. There are bulletin boards on the walls with information for parents. The center is NAECP accredited. There are NAEYC posters on the walls that feature pictures of young children and a statement that has meaning for early childhood education or development. A counter and desk area is located to one's immediate right upon entering the building. This is where the assistant director works. The director's office adjoins it. The kitchen and a storage area are in the center of the building and the five classrooms are arranged in a semi-circle around them.

The interview with Director B.1 was conducted over a two hour period during which I also observed in the classrooms. The assistant director was gone from the site shopping and two sets of prospective parents came to see the center, one with an appointment, and one without. While Director B.1 met with these parents, I observed in the rooms.

Center B.1, has a total licensed capacity (number of students at any one time) of 126 and a total student enrollment (part plus full time) of 130 . There are 17 staff members, 10 of whom work $35+$ hours per week. (Director B.1 considers anyone working $30+$ hours per week to be full time.) They provide care for toddlers, preschoolers, kindergarten and school-aged children. They are open from 6:30 a.m. until 6:30 p.m. They provide additional classes for the children (for which parents pay an 
additional fee if the child enrolls in the class) at the center. These include classes in ballet, Tai Kwon Do, tumbling, and computers.

Staff members receive pay plus benefits which include: medical and dental insurance; annual leave time which accrues during the first year of employment ( and can be used for vacation, personal business, and illness); holiday pay; discount on child care at the center; loans for education; reimbursement for college level E.C.E. classes; and ongoing training opportunities. The yearly salaries at Center B.1 range from $\$ 14,000$ at the top to below $\$ 5,000$ at the bottom. This center had the lowest salary range of all four centers. This is consistent with the literature on salaries which states that for-profit centers have lower salary ranges than non-profit centers, however the most recent literature also reports that in spite of this pay disparity "quality is not significantly different" between the two sectors. (Cost, Quality, and Child Outcomes in Child Care Centers April 1995, 8).

The Interview with Director B.1

Director B.1 has been the director of Center B.1 for eight years, and has been with the corporation a total of 10 years. Before coming to this site she was twice promoted and transferred to different centers. She has a B.A. degree in Early Childhood Education from an area State University. The questions and Director B.1's responses follow:

\section{Describe your "style" of administration:}

Director B.1 stated that she didn't consciously choose a style, but rather "felt" her 
way through as she went along. She said that she tries to find "strong" people for staff positions and then likes to "give them autonomy" within the rules and requirements set by state child care licensing, the Center B.1's parent corporation, and NAECP accreditation. As long as the requirements are met, the teachers can "do their own thing." ${ }^{2}$ She feels that this approach has been instrumental in the longevity that they have among staff. One person has been there since the center opened, one for eight years and another for five.

"Teamwork is stressed" according to Director B.1. She feels that when the staff have common goals and one of those is "being the best" they can be, that quality caregiving is increased. One of the goals of the center is to care for the "whole family unit," not simply the child in care. ${ }^{3}$

What I observed during my visit was that Director B.1 made the time to personally greet and casually talk to both parents and staff moving in and out of her office in a relaxed manner. Staff member's time sheets and memo boards were in Director B.1's office as was the copy machine. Thus, staff members moved freely in and out of her

\footnotetext{
${ }^{2}$ To be healthy, "leadership in organizations would be diffused and situational;" and, "the concept that every person has a leadership role and responsibility (the ability and necessity to respond) would be integral to the structure and process of the organization" (Schaef and Fassel 1998, 221).

${ }^{3}$ In a discussion on women as teachers, the authors comment that the role of being a "connected" teacher ["leadership must involve teaching..." (Maxcy 1991, 50)] "...does not entail power over the students; however it does carry authority, an authority based not on subordination but on cooperation" (Belenky et al. 1986, 227).

In a discussion on perceptions of power, Gilligan (1982) states that "while men represent powerful activity as assertion and aggression, women in contrast portray acts of nurturance as acts of strength" (167-68).
} 
office. (Director B.1's office has a desk, her chair, an additional chair and a small couch as furniture. The couch made the office inviting for staff to come in and sit down in a comfortable place. $)^{4}$

2. Tell me how decisions are made, regarding:

Staffing and scheduling. Director B.1 makes staffing decisions and tries to maximize the use of full time (30+ hours/week) teachers so that the children have the fewest number of teachers as possible, resulting in greater consistency. She selects staff and places them in particular rooms based on how well they fit with other staff in order to build a successful team, and how suited they are for working with the particular age groups. ${ }^{5}$

Budgeting. The B.1 corporation provides the director with a budget which she must follow. The teachers are allotted a budget each month for purchasing materials (a new game, glitter, special markers, etc.) other than the basics (paper, paint, paste, crayons, etc.). The amount the teacher gets each month is prorated based upon enrollment in that classroom. Director B.1 has the teachers make wish-lists for bigger equipment, and this is

\footnotetext{
${ }^{4}$ According to Heffron (1989), Karl Weick suggests that in effective organizations, people talk a lot (339), thus, there should be a focus on face-to-face communication among staff.

${ }^{5}$ In her interviews of four women leaders, Helgesen (1990) found that women "focused on the ecology of leadership" (25), were process oriented, and emphasized relationships with people (29).
} 
purchased when the budget allows. ${ }^{6}$

Children's program. Center B.1's parent corporation has an education department which does on-going training and produces training materials such as skill lists, samples of activities, etc. The training materials are designed to be developmentally appropriate for each age group, and give an outline of curriculum for each class. It is up to each teacher to decide specifically on what will happen in her or his room. ${ }^{7}$ Staff meetings are held monthly where curriculum idea brainstorming happens frequently. ${ }^{8}$

Physical facility. Director B.1 believes in keeping teachers in their same rooms year after year, if possible, so they can feel a sense of ownership. ${ }^{9}$ Teachers decide on their room arrangement and decoration. The center has a maintenance person who comes in on a monthly basis to do small repairs and major cleaning, though Director B.1 complained that it was hard to get someone who was really good. She is currently trying

\footnotetext{
${ }^{6}$ Kanter and Fassel (1977) found that those women in leadership who were most successful and effective were "interested in empowering subordinates (sharing power with them)"(302).

${ }^{7}$ In a discussion of the teacher as a "midwife" to her students, Belenky et al. (1986) describe the teacher as one "who would help [the students] articulate and expand their latent knowledge" (217).

${ }^{8}$ Karl Weick (as cited in Heffron 1989) states that the people in effective organizations do not adapt to change too easily; yet they are not always rational for, in spite of resistance to change, to be effective, one "avoids over reliance on past experiences and the knowledge derived from it, which is not necessarily valid in changed circumstances" (339).

${ }^{9}$ According to Gilligan (1982), "Women... are ideally situated to observe the potential in human connection both for care and for oppression.... In relationships of temporary inequality... [such as center director and teacher], power ideally is used to foster the development that removes the initial disparity" (168).
} 
an experiment with a new form of sound proofing to control noise levels, a common problem in child care.

\section{How do you organize your time and responsibilities? What are your priorities?}

Director B. 1 is a morning person, so she comes in at opening (6:30 a.m.) and is able to greet parents daily. ${ }^{10}$ She delegates responsibilities to others, but supervises. She tries to be available to both parents and staff. Her top priorities (not necessarily in this order) are: 1. children and families; 2. emergencies; and, 3. staff.

Through observation, two of these priorities were clear: children and families; and, staff. I observed Director B.1 personally greeting parents and children by name. She knew a lot about them and was able to have meaningful conversations with them. Two families came in to see the center and I observed her personally talk to the parent(s) and give them the center tour. In addition, during the interview, she had several phone calls from prospective parents and I observed her speak to each person in a very personal and patient manner, even though in most cases, the requests were for the school-age program which had a waiting list of 25 at that point."

I also observed Director B.1 interact with staff as she moved about the center. The staff seemed comfortable having her in their rooms and she seemed to have a very

\footnotetext{
10 "When women construct the adult domain, the world of relationships emerges and becomes the focus of attention and concern" (Gilligan 1982, 167).

${ }^{11}$ Successful women in leadership "did not view unscheduled tasked and encounters as interruptions" (Helgesen 1990, 19).
} 
collegial relationship with each member. At the staff meeting ${ }^{12}$ that I attended, Director B.1 provided dinner for the staff, in a casual, though organized, atmosphere. Staff were friendly, relaxed, and joking with each other. The staff, including the assistant director, chose to sit with each other rather than at the table where the director's notebook was placed. The last staff member to sit down with her plate noted that no one else was sitting at Director B.1's table and chose to sit there, making a statement to the effect.

Director B.1 is a list maker, and each day she makes a list for the next. She uses a calendar for appointments and planning. Director B.1 stated that due to the number of years of experience that she has had, she is able to project needs of the staff and center and thus be proactive and anticipatory. Administrator's prior experience is one of the specific variables related to quality of child care (Cost, Quality, and Outcomes Study Team 1995, 41).

The assistant director is Director B.1's support person. Director B.1 talked about having had one assistant director with whom she teamed extremely well. That person was eventually promoted to a position of Center Director at another site and Director B.1 had to get a new assistant. She talked about how much easier her job is when she has a highly compatible assistant.

Director B. 1 noted that she often gets many tasks started but doesn't get them finished until later, due to interruptions. She feels that this is something she should change

\footnotetext{
${ }^{12}$ In Helgesen's interviews with four successful women in leadership, she found that the women "scheduled time for sharing information" $(1990,27)$.
} 
or improve upon. ${ }^{13}$

\section{How do you maintain quality caregiving by staff?}

Center B.1's parent corporation provides a check list for quality assurance that is done regularly. Staff get on-going training once a week during nap time on topics such as child development, guidance, practices, etc. At the monthly staff meetings there is often some type of training. Staff are also encouraged to take local workshops provided by the Educational Service District and regional workshops provided by Center B.l's parent organization. College classes in early childhood education are encouraged and the director will reimburse staff for tuition of classes that are successfully completed. ${ }^{14}$

\footnotetext{
${ }^{13}$ Here is the first example from the interviews of an observation that I made during this research. I observed that, in spite of the fact that these centers were known to be of high quality both by reputation and objective evaluation by others, and in spite of the fact that: the use of a female style of leadership is reported in the literature as being both effective and necessary to achieve a needed balance in organizations, the administrators of these high quality centers felt that some aspects of the way they were leading were wrong or ineffective and needed change or improvement, typically in the direction of a more linear or "male" style of behavior.
}

${ }^{14}$ Heffron (1989) brings economic priorities into the picture. Child care has never had generous financial resources, so administrators have to make choices of how to spend what they have. "Organizations suffering from decreased resource availability are not going to be able to avoid serious employee morale and satisfaction problems. Reality and fairness indicate that a new set of criteria for measuring treatment of employees be derived for organizations experiencing decline [of resources compared to need]" (Heffron 1989, 342).

In their discussion of teachers as midwives, Belenky et al. (1986) describe the process that women engage in whereby the teacher [or administrator] encourages the student [or staff member] to start with their own learning or knowledge and to confirm that which is true. Then the teacher through presentation of more information or a question evokes the student to come up with yet more knowledge which the teacher and student can then confirm again (219), 
Quality is also maintained through casual peer observation by team members and administrators. ${ }^{15}$ When I attended the monthly staff meeting to give instructions to the staff for completing the questionnaires, a "Good Interaction" award was given to two staff members. They were nominated by co-workers who observed the members in an particularly appropriate interaction with a child or group of children. The award itself was a small, attractively wrapped gift that Director B.I bought for this monthly award.

\section{How do you balance your job here in the child care center and your life outside?}

Director B.1 laughed when I asked this question. She lives in City A. She has two children and a husband. One of the children is enrolled in the center, which makes child care pick-up and delivery much easier. Her husband is also in education and is very supportive of her career, as she is of his.

Director B. 1 comes in at opening, and tries to leave before 5:00 in the evening. She copes with the early morning staff calls due to illness by being at the center at $6: 30$. The rule is that a staff member who is ill must call the center between 6:30 and 7:00 a.m., and Director B.1 arranges a substitute. If the ill employee anticipates that he or she will still be absent the next day, she or he must call by 5:00 p.m. the day before. (Getting calls early in the morning at home from ill employees is a common intrusion of center business into the home life of a child care center director.)

\footnotetext{
15 "A service/information economy does not lend itself to massive bureaucratic organization" (Lenz and Myerhoff 1985, 82).
} 
Director B.1 stated that she "forces" herself to make time for her family and "tries" not to take major projects home, though that is not always possible. ${ }^{16}$ She attempts to pick up her older child by 4:00 on as many days as she can.

\section{What about the personal lives of staff members - what are your expectations for how} much of the personal can come into the workplace or into your awareness?

In response to this question, Director B.1 stated that she has rules, but bends them. She talked of the contradiction that one faces when the philosophy of the center is to be understanding and supportive of families and their problems and, at the same time, staff members are expected to keep all their personal and family problems separate from their work. She said that she tries to know what is happening with each staff member in their personal lives but not to be overly involved. ${ }^{17}$

The point that Director B.1 emphasized was that she tries to be consistent in how she treats each staff member. She feels that to be consistent is to be fair, and to be fair is

\footnotetext{
${ }^{16}$ In her book, Women Changing Work, Lunneborg found that one of the "four, major dominant, higher order themes" was that of "insistence upon a balanced life-style" (1990, xviii).

In her discussion of men and women's languages of rights vs. responsibilities, Gilligan states that "these languages articulate with one another in critical ways. Just as the language of responsibilities provides a weblike imagery of relationships to replace a hierarchical ordering that dissolves with the coming of equality, so the language of rights underlines the importance of including in the network of care not only the other but also the self" $(1982,173)$.

${ }^{17}$ Gilligan (1982) notes that women "define their identity through relationships of intimacy and care..., attachment is supported by an ethic of care" (169).

One of the "four major, dominant, higher order themes..." that Lunneborg (1990) found was "a nurturant approach to coworkers" (xviii).
} 
very important.

7. How do you work with parents? How do you expect staff members to work/interact with parents?

Director B.1 encourages staff to have open communication with families. She hopes that there is a close rapport between staff and parents from the outset, and that staff practice consistency in working with all families. The hallway bulletin board has memos to parents from each of the classroom teachers about what activities the children have been doing. Director B.1 feels that part of their job is parent education. They need to educate families about their children, but also about child care as a profession. ${ }^{18}$

${ }^{18}$ One of the "four, major, dominant, higher order themes" that Lunneborg (1990) found about women in leadership was that they had a "service orientation to clients" (xviii). 


$$
\text { Center B.1 - Director B.1 }
$$

SCORING SHEET FOR LEADERSHIP STYLE ASSESSMENT TOOL

To score part I, tally the responses by noting with a mark each time staff checked a particular response:

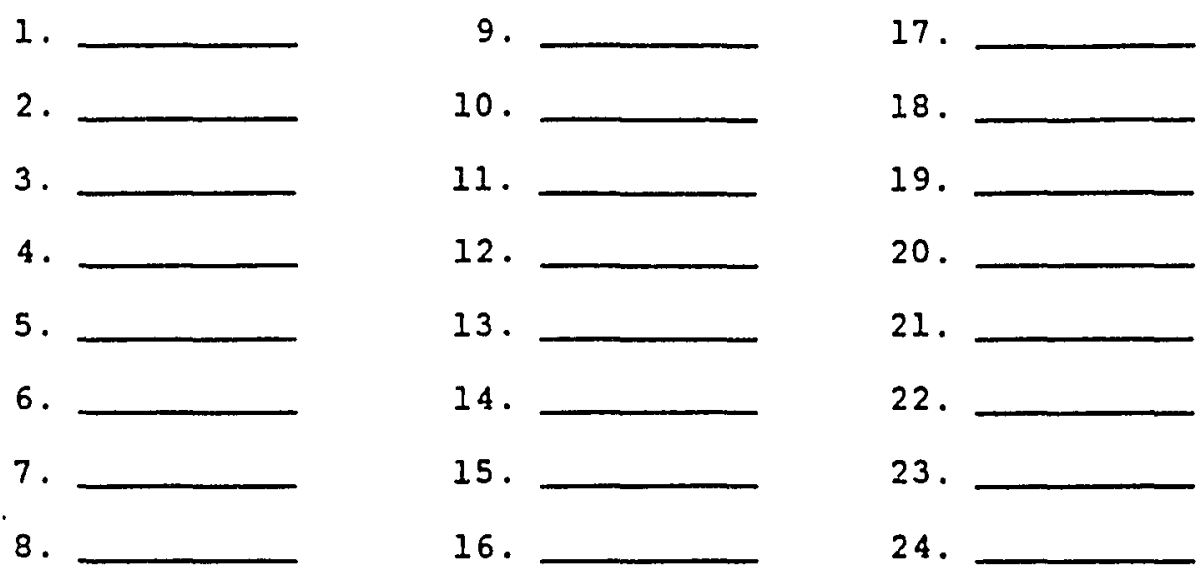

Now total the marks for the following responses:

Task-oriented: $1,6,8,10,14,17,19,22$

Total $=\underline{x}=2.86$

Achieving center goals is most important in this leadership style. Strong concern for high performance and accomplishing tasks. Emphasis is on planning, directing, following procedures, and applying uniform standards and expectations for all. This director may be viewed as too structured, bureaucratic, and inflexible.

People-oriented: $2,4,7,11,15,18,20,24 \quad$ Total $=\underline{x}=1,4$

Achieving harmonious group relations is foremost in this leadership style. Strong emphasis on maintaining comfortable, friendly, and satisfying working conditions. Allows staff to exercise control and be self-directed with minimal intrusion of center-wide policies and procedures. Staff working in centers with this style of leadership may complain about the lack of order and coordination.

Transactional: $3,5,9,12,13,16,21,23 \quad$ Total $=\bar{x}=3,8$

Achieving both center goals and maintaining high morale is important in this leadership style. This director is flexible and fair, recognizing that different situations may require a different emphasis on center-wide needs or individual needs. 


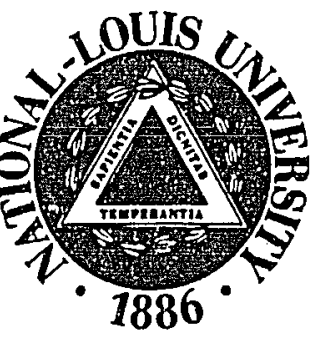

Nomo: CENTER B.I -....

Total administrative, teaching, and support staff: 17

Number of staff completing survey: 13

Employmens pattem of respondents:

7 employed full-time (35 hours por week or more)

4 employed part-time $(20.34$ hours por week)

2 employed part-time (10-19 hours por wook)

0 data not provided by respondent

PART A. ORgaNIZATIONAL CLIMATE $(N=13)$
EARLY CHILDHOOD PROFESSIONAL DEVELOPMENT PROJECT 1000 Capitol Drive, Wheeling, llinois 60090-9066

Phone: 708/465.0575 ext. 5551 Fax: 708/465.5617

\section{WORK ENVIRONMENT PROFILE}

Date: March 8, 1995

Code: 390

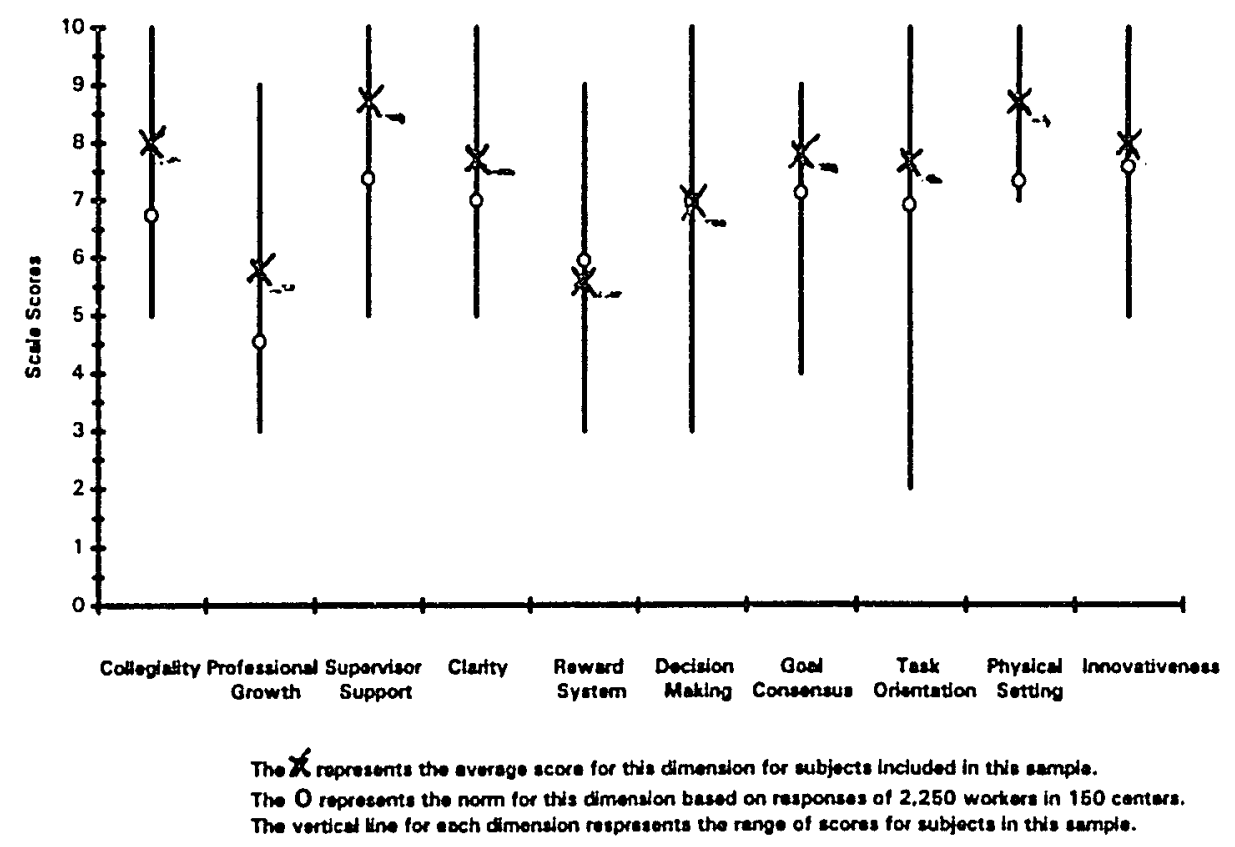




\section{Part A. Qrganizational Climate}

This profile provides a summary of the respondents' answers to questions pertaining to the ten dimensions of organizational climate. The vertical axis indicates that the lowest possible score for each dimension is 0 and the highest possible score is 10. The vertical line for each dimension indicates the range of scores (high and low) for your school. The circle represents the mean score on this dimension for 2,250 early childhood workers who have completed the Work Environment Survey. The $X$ shows the average rating of the respondents from your center with respect to each dimension.

The number of respondents' surveys used for Part A of your Work Environment Profile is indicated by the notation $N=$. If this number differs from the total number of staff who completed surveys, it is because some surveys were incomplete or filled out incorrectly. Incomplete surveys were not used in the data analysis.

The following provides a fuller explanation of how to interpret the ratings for each dimension.

Collegiality: This dimension measures the extent to which staff are friendly, supportive, and trust one another. A high score indicates that staff feel free to express their feelings. They believe communication is generally trank and candid. Individuals working at centers with a high rating on the collegiality dimension usually feel that morale is high and that a strong sense of team spirit characterizes their work relationships.

Professiona/ Growth: This category measures the extent to which professional growth opportunities are available for the staff. Centers that score high on this dimension provide regular staff development workshops, encourage staff to share resources with each other, provide released time for teachers to attend conferences and visit other schools, and provide financial support and guidance for professional advancement.

Supervisor Support: The collective perceptions of workers at centers scoring high on this dimension is that the supervision they receive is both supportive and helpful. Individuals who rank supervisor support positively feel that high but reasonable standards are set and that staff are helped to develop their skills. A low rating on this dimension may indicate that the supervisor does not provide enough feedback or that he/she is too critical and hard to please.

Clarity: This dimension refers to the way in which policies, procedures, and responsibilities are defined and carried out. Early childhood workers at centers scoring high on this dimension generally feel that communication is good and that work schedules, job descriptions, and rules are clear and well-defined. Low ratings on this dimension indicate that 
people are often confused about policies and procedures and that conflicting demands are often placed on workers.

Reward System: This dimension measures the extent to which individuals in the setting feel that pay and fringe benefits are fair and equitably distributed. Centers scoring high in this category provide good job security for their workers and handle promotions and raises fairly. Workers in these settings feel that their pay is fair compared to what other early childhood centers pay. A low score in this dimension indicates that people feel that some individuals are paid more than they are worth, that raises are based on favoritism, and that people are taken advantage of.

Decision-Making: This dimension refers to the extent to which autonomy is valued and staff are encouraged to make decisions about those things which directly affect them. Centers that score high in this category are those where staff are also encouraged to provide input on schoolwide policies. A low rating on this dimension indicates that the overall perception of workers is that the center values conformity and individuals do not feel free to express their opinions on important issues.

Goal Consensus: The dimension of goal consensus refers to the degree to which staff agree on school philosophy, are unified in their approach, and are committed to program goals and objectives. A high score in this area reflects the ability of staff to appreciate differing points of view and to be able to compromise and agree on important programmatic issues.

Task Orientation: This dimension measures the degree of emphasis placed on good planning, efficiency, and getting the job done. Workers who rate their centers high in this area believe that they work hard but still have time to relax, that program procedures are efficient, and that meetings are productive. Low ratings generally indicate that time is often wasted, things get put off, and people often procrastinate.

Physical Setting: This dimension measures the extent to which staff feel that their work environment is well-arranged, organized, and provides sufficient supplies and equipment for them to do their job. A low score in this category indicates that the center may appear drab or need major repairs, that the temperature may be too hot or too cold, that parking may be inadequate, or that classroom space is cramped and crowded.

Innovativeness: This final dimension measures the extent to which the center encourages staff to be creative and innovative in their work. Individuals rating their setting high in this area believe that they are encouraged to try out new ideas to solve problems and then are supported in implementing needed changes. Programs rating low in this dimension are characterized by $\mathrm{a}$ traditional approach that avoids risk and allows many problems to go unsolved. 
PART B. SUMMARY OF WORKER VALUES $(N=13$ )

Center B.I

How important is...

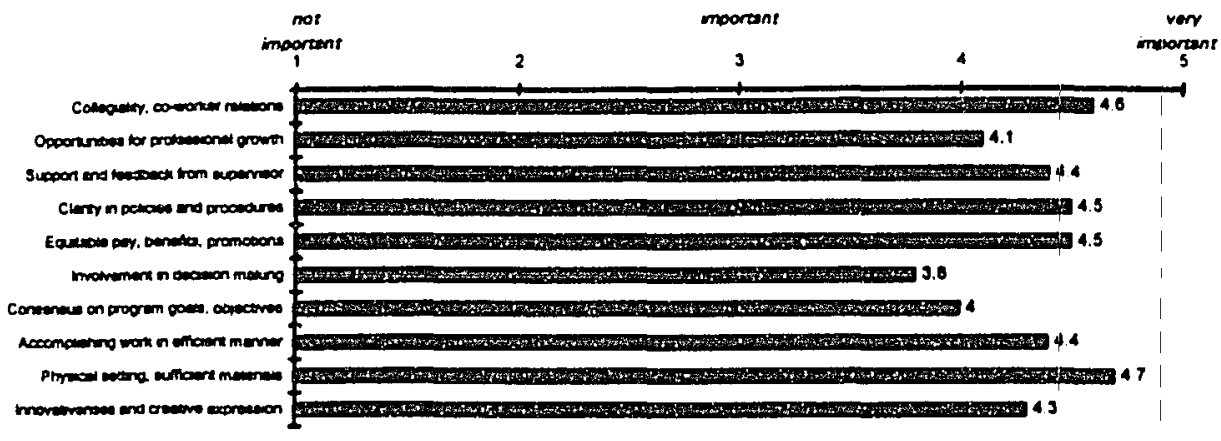

PART C. SUMMARY OF OVERALL COMMITMENT TO THE ORGANIZATION $(N=13)$

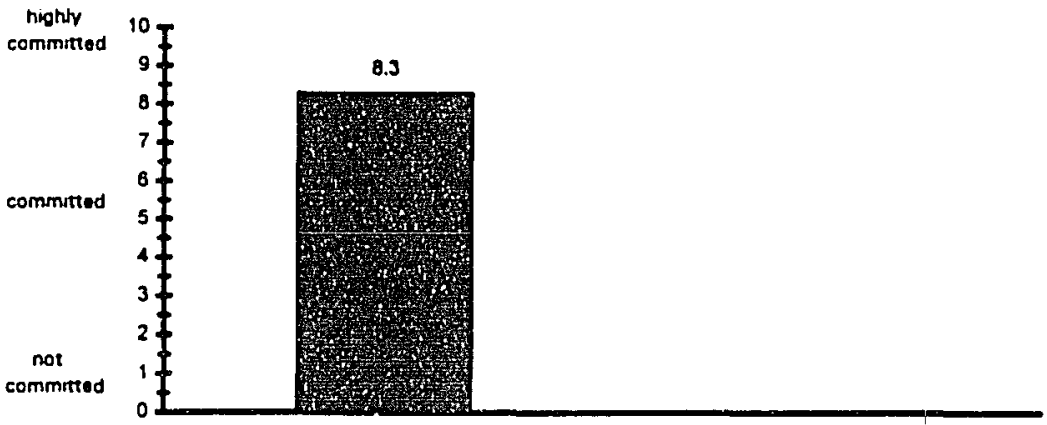

PART D. SUMMAAY OF HOW CURRENT WORK ENVIRONMENT RESEMBLES IDEAL $(N=13)$

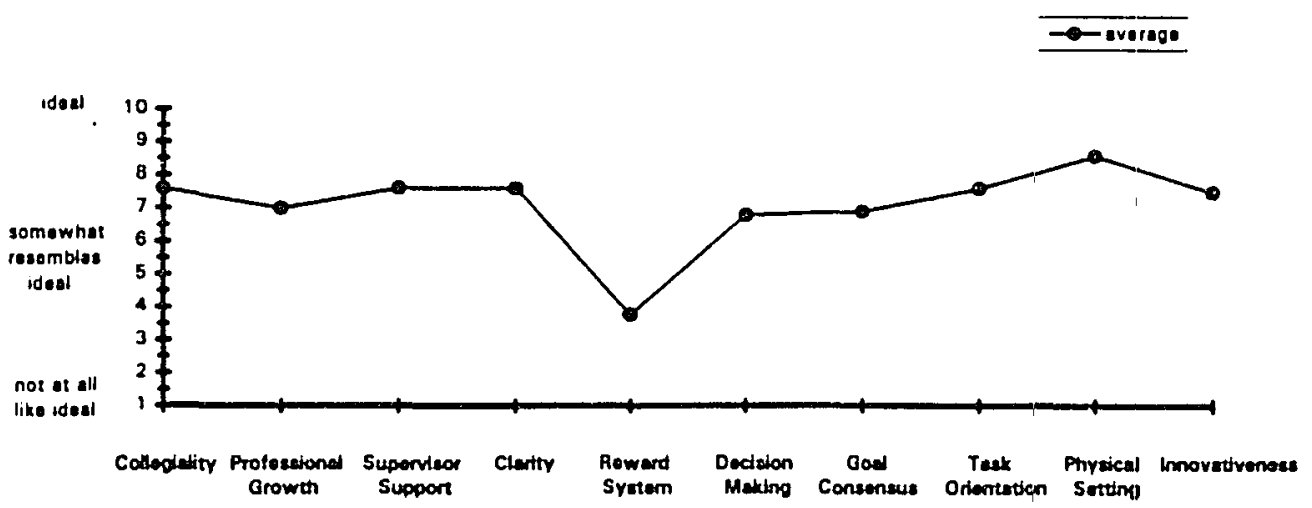


People do not all want or value the same things from their work. For some individuals, a sense of collegiality may be important and essential for job satisfaction. For others who prefer to work alone, the need for affiliation may be less. Likewise. for some people the comfort level of the physical serting and the availability of materials and supplies may be of considerable importance. For others, however, the physical setting may be minimally important.

This profile will help you assess the importance or value that your staff attaches to each of the dimensions of organizational climate. The profile provides a summary of the importance they assign to each dimension. Each score thus represents a composite evaluation of how important that dimension is to them in their work setting.

This profile can guide you in knowing which dimensions should be given high priority. In other words, you will probably achieve more lasting results in your school improvement efforts if you focus on those areas that the staff rated as low in Part $A$ and valued as high in Part $B$. Looking at Part $A$ and $B$ together will help you and your staff appreciate the uniqueness of your setting. Each center must develop its own formula for achieving a healthy organizational climate. There is no one prescription that applies equally to all settings.

\section{Part C. Summary of Qverall Commitment to the Qrganization}

This scale provides a summary of the staff's overall commitment to the center. Individuals who feel deeply committed to their jobs tend to put extra effort into their work and take pride in their center. It is not surprising that commitment is strongly correlated with staff turnover.

\section{Part D. Summary of How Current Work Environment Resembles Ideal}

One additional way to understand how workers perceive their present work conditions is to measure their perceptions of how closely their current work situation resembles their ideal work environment. This section summarizes the descrepancy between real and ideal conditions along the ten dimensions of organizational climate. 
Center B.I

PART E. RANKING OF VARIOUS ECUCATIONAL GOALS AND OBNECTIVES $(N=12)$

\begin{tabular}{|l|c|c|c|c|c|c|}
\hline & \multicolumn{7}{|c|}{ Number of eubjocte who rasked hem as } \\
\hline To holp chindren devesop... & 1 & 2 & 3 & 4 & 6 & 6 \\
\hline langusge and problem solving skills & 1 & 2 & 4 & 5 & 0 & 0 \\
\hline strong friondships, skills in sharing & 0 & 6 & 3 & 3 & 0 & 0 \\
\hline concepts needed for reading ond math & 1 & 0 & 0 & 1 & 4 & 6 \\
\hline independence in caring for themselves & 0 & 4 & 3 & 3 & 2 & 0 \\
\hline physical skill and coordination & 0 & 0 & 0 & 0 & 6 & 6 \\
\hline positive self-concepts ond self-esteem & 10 & 0 & 2 & 0 & 0 & 0 \\
\hline
\end{tabular}

PART F. DEGREE OF INFLUENCE OF THE TEACHING STAFF AEGARDING VARIOUS ORGANIZATIONAL DECISIONS (N $=13$ )

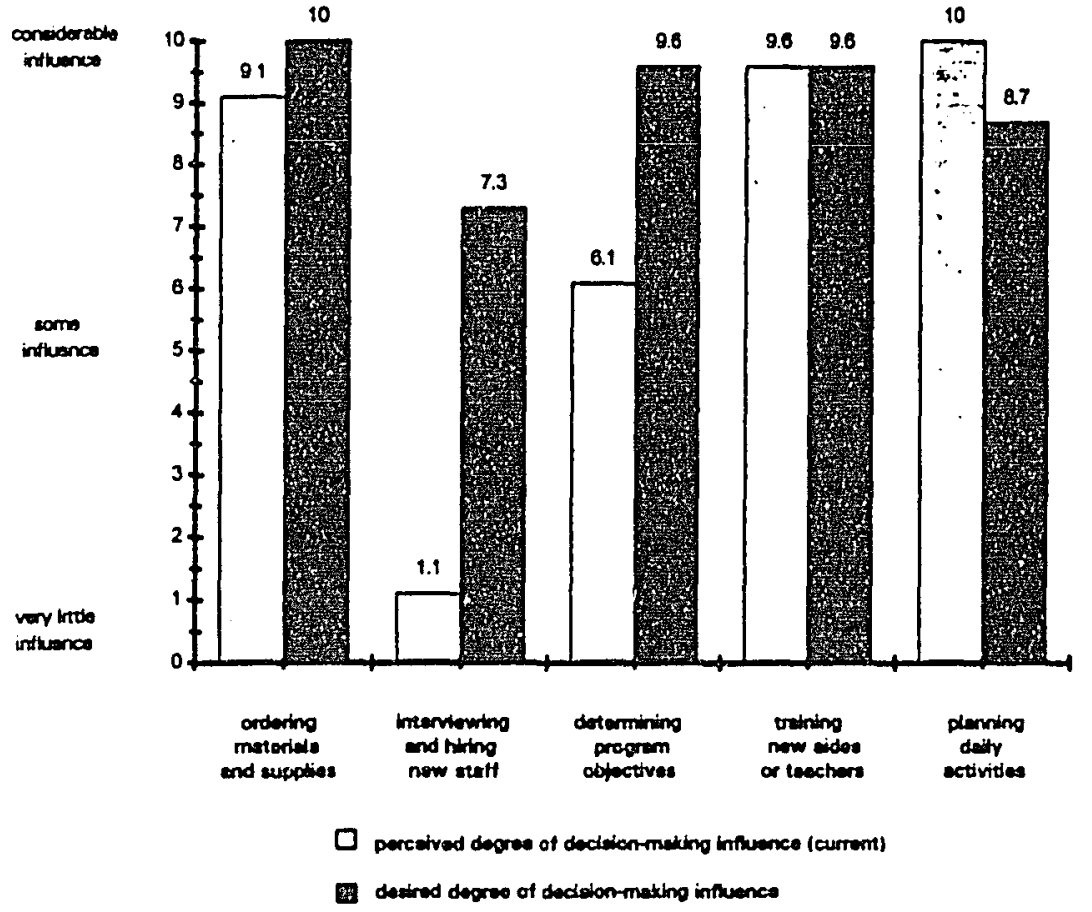




\section{Part E. Ranking of Various Educational Goals and Objectives}

There are many educational goals and objectives that guide curricular policies and procedures in our early childhood programs. But the priority that individual staff assign to different goals may vary. This section of the Work Environment Profile details the rankings that respondents assigned to six different early childhood educational objectives. If goal consensus is high at your center, the rankings for each objective should cluster. If staff have strong differences in the importance of different objectives, however, you will notice that the rankings will be widely dispersed.

\section{Part F. Degree of Influence of the Teaching Staff Regarding Various Organizational Decisions}

This section of the Work Environment Profile describes the perceptions of workers regarding the degree of influence of the teaching staff with respect to various organizational decisions. It includes both workers' perceptions of teachers' degree of current decision-making influence as well as their desired degree of influence.

This section of the profile provides a fuller explanation of the decision making dimension of organizational climate as reflected in Part $A$. It may prove useful in understanding some of the different decisions that are typically made in early childhood programs - both those where centralized decision making may be preferred and those where shared decision making may be possible. The appropriate amount of decision-making influence by the teaching staff will depend on your unique set of circumstances and will be different from other programs. 


\section{SYMLOG}

Field Diagram

Your Name. Average of All Raters

Diagram of what Group:

Center B.I Present Date Fall 1994

Group met from what date to what date Page_ 1 of 1

Diagram based on whose perceptions Playing whose role

Rating or Scoring Rating If Rating, scale $(0,1,2)$ or $(0,1,2,3,4 / 2)$

Expansion Multiplier 1.19 Comment

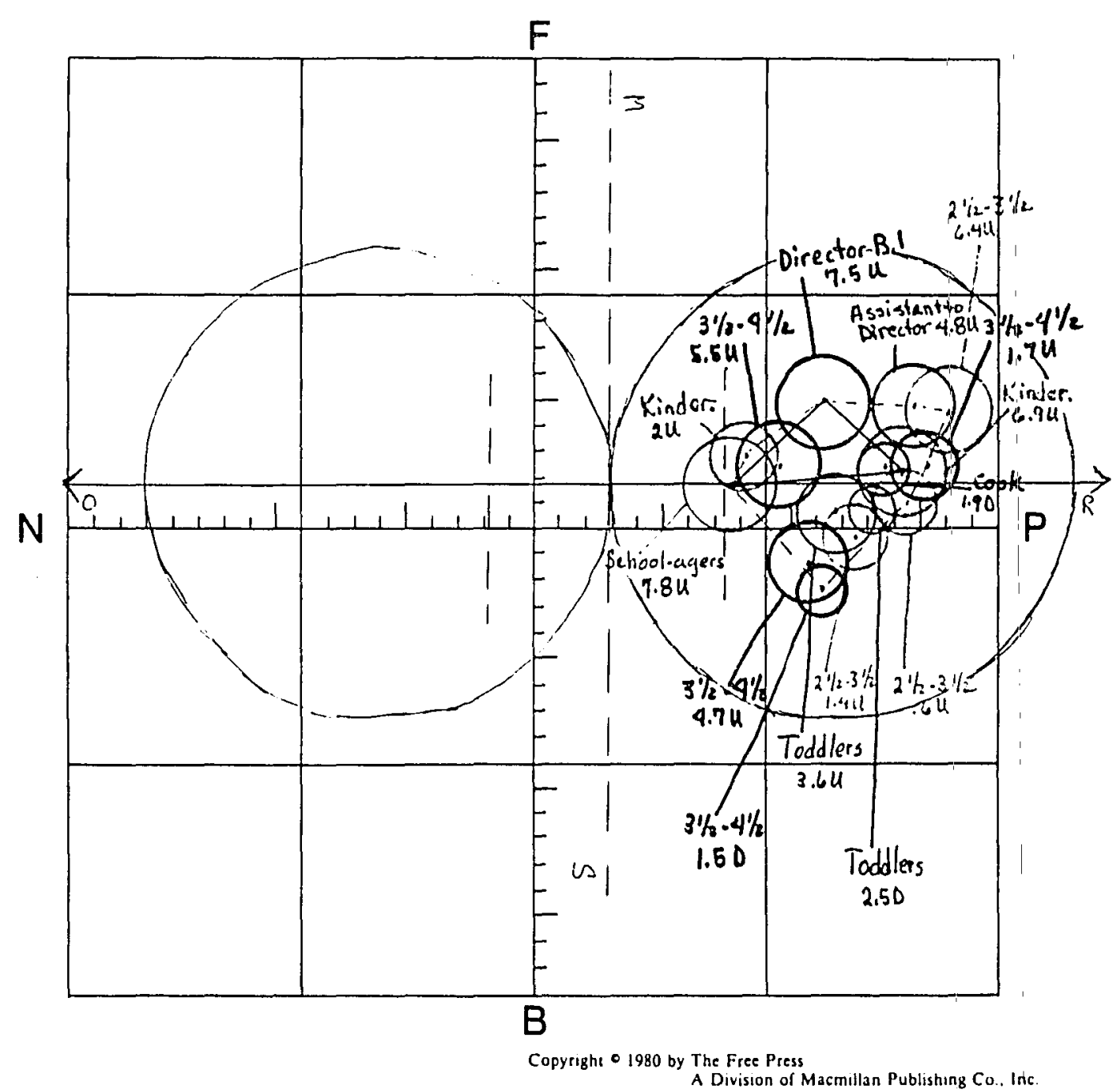




\section{SYMLOG}

DIRECTONIAL DEFINITIONS

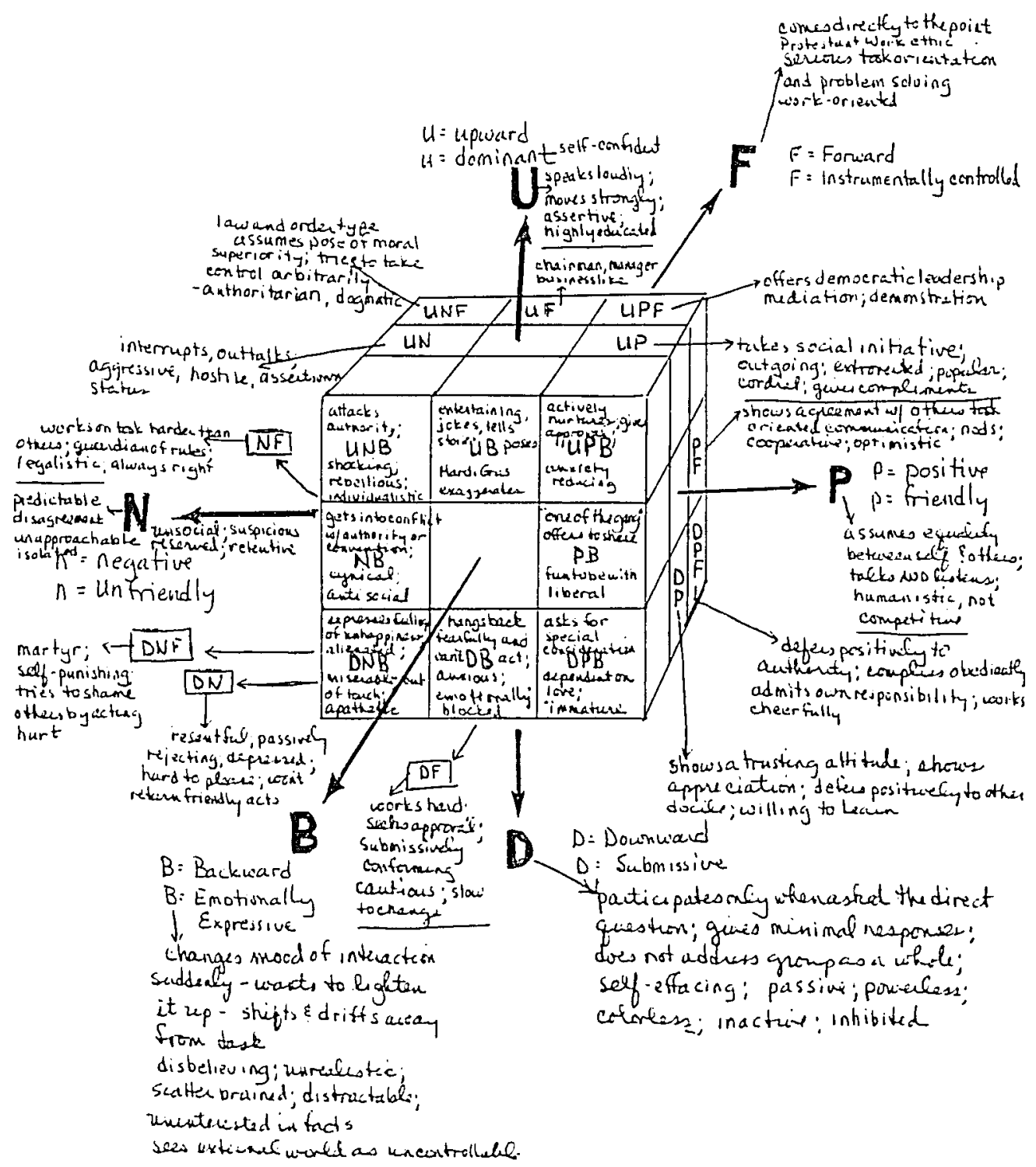


Summary of Director B.1's Leadership Characteristics and Center B,1's Organizational Climate

Interview

As indicated from her responses in the interview, Director B.1 displayed an essentially female style of approaching her role as leader. She has a nurturing approach and a focus on relationships. She sees the staff as a team that cooperates to provide this service to children and their parents. Though she appeared very comfortable with this style, she did express some concern that she often gets many tasks started but doesn't get them finished until later, due to interruptions, (implying that she is not task oriented enough). In the interview she did not stress a task orientation, however the Leadership Style Assessment Tool provides insight on this matter from another perspective.

Leadership Style Assessment Tool

In looking at the way Director B.1 was rated on the Leadership Style Assessment Tool, she clearly favors a Transactional Style (mean $=3.8 / 8$ ), which is the style considered to be most effective as it entails an "appropriate emphasis on both the center's needs and the individual worker's needs depending on the situation" (Jorde-Bloom et al. 1991, 12). However, for Director B.1, a Task-oriented Style was the second most selected description (mean of 2.86). The Task-oriented Style emphasizes organizational needs, whereas the People-oriented Style focuses on people and their individual needs. For Director B.1, People-oriented items were selected the least (mean of 1.4). Director 
B.1 employs a balanced style of leading, and appears to the staff to tend more toward a Task-Oriented Style than a People-Oriented Style, which appears to contradict Director B.1's self-perception.

Work Environment Profile

In examining the results from the Work Environment Profile, staff have rated the Organizational Climate (Part $\mathrm{A}$ ) as being higher than the norm ${ }^{19}$ on eight dimensions, including Collegiality, Professional Growth, Supervisor Support, Clarity, Goal Consensus, Task Orientation, Physical Setting, and Innovativeness. The dimension of Decision Making was rated as being at the norm, with the dimension Reward System being just below the average. This center is the only one of the four centers studied that rated Reward System below the norm that was established for this dimension. One might predict this as salaries at this center were the lowest in the study. Center B.1 is also the only center in this study that is organized on a for-profit basis. The dimensions, Reward System and Professional Growth, got the lowest overall ratings from the respondents, whereas the dimensions, Supervisor Support and Physical Setting, got the highest ratings. The Physical Setting dimension had the smallest range of scores (a range of 3.5 out of a

\footnotetext{
${ }^{19}$ The norms established for the dimensions on the Work Environment Profile are based on responses of 2,250 workers in 150 centers. Since the use of this tool is purely voluntary for a center and is typically used for the purpose of program quality improvement, one can most likely assume that the centers used for creating the norms were of good to high quality centers since they are motivated to engage in selfimprovement.
} 
possible 10); meaning the respondents had their highest level of agreement in their perception of the physical space in which they work. The dimension with the widest range was that of Task Orientation (which had a range of 8.1 extending from 1.9 to 10 ) which indicated little agreement on the amount of emphasis in the program on getting the job done and in the most efficient manner. This wide range might clarify the seeming disparity between how the director feels she is doing in terms of task orientation, how the various staff think she is doing in this area, and how much emphasis the various staff want on task orientation. Task Orientation in child care is difficult to achieve because the client being directly served (an immature child who is typically between the ages of 6 weeks to 6 years) has characteristic behaviors that are often hard to predict and are very inefficient to respond to appropriately from an organizational point of view. Also, teacher-caregivers with more training will likely be more task oriented, because they know more about what needs to be done.

In looking at the Summary of Worker Values (Part B), directors are advised by the author of the instrument Jorde-Bloom that the best areas for them to work on in terms of initiating change would be those dimensions that are rated low in Part A and high in Part B. The dimension of Reward System is the one dimension that the staff rated below the norm; and, it received a relatively high rating in terms of worker values ( 4.5 out of 5 within a range of 3.8 to 4.7). Decision Making was the only dimension in Part A that was rated on the norm, making it a potential for being an area to work on, but in terms of Worker Values, it is ranked the lowest of all at 3.8 out of 5. Professional Growth is a dimension that was rated lower compared to the other dimensions, and yet, it too received 
a relatively low score (4.1) in terms of its importance as a Worker Value. Overall Commitment to the organization (Part $C$ ) is high at 8.3 on a scale of 1 to 10 . This score is more than half-way between Committed (5.5) and Highly Committed (10).

In Part D, Summary of How Current Work Environment Resembles the Ideal, all dimensions but Reward System are rated at 7 or above on a scale of 1 to 10 . A rating of 1 indicates Not At All Like Ideal; 5.5 represents Somewhat Resembles Ideal; and, 10 is the ideal. Reward System was rated between Not At All and Somewhat, giving further support for the interpretation that this would be an area on which to work. In the Ranking of Various Educational Goals and Objectives, $83 \%$ of the staff ranked Positive Selfconcepts and Self-esteem as their number one goal for the children showing strong group consensus on their primary educational goal.

Finally, Part F looks at the Degree of Influence of the Teaching Staff Regarding Various Organizational Decisions. In this part the staff's perceived degree of current decision-making influence is compared to the staff's desired degree of decision-making influence. The staff indicated that they would like significantly more influence in the areas of Interviewing and Hiring New Staff ${ }^{0}$ and Determining Program Objectives, yet Decision Making and Goal Consensus were not highly valued in Part B.

\footnotetext{
${ }^{20}$ As it turned out, the staff in 3 out of the 4 centers in this study wanted more influence in Interviewing and Hiring New Staff.
} 


\section{SYMLOG Field Diagram}

The Group Average Field Diagram provides a more accurate picture of group dynamics. When rating members of a group using SYMLOG, each individual member "tends to distort somewhat. There is no perfectly objective diagram. Usually the best estimate of the way a group member would be seen by observers outside of the group is the average of the way all group members see that member" (Bales 1980,12). This is called the group average location of each of the members.

When looking at the Group Average Diagram for Center B., the first thing to be noted is that all of the images are contained within an area called the Reference Circle (R). The Reference Circle represents the presumed tendency for a person, when he or she rates others, to want to have the images of the others in the group close to his or her own selfimage on the Field Diagram which is indicated by the rating the person does on him or herself (Bales and Cohen 1979, 43). "Two images that are close together suggest a tendency of the perceiver to transfer attitudes from one to the other - to regard them in the same way, as closely connected, unified, or identified with each other. Two images that are far removed from each other suggest a conflict or polarization between the two in the mind of the perceiver" (Bales 1980, 12). What determines if two or more images are close or far apart? According to Bales, two or more people whose images are "close enough to each other to be held within the same Reference Circle" are considered to be close $(1980,12)$. "A pair separated by a distance greater than the diameter of the Reference Circle may be considered far apart" (Bales 1980, 12). Thus, all of the group members of Center B.1 can be considered to be close to each other and thus to perceive 
themselves as similar to one another. One would expect a group of people who see themselves as similar to get along well and to work fairly effectively as a team.

All of the images in the Center B.1 Field Diagram have "P" (or Positive) as one of their three dimensions. Positive behaviors are described by Bales and Cohen (1979):

Acts overtly toward others in a way that seems Friendly (Positive). Examples: assumes equality between self and others, asks others for their opinions, balances talking with listening, or starts talking and stops talking flexibly and easily in response to the needs of others. Gives nonverbal signs that seem Friendly (Positive). Examples: pays attention to others with eyes, pays attention by turning to other, by approaching the other physically to a comfortable distance, or by listening carefully (366).

All of the images are clustered close together and in a positive direction indicating that the people doing the ratings see themselves and the others they work with as being Friendly. "Members (on the Positive side at least) who appear close to each other on the Group Average Diagram are likely, over time, to form alliances with each other to some degree and to become a recognizable subgroup with one or more leaders" (Bales and Cohen 1979, 98). In fact, according to Bales and Cohen, "it seems probable that persons on the Positive side of the Field Diagram are more likely to form such a subgroup than persons on the Negative side" $(1979,98)$. Since all of the members are close together and on the Positive side, it would seem likely that they would be a cohesive group as a whole staff.

Director B.1 is in a UPF location which is described on the rating sheets as "purposeful, democratic task leader" (Bales and Cohen 1979, 21). UPF behavior is a combination of Upward/Dominant, Positive/Friendly, and Forward/Instrumentally Controlled. Examples of this type of behavior include: 
takes the initiative in persuading or offering to help the group on a task... confronting the group as a whole, offers democratic leadership, or tries to smooth out conflicts between group members by mediating, conciliating, or moderating so as to get ahead with the tasks of the group (Bales and Cohen 1979, 357).

This is the group's overall perception of Director B.1. Bales and Cohen caution, however, that "it is not helpful, in general, for a parent, teacher, therapist, or group leader to have an extreme or fixed image of the self, or a one-directional conception of the proper behavior for the role" $(1979,106)$. They state that in order to do the "best job" in any of the above mentioned roles, "one should be able to respond to the periodic need for Dominant, Friendly, and Emotionally Expressive Behavior (UPB)" (1979, 106), which Bales and Cohen describe in the following way:

takes the initiative in protecting or nurturing the other(s), gives unconditional praise or reward, boosts the status of the other, gives approval and encouragement, gives warm acceptance without regard to the excellence or failure of performance of the other, or gives support, reassurance, comfort, or consolation $(1979,365)$.

UPB behaviors are characteristically similar to many of the so-called female behaviors and the UPF behaviors are stereotypically male. The interview with Director B.1 clearly demonstrated UPB or female behaviors. In addition, the staff rated Director B.1 as being well above the norm on Supervisor Support on the Work Environment Survey. It appears that leaders (as well as parents, teachers, and therapists), in order to do the "best job" need to be balanced and able to appropriately exhibit both UPF and UPB (male and female) behaviors.

Director B.1 is also a member of the Dominant Triangle which is made up of the 
three (unless there is a tie) members who have the largest $U$ or Upward/Dominant ratings.

It is the assumption of SYMLOG theory that "the most dominant images are likely to draw the most attention of the perceiver, and to dominate his motivation" (Bales 1980,

12).

Empirically we know that there is a high correlation between how dominant a member is according to ratings received... and how much he or she talks, though the amount of talking is not the only determinant.... We also know, from empirical experience, that the persons who talk the most in face-to-face groups also typically get talked to the most, and, not unexpectedly, they talk with each other for the most part. (Bales and Cohen 1979, 52).

Dominant $(\mathrm{U})$ behaviors ('takes initiative in speaking..., speaks loudly..., moves strongly..., holds the floor with "uh...") are also stereotypically male behaviors. Director B.1's inclusion in the Dominant Triangle is another demonstration, (along with the rest of the SYMLOG data, the interview, and the Leadership Style Questionnaire), of this administrator's balanced leadership style. 


\section{Center A, 2; Observation, Interviews and Findings}

The center observation and interviews with the administrative team happened on October 14, 1994 with the Executive Director (herein referred to as Director A.2); the Infant-Toddler Coordinator (herein referred to as I-T Coordinator); and the Preschool Coordinator (herein referred to as P-S Coordinator).

\section{The Setting}

Center A.2 is an organization that has been serving children and families for over 100 years and is located in a hilly section of city $\mathrm{A}$ in a building constructed in the mid1960s for the organization. The center was built into a hillside in this dense urban neighborhood yielding a complex physical environment. It has two levels with most of the classrooms and outdoor play spaces on the upper level (except for the infants) and the administrative offices, reception area and staff lounge on the lower level. The entrance is all glass, affording a full view of the spacious reception area and stairs to the upper level. On one wall is a photo display of the history of the center. With parking in this neighborhood at a premium, the building was set back from the street in order to make space for a semicircular driveway in which parents can park temporarily to drop off and pick up their children at the center.

Center A.2 is a private, nonprofit agency which receives partial funding from an area wide charitable organization. The center serves 118 children including infants, toddlers, and preschoolers, though they are technically licensed to care for 128 . All 
children are enrolled on a full-time basis only and the center is open from 6:45 a.m. to 6:00 p.m., five days a week. The center is NAECP accredited. There are 41 employees of Center A.2, 30 full- and 11 part-time. Many of the part-time aides are students at a local state university. Of the 41 staff, 6 are administrative staff(director, administrative assistant, 2 program coordinators, bookkeeper, and development director), 31 are teaching staff ( 7 each of teachers and assistant teachers, and 17 aides) and 3 support staff (cook, housekeeping, and receptionist). Ethnically, the staff is mixed, with a majority being apparently European-American. The families being served are middle or upper middle class and from various ethnic backgrounds.

Being a private, non-profit agency, the center has a board of directors that has fiscal and administrative oversight of the agency. Director A.2 is the C.E.O. of sorts, with two program coordinators who do direct teaching staff supervision and have significant contact with parents and children. The teaching staff are unionized so working conditions are governed by a negotiated contract. Director A.2 directly supervises the administrative staff.

When Director A.2 agreed to consider having her center participate in the research, she did so with the qualifier that the center "administrator" for this center be defined as their administrative team including Director A.2 and the two coordinators, I-T Coordinator and P-S Coordinator. Thus, 1 interviewed all three of them concerning their leadership styles. 
The Interview with Director A.2

Director A.2 began working at Center A.2 in 1978 when she began as a teacher (after having been a substitute for a period of time) and subsequently became a program coordinator. At the time of the interview, she had been director for 5 years. The interview took about $1 / 2$ hour and was conducted in her office. Director A.2 has both an M.A. and an M.S. degree.

\section{Describe your "style" of administration:}

Director A.2 described her style as being |"relaxed, disorganized, [and] spontaneous. "21 She tries to strike a balance between a "controlling" and a "collaborative" style. ${ }^{22}$ She is very flexible with staff, but said that no one takes advantage of the flexibility. People know what they need to do in their jobs. Director A.2 stated at the end of the interview, that the two program coordinators and her administrative assistant feel comfortable to confront her about decisions she has made. They each do it in their own way, but they do it.

${ }^{21}$ Gilligan (1982) states that women develop in a way different from men. "Women find order where others... [see] chaos." (169)

To be healthy, according to Schaef and Fassel (1988), "leadership in organizations would be diffused and situational" (221).

${ }^{22}$ In discussing women as teachers ( 'all leadership must involve teaching" Maxcy 1991, 50), Belenky, et al (1986) comment that the role of being a "connected" teacher "does not entail power over the students; however it does carry authority, an authority based not on subordination but on cooperation." (227). 
2. Tell me how decisions are made, regarding:

Staffing and scheduling. Director A.2 works with the administrative staff and program coordinators in scheduling their time. The program coordinators, in turn, make the staffing and scheduling decisions for the classrooms. Director A.2 tries to allow the administrative staff flexibility in their work schedules within programmatic constraints. The bookkeeper, for example, is allowed to set her own hours, which can be on the weekend or in the evening. ${ }^{23}$

Budgeting. Director A.2 and the bookkeeper develop each year's budget with support from the board. In the past, the two coordinators were given budgets and told to stay within them, but this did not work out very well, because it turned out to be too hard to track. Now, the coordinators have an idea of about how much they can spend and they go through Director A.2 with larger purchases. $^{24}$

Children's program. Director A.2 and the two coordinators have a weekly meeting about the classrooms and the coordinators, in turn, meet weekly with the teachers in their area. The staff have one hour a week each for planning. Teachers have autonomy

\footnotetext{
${ }^{23}$ Kanter and Fassel (1977) found that those women in leadership positions who were most successful and effective were "interested in empowering subordinates (sharing power with them)" (302)

${ }^{24}$ Gilligan has noted that "women... are ideally situated to observe the potential in human connection both for care and oppression.... In relationships of temporary inequality, such as parent and child or teacher and student, power ideally is used to foster the development that removes the initial disparity" $(1982,168)$.
} 
to plan their curriculum; the program coordinators supervise and support their planning. ${ }^{25}$

Physical facility. The administrative assistant, and Director A.2 oversee the physical facility. Teachers put in requests for equipment or other physical plant requests. There is a safety committee, composed of representatives from the different areas of the program. ${ }^{26}$ They conduct a monthly inspection of the whole facility and make recommendations for improvement, maintenance, remodeling, etc. The center recently had $\$ 35,000$ in repairs and changes completed in order to make the building more earthquake resistant and safe.

\section{How do you organize your time and responsibilities? What are your priorities?}

Director A.2 has a "terrible time at time management."127 Each morning she "checks in" with each room and "hangs out" in the lobby when parents arrive with their children. She tries to achieve a balance between putting her time into day to day business,

${ }^{25}$ Women who were most successful and effective were "interested in empowering subordinates" (Kanter and Fassel 1977, 302).

Gilligan supports this when she states that "in relationships of temporary inequality...power ideally is used [by women] to foster the development that removes the initial disparity" $(1982,168)$.

${ }^{26}$ Successful and effective women are "interested in empowering subordinates" and are the most "collaborative and humane" (Kanter and Fassel 1977, 302).

${ }^{27}$ Gilligan (1982) says that "women find order where others... [see] chaos" (169) and Helgesen (1990) found that successful women in leadership "did not view unscheduled tasks and encounters as interruptions" (19). In this interview, as in the first, the administrator is suggesting by her comment that there is something "wrong" with not being able to be very task oriented and "on time". 
staff, and families ${ }^{28}$. Her number one priority is "small burning fires." After those are put out or under control, she goes to "calendar stuff", in other words, things she is scheduled to do at a specific time. Her third priority is the maintenance and application of personnel policies, and by-laws.

Director A.2 does a lot of work outside of the center. She speaks to groups about child care related topics frequently, does fund-raising presentations for United Way, provides training for the child care community, is involved in professional associations, and is involved in public policy related to child care. ${ }^{29}$

\section{How do you maintain quality caregiving by the staff?}

Director A.2 stated that the first thing in maintaining quality caregiving is in hiring the best staff they can. Staff receive on-going training through receiving payment for it and earning compensatory time for going. ${ }^{30}$ In addition, there is a bonus of $\$ 50$ for every

\footnotetext{
${ }^{28}$ According to Gilligan (1982), "when women construct the adult domain, the world of relationships emerges and becomes the focus of attention and concern" (167).

${ }^{29}$ Kanter and Fassel (1977) found that those women who were most successful and effective "have political connections in the wider system, and they know how to make subordinates feel powerful in their own right" (303).

${ }^{30}$ This center does a lot of fund raising to supplement its income from tuitions. Heffron (1989) states that "unfortunately, organizations suffering from decreased resource availability are not going to be able to avoid serious employee morale and satisfaction problems. Reality and fairness indicate that a new set of criteria for measuring treatment of employees be derived for organizations experiencing decline [of resources compared to need]" (342). Resources are clearly directed toward staff training and morale boosting in this center.
} 
5 hours of training beyond 15 per year. Most, though not all, take part in these

opportunities. Director A.2 frequently reproduces articles to pass around among the staff to read and discuss. Director A.2 and the two coordinators visit rooms and meet weekly with staff away from the children to get ideas for program improvement.

5. How do you balance your job here in the child care center and your life outside?

Director A.2 said that first of all, she is single, with no children and she lives only 3 blocks from the center. She works only 40 hours a week, which is unusual for a child care director. She feels this is extremely important for both she and the program coordinators so they can avoid burnout. To give herself balance for what are the real problems in the child care center, she does "wild things" like scuba diving and learning to fly an airplane. ${ }^{31}$

6. What about the personal lives of staff members -- what are your expectations for how much of the personal can come into the workplace or into your awareness?

Director A.2 began her answer to this question with "it depends." She stated that

\footnotetext{
${ }^{31}$ Lunneborg (1990) points to one of the "four major, dominant, higher order themes" of "an insistence upon a balanced life-style" (xviii).

Gilligan (1982) in discussing rights and responsibilities, states that "the language of rights underlines the importance of including in the network of care not only the other but also the self' (173).
} 
she tries to "address moods." Some she chooses to ignore and some she cannot. ${ }^{32}$ If someone is having a crisis or major event in their life and this becomes a constant topic of staff discussion when working with the children, then functioning begins to drop off and it must be addressed. The lead teacher in each room is responsible for talking with staff first, and if the problem continues, another approach is taken. The center takes part in an employee assistance program that provides counseling and mediation services for staff in the program. This is utilized when a problem cannot be resolved from within. ${ }^{33}$

\section{How do you work with parents? How do you expect staff members to work/interact} with parents?

Communication with parents is a high priority with Director A.2 as you "cannot second guess a parent." ${ }^{134}$ She expects staff to employ "complete professionalism"' when interacting with parents. She also expects staff to have positive interactions with

\footnotetext{
${ }^{32}$ One of the "four major, dominant, higher order themes" that Lunneborg (1990) found among women leaders was "a nurturant approach to coworkers" (xviii).

Gilligan (1982) also notes that women "define their identity through relationships of intimacy and care..., attachment is supported by an ethic of care" (169).

${ }^{33}$ In their work, The Addictive Organization, Schaef and Fassel (1988) state that a healthy organization that heals should promote health in the people who work there; and, likewise, organizations that provide caregiving should care for their employees (219).

${ }^{34}$ Gilligan (1982) states that women use an "ethic of responsibility" which "relies on the concept of equity, the recognition of differences in need" (164).
} 
parents, ${ }^{35}$ and when these things do not happen it "pushes her buttons."

Director A.2 tries to get to know and communicate with all the families by greeting them in the morning, being at all parent meetings, and through written communication to them. However, in terms of working closely $\mid$ with individuals, she usually just "gets the big problems."

\section{Interview with Infant-Toddler Coordinator}

At the time of the interview, I-T Coordinator had worked at Center A.2 since 1977 , first with infants, then toddlers, and for the last 5 years, she has been the program coordinator for the infant and toddler classrooms. I-T Coordinator and Director A.2 moved up to their current positions at the same time. She holds a B.A. degree plus some graduate work.

\section{Describe your "style" of administration:}

I-T Coordinator described herself as being "pretty relaxed" as a supervisor. She gives teachers "space" to do their job, i.e., autonomy. ${ }^{36}$ She is there to talk over concerns

\footnotetext{
${ }^{35}$ One of the major themes that Lunneborg (1990) found about women in leadership is that they had a "service orientation to clients" (xviii).

${ }^{36}$ To be healthy, "the concept that every person has a leadership role and responsibility (the ability and necessity to respond) would be integral to the structure and process of the organization" (Schaef and Fassel 1988, 221).
} 
and issues. ${ }^{37}$

2. Tell me how decisions are made, regarding:

Staffing and scheduling. The center has guidelines on staffing. For example, the lead teacher and the assistant teacher must cover the opening and closing of the room so they can meet with parents at arrival and departure. The aides work in the middle of the day. It is up to the teachers themselves, though, to work out switches in shifts and to find substitutes. $^{38}$

Children's program. The classroom teachers meet once a week to plan curriculum and to make suggestions for changes, etc.

Physical facility. If the staff wanted to see a change in how the rooms are used or a major change in the facility, the coordinator would talk with the groups involved and then discuss this with the administration and then the coordinator would bring the decision back to the staff member(s) who suggested it.

3. How do you organize your time and responsibilities? What are your priorities?

I-T Coordinator's main function is to supervise staff working with parents and children, so she spends time in each room every day flowing in and out, and she meets

\footnotetext{
${ }^{37}$ Heffron (1989) cites Karl Weick as suggesting that in effective organizations, people talk a lot (339).

${ }^{38}$ Kanter and Fassel (1977) found that the most effective and successful women leaders were "interested in empowering subordinates" (302).
} 
with staff for a time each week ${ }^{39}$ to discuss individual children's needs. This is the first priority. ${ }^{40}$ I-T Coordinator has a "running to-do list" and she works on this list in between her times in the classrooms and meeting with staff and/or parents.

I-T Coordinator's concern for staff was seen when we tried to set up the time when I would introduce the instruments for this research project to the staff. She asked when I planned to do this and I said that I would be arranging it with Director A.2. She mentioned that currently the staff were working on individual children's reports and that they would be doing this during most of their out-of-the-classroom time for the rest of the month. I said I would be happy to wait until this report writing was completed and I-T Coordinator said that would be best for staff. I sensed that she was careful to protect the staff from too much paperwork.

\section{How do you maintain quality caregiving by the staff?}

The staff in her area have worked together a long time and she feels that the staff know what she thinks is important. ${ }^{41}$ She helps them keep up on quality by giving them

\footnotetext{
${ }^{39}$ Helgesen (1990) found that successful women in leadership "scheduled time for sharing information" (27).

40 "When women construct the adult domain, the world of relationships emerges and becomes the focus of attention and concern" (Gilligan 1982, 167).

${ }^{41}$ Heffron (1989) states that "schools' efficience is frequently measured by cost per student, but students are not really their outputs - they are in fact one of the inputs" (3412).
} 
articles and by being vocal about what she thinks is quality ${ }^{42}$ and by giving support to staff on achieving this.

5. How do you balance your job here in the child care center and your life outside?

I-T Coordinator says it's not too difficult. She works a 40 hour week, from 9 to 6:00 without a lot of stressful overtime. She also stated that they get real compensatory time for any work done outside of the 40 hours. $^{43}$

6. What about the personal lives of staff members - what are your expectations for how much of the personal can come into the workplace or into your awareness?

I-T Coordinator wants to be "aware of major stuff." If it is influencing their job performance, then she feels she needs to talk to them about it. However, she respects staffs life needs at home. At Center A.2, staff can use sick leave for care needs (like elder

$\$ 2$ Karl Weick states that effective organizations have "grouchy" members who complain a lot and are "never satisfied". This he contends is the sign of a healthy organization and of healthy people, as a lack of complaints is "dangerous in a dynamic environment" (cited in Heffron 1989, 340).

43 "An insistence upon a balanced life-style" was a major theme among women in leadership (Lunneborg 1990, xviii).

Gilligan (1982), in her discussion of rights vs. responsibilities, states that "the language of rights underlines the importance of including in the network of care not only the other but also the self' (173). 
care).$^{44}$

7. How do you work with parents? How do you expect staff members to work/interact with parents?

Parents are as important as the children, especially in infant and toddler care. I-T Coordinator expects staff to treat parents with respect by taking their opinions and worries seriously. ${ }^{45}$ She wants parents to feel free to express their concerns about the care of their child. ${ }^{46}$ Parent concerns are a topic of many weekly meetings.

The Interview with Preschool Coordinator

P-S Coordinator had been at A.2 Child Care Center close to 15 years at the time of the interview, first working with the babies and then with preschoolers. Then, for the last $51 / 2$ years, she has been Preschool Coordinator. She holds a B.A. degree plus some

\footnotetext{
${ }^{44}$ One of the themes of women in leadership that Lunneborg (1990) found was "a nurturant approach to coworkers" (xviii).

Gilligan (1982) notes that women "...define their identity through relationships of intimacy and care..., attachment is supported by an ethic of care" (169).

According to Schaef and Fassel (1988), in a healthy organization, "there would be awareness that the structure and the system, that is, the way of organizing the work, are integral to the company's mission and must support and facilitate the work of the organization" (219).In other words, organizations that provide caregiving should care for their employees.

${ }^{45}$ Gilligan (1982) points to an "ethic of responsibility" that women use which "relies on the concept of equity, the recognition of differences in need" (164).

${ }^{46}$ A "service orientation to clients" was one of the themes of women in leadership (Lunneborg 1990, xviii).
} 
graduate work.

1. Describe your "style" of administration:

P-S Coordinator described her style as being "not directive or authoritarian" though it depends on the issue, for example if it were one of health or safety, she might be directive. ${ }^{47}$ Instead, she described herself as "laid back, sort of" but "not carefree." She supervises in an "indirect" way. She is "thoughtful" about her approaches to people, and she "worries" a lot. 48

2. Tell me how decisions are made, regarding:

Staffing and scheduling. The classroom staff decide on their own schedules within the shifts that are established. P-S Coordinator opens, so she takes care of staffing for substitutes in the morning.

Budgeting. Director A.2 takes care of budgeting. The coordinators order the classroom supplies on their own, but when there is a big purchase, Director A.2 approves it. P-S Coordinator said that she is very careful about money stuff, and that she considers

\footnotetext{
${ }^{47}$ According to Schaef and Fassel (1988), to be healthy, "leadership in organizations would be diffused and situational" (221).

${ }^{48}$ In Helgesen's (1990) interviews with four women who were leaders, she found that women "focused on the ecology of leadership" (25) and "saw their identities as complex and multifaceted" (26). They were process oriented and emphasized relationships with people. They saw people and work as ends in themselves, rather than as means to another end (29).
} 
something that is not a usual supply and is over $\$ 25$ as being big.

Children's program. There is a program committee on the board of directors whose job it is to make any major changes in the children's program. The teachers plan the daily activities, with input from the coordinators and Director A.2 when needed. There is a planning meeting time set aside each week for the teaching staff to use for this.

Physical facility. In terms of the physical facility, the rooms are assigned to certain age groups, but the teachers do the room arrangement.

\section{How do you organize your time and responsibilities? What are your priorities?}

"Not well!" was P-S Coordinator's reply to the first question, accompanied by a laugh $^{49}$. She makes lists each day, though "immediate needs come up a lot." ${ }^{50}$ She does a walk-through each day getting her into each room. P-S Coordinator's first priority is to see that the children are doing well and that the staff are doing well with the children. Her second priority is to do problem solving around the needs of the children.

4. How do you maintain quality caregiving by the staff?

P-S Coordinator stated that planning time was very important for them. The

${ }^{49}$ Gilligan (1982) states that women develop in a different way; that "women find order where others saw chaos" (169). Here is the third example of an administrator expressing concern or judgment about time management, with the implication that it could be more organized.

${ }^{50}$ Helgesen found that successful women in leadership "did not view unscheduled tasks and encounters as interruptions" $(1990,19)$. 
teachers meet for 1 hour a week as a group for planning and each teacher has 1 hour a week for themselves for planning. She feels they could use more set up time. They have on-going training for staff as well as books and articles as resources. They frequently review rules and practices as a staff. P-S Coordinator stated that their "jobs are important to the staff!" and this helps keep quality up..$^{51}$

On a more formal basis, the center is accredited and gets reaccredited every 3 years. They employ check lists for health, safety, and building problems. They have an open door policy for parents and the coordinators do frequent walk-throughs for quality maintenance. $^{52}$

5. How do you balance your job here in the child care center and your life outside?

P.S Coordinator says that she typically forgets about work once she is home, though she sometimes worries in the middle of the night. She also can find herself having a hard time "just leaving" in the middle of some problem or incident and frequently ends

\footnotetext{
${ }^{51}$ In a time of declining resources, especially for social services, "organizations suffering from decreased resource availability are not going to be able to avoid serious employee morale and satisfaction problems. Reality and fairness indicate that a new set of criteria for measuring treatment of employees be derived for organizations experiencing decline [of resources compared to need]" (Heffron 1989, 342).

52 An organization that "welcomes complaints" and constructive criticism is a healthy organization (Heffron 1989, 340).
} 
up staying until it is resolved. ${ }^{53}$ For balance, she goes away on day trips and has outside interests of sewing and photography. ${ }^{54}$

6. What about the personal lives of staff members -- what are your expectations for how much of the personal can come into the workplace or into your awareness?

According to P-S Coordinator, if a person's personal life is affecting their job, then she talks to them. ${ }^{55}$ The staff lounge is a place for people to blow off steam when they have that need. In addition, she will listen to their cares and concerns, but she sets a limit at staff members talking to parents about their personal problems.

7. How do you work with parents? How do you expect staff members to work/interact with parents?

The teachers are the staff who have the most direct contact with parents. P-S

${ }^{53}$ Lenz and Myerhoff (1985) state that the feminization of the workplace is providing a needed balance to this traditionally male dominated environment. "Much of this change is linked to women's deeply rooted need to integrate love and work. The work-home division grates against the feminine sensibility" (81).

${ }^{54}$ Gilligan (1982) notes that men and women's languages of rights vs. responsibilities "articulate with one another in critical ways. Just as the language of responsibilities provides a weblike imagery of relationships to replace a hierarchical ordering that dissolves with the coming of equality, so the language of rights underlines the importance of including in the netwark of care not only the other but also the self' (173).

${ }^{55}$ Women, according to Gilligan (1982) "define their identity through relationships of intimacy and care..., attachment is supported by an ethic of care" (169); and women in leadership employ a "nurturant approach to coworkers" (Lunneborg 1990, xviii). 
Coordinator follows up on parent concerns. She does intake for the preschool and greets parents as she opens from 6:30 to 7:30 in the morning. She stated that staff "must be respectful" of parents "no matter what." "s6

${ }^{56}$ Women use an "ethic of responsibility...[which] relies on the concept of equity, the recognition of differences in need" (Gilligan 1982, 164). In addition, women in leadership, according to Lunneborg have a "service orientation to clients" (1990, xviii). 
To score Part I, tally the responses by noting with a mark each time staff checked a particular response:

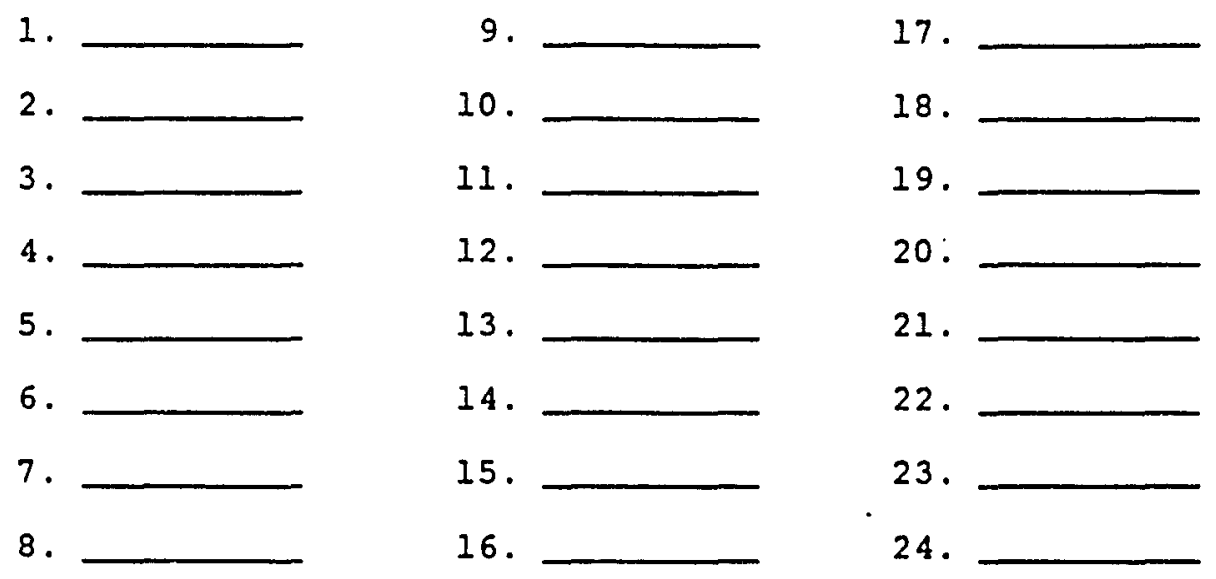

Now total the marks for the following responses:

Task-oriented: $1,6,8,10,14,17,19,22 \quad$ Total $=\bar{x}=2.7$

Achieving center goals is most important in this leadership style. Strong concern for high performance and accomplishing tasks. Emphasis is on planning, directing, following procedures, and applying uniform standards and expectations for all. This director may be viewed as too structured, bureaucratic, and inflexible.

People-oriented: $2,4,7,11,15,18,20,24 \quad$ Total $=\underline{X}=1.0$

Achieving harmonious group relations is foremost in this leadership style. Strong emphasis on maintaining comfortable, friendly, and satisfying working conditions. Allows staff to exercise control and be self-directed with minimal intrusion of center-wide policies and procedures. Staff working in centers with this style of leadership may complain about the lack of order and coordination.

Transactional: $\quad 3,5,9,12,13,16,21,23 \quad$ Total $=\bar{x}=3.7$

Achieving both center goals and maintaining high morale is important in this leadership style. This director is flexible and fair, recognizing that different situations may require a different emphasis on center-wide needs or individual needs. 


\section{Center A.2 - I-TCoordinator}

SCORING SHEET FOR LEADERSHIP STYLE ASSESSMENT TOOL

To score Part I, tally the responses by noting with a mark each time staff checked a particular response:
1 .
9.
17.
2 .
10 .
18.
3.
11 .
19.
4.
12.
20.
5.
13.
21.
6.
14.
22.
7.
15.
23.
8.
16.
24.

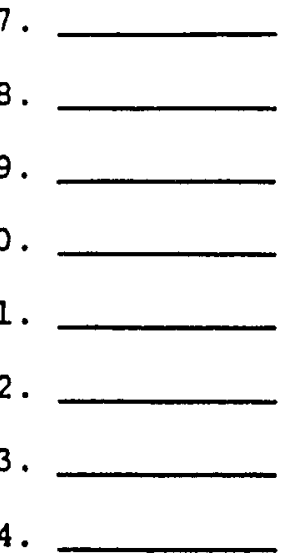

Now total the marks for the following responses:

Task-oriented: $1,6,18,10,14,17,19,22$

Total $=\bar{x}=1.45$

Achieving center goals is most important in this leadership style. Strong concern for high performance and accomplishing tasks. Emphasis is on planning, directing, following procedures, and applying uniform standards and expectations for all. This director may be viewed as too structured, bureaucratic, and inflexible.

People-oriented: $2,4,7,11,15,18,20,24 \quad$ Total $=\bar{x}=1.95$

Achieving harmonious group relations is foremost in this leadership style. Strong emphasis on maintaining comfortable, friendly, and satisfying working conditions. Allows staff to exercise control and be self-directed with minimal intrusion of center-wide policies and procedures. Staff working in centers with this style of leadership may complain about the lack of order and coofdination.

Transactional: $3,5,9,12,13,16,21,23$ Total $=\bar{x}=3.8$

Achieving both center goals and maintaining high morale is important in this leadership style. This director is flexible and fair, recognizing that different situations may require a different emphasis on/center-wide needs or individual needs. 


\section{Center A.2 - P.S. Coordinator}

SCORING SHEET FOR LEADERSHIP STYLE ASSESSMENT TOOL

To score Part I, tally the responses by noting with a mark each time staff checked a particular response:
1 .
9.
17.
2 .
10.
18.
3 .
11.
19.
4.
12.
20.
5.
13.
21.
6.
14.
22.
7.
15.
23.
8.
16.
24.

Now total the marks for the following responses:

Task-oriented: $1,6,8,10,14,17,19,22$

Total $=\bar{x}=2.1$

Achieving center goals is most important in this leadership style. Strong concern for high performance and accomplishing tasks. Emphasis is on planning,. directing, following procedures, and applying uniform standards and expectations for all. This director may be viewed as too structured, bureaucratic, and inflexible.

People-oriented: $2,4,7,11,15,18,20,24 \quad$ Total $=\underline{x}=1.7$

Achieving harmonious group relations is foremost in this leadership style. Strong emphasis on maintaining comfortable, friendly, and satisfying working conditions. Allows staff to exercise control and be self-directed with minimal intrusion of center-wide policies and procedures. Staff working in centers with this style of leadership may complain about the lack of order and coordination.

Transactional: $3,5,9,12,13,16,21,23$ Total $=\bar{x}=4.1$

Acnieving both center goals and maintaining high morale is important in this leadership style. This director is flexible and fair, recognizing that different situations may require a different emphasis on center-wide needs or individual needs. 


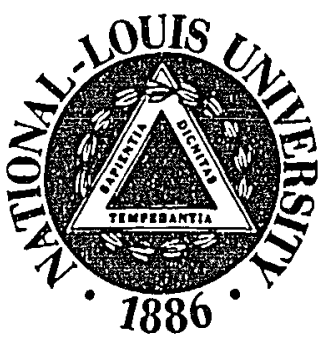

Name:

\section{CRNTER A.2}

Total administrative, teaching, and support staff: 41

Number of staff completing survey: 21

Employment pattom of respondents:

20 employed full-time (35 hours per week or more)

1 employed part-time (20-34 hours per weok)

0 employad part-time (10-19 hours per weak)

0 dota not provided by respondent

'PART A. ORgANIZATIONAL ClIMATE $(N=21)$

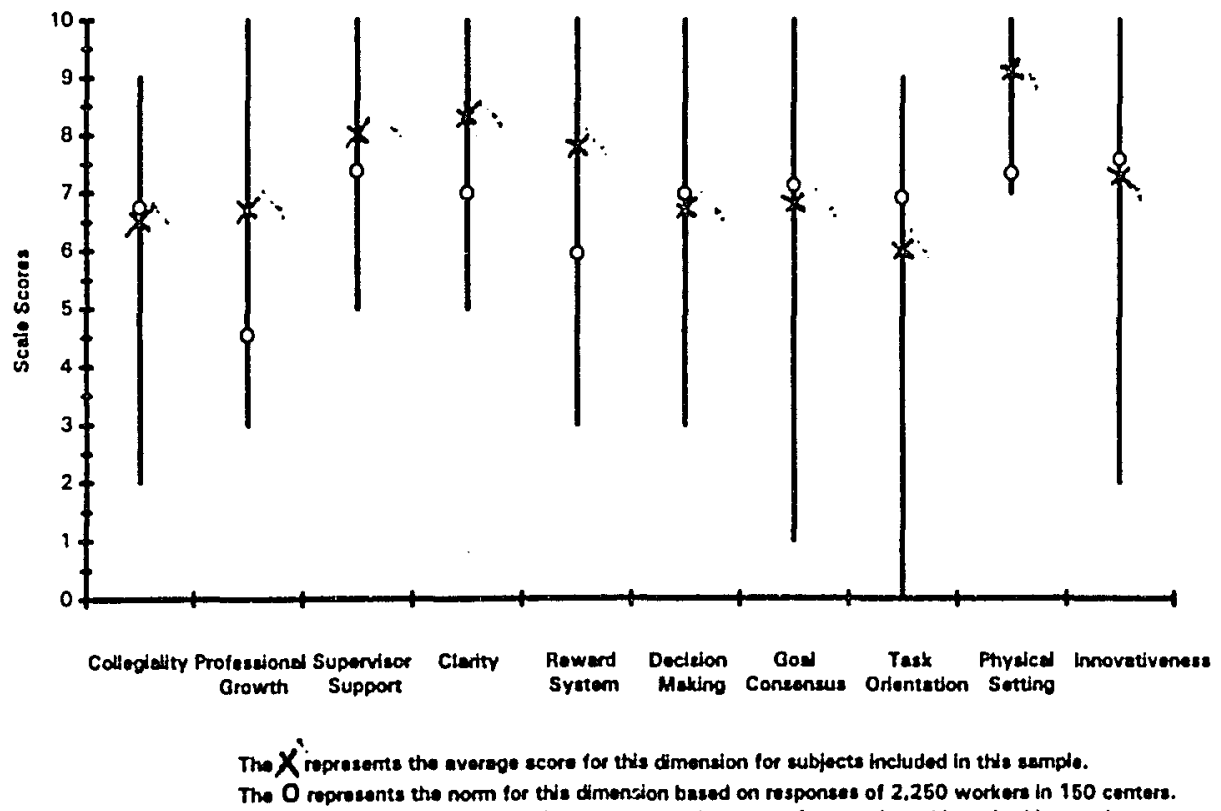

Dato: May 3, 1995

Code: 393 


\section{INTERPRETING THE WORK ENVIRONMENT PROFILE}

\section{Part A. Qrganizational Climate}

This profile provides a summary of the respondents' answers to questions pertaining to the ten dimensions of organizational climate. The vertical axis indicates that the lowest possible score for each dimension is 0 and the highest possible score is 10 . The vertical line for each dimension indicates the range of scores (high and low) for your school. The circle represents the mean score on this dimension for 2,250 early childhood workers who have completed the Work Environment Survey. The $X$ shows the average rating of the respondents from your center with respect to each dimension.

The number of respondents' surveys used for Part A of your Work Environment Profile is indicated by the notation $N=$. If this number differs from the total number of staff who completed surveys, it is because some surveys were incomplete or filled out incorrectly. Incomplete surveys were not used in the data analysis.

The following provides a fuller explanation of how to interpret the ratings for each dimension.

Collegiality: This dimension measures the extent to which staff are friendly, supportive, and trust one another. A high score indicates that staff feel free to express their feelings. They believe communication is generally frank and candid. Individuals working at centers with a high rating on the collegiality dimension usually feel that morale is high and that a strong sense of team spirit characterizes their work relationships.

Professiona/ Growth: This category measures the extent to which professional growth opportunities are available for the staff. Centers that score high on this dimension provide regular staff development workshops, encourage staff to share resources with each other, provide released time for teachers to attend conferences and visit other schools, and provide financial support and guidance for professional advancement.

Supervisor Support: The collective perceptions of workers at centers scoring high on this dimension is that the supervision they receive is both supportive and helpful. Individuals who rank supervisor support positively feel that high but reasonable standards are set and that staff are helped to develop their skills. A low rating on this dimension may indicate that the supervisor does not provide enough feedback or that he/she is too critical and hard to please.

Clarity: This dimension refers to the way in which policies, procedures, and responsibilities are defined and carried out. Early childhood workers at centers scoring high on this dimension generally feel that communication is good and that work schedules. job descriptions, and rules are clear and well-defined. Low ratings on this dimension indicate that 
people are often confused about policies and procedures and that conflicting demands are often placed on workers.

Reward System: This dimension measures the extent to which individuals in the setting feel that pay and fringe benefits are fair and equitably distributed. Centers scoring high in this category provide good job security for their workers and handle promotions and raises fairly. Workers in these settings feel that their pay is fair compared to what other early childhood centers pay. A low score in this dimension indicates that people feel that some individuals are paid more than they are worth, that raises are based on favoritism, and that people are taken advantage of.

Decision-Making: This dimension refers to the extent to which autonomy is valued and staff are encouraged to make decisions about those things which directly affect them. Centers that score high in this category are those where staff are also encouraged to provide input on schoolwide policies. A low rating on this dimension indicates that the overall perception of workers is that the center values conformity and individuals do not feel free to express their opinions on important issues.

Goal Consensus: The dimension of goal consensus refers to the degree to which staff agree on school philosophy, are unified in their approach, and are committed to program goals and objectives. A high score in this area reflects the ability of staff to appreciate differing points of view and to be able to compromise and agree on important programmatic issues.

Task Orientation: This dimension measures the degree of emphasis placed on good planning, efficiency, and getting the job done. Workers who rate their centers high in this area believe that they work hard but still have time to relax, that program procedures are efficient, and that meetings are productive. Low ratings generally indicate that time is often wasted, things get put off, and people often procrastinate.

Physical Setting: This dimension measures the extent to which staff feel that their work environment is well-arranged, organized, and provides sufficient supplies and equipment for them to do their job. A low score in this category indicates that the center may appear drab or need major repairs, that the temperature may be too hot or too cold, that parking may be inadequate, or that classroom space is cramped and crowded.

Innovativeness: This final dimension measures the extent to which the center encourages staff to be creative and innovative in their work. Individuals rating their setting high in this area believe that they are encouraged to try out new ideas to solve problems and then are supported in implementing needed changes. Programs rating low in this dimension are characterized by $a$ traditional approach that avoids risk and allows many problems to go unsolved. 


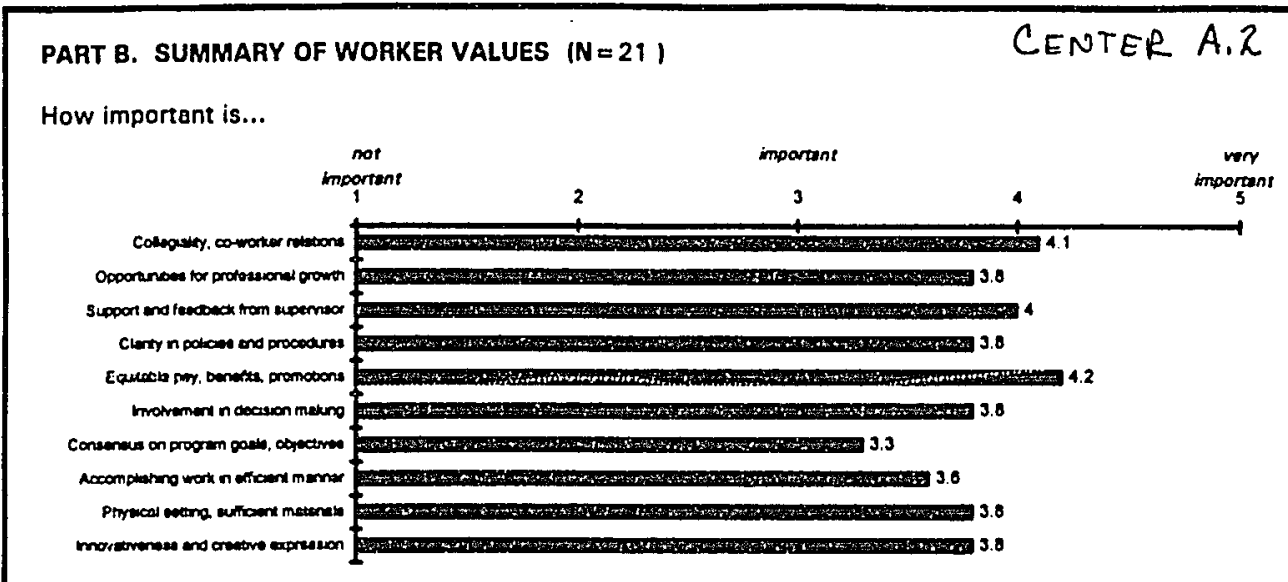

PART C. SUMMARY OF OVERALL COMMITMENT TO THE ORGANIZATION (21)

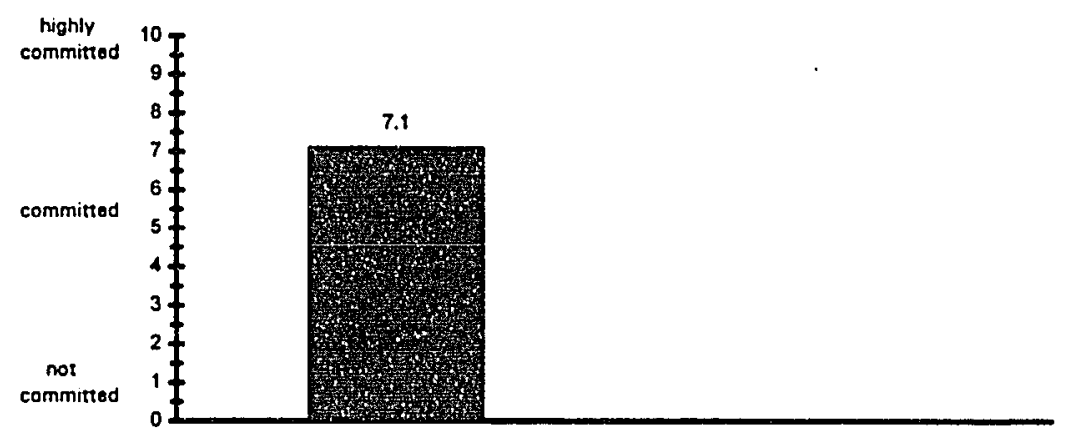

PART D. SUMMARY OF HOW CURRENT WORK ENVIRONMENT RESEMBLES IDEAL (N=21)

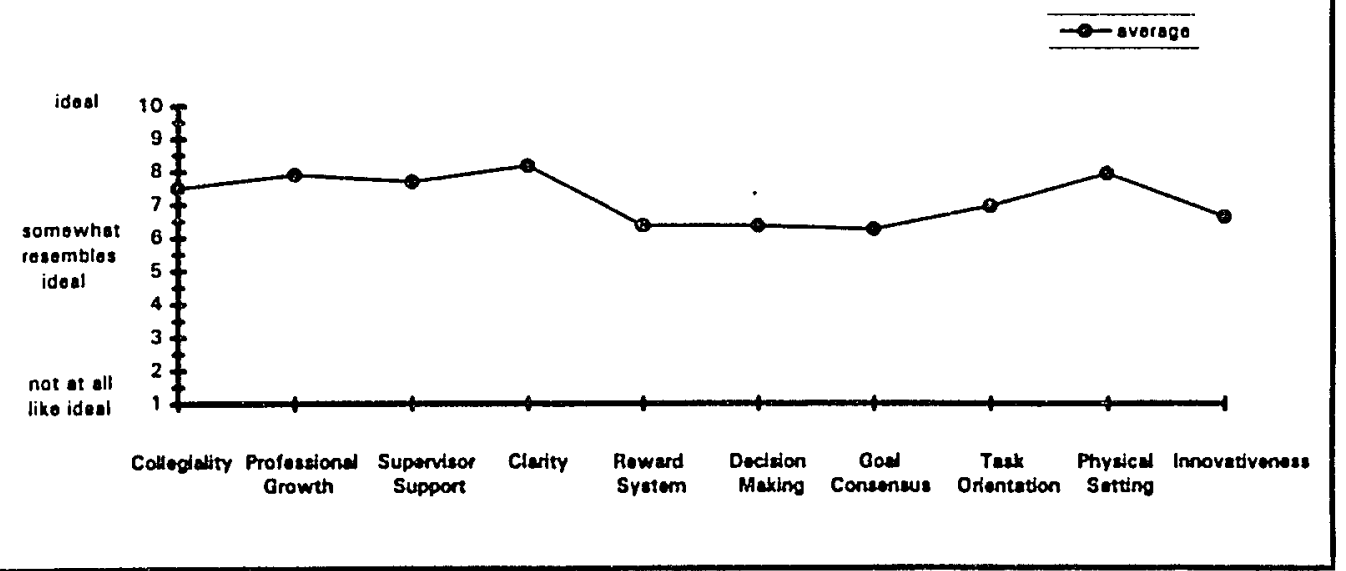




\section{Part B. Summary of Worker Values}

People do not all want or value the same things from their work. For some individuals, a sense of collegiality may be important and essential for job satisfaction. For others who prefer to work alone, the need for affiliation may be less. Likewise, for some people the comfort level of the physical setting and the availability of materials and supplies may be of considerable importance. For others, however, the physical setting may be minimally important.

This profile will help you assess the importance or value that your staff attaches to each of the dimensions of organizational climate. The profile provides a summary of the importance they assign to each dimension. Each score thus represents a composite evaluation of how important that dimension is to them in their work setting.

This profile can guide you in knowing which dimensions should be given high priority. In other words, you will probably achieve more lasting results in your school improvement efforts if you focus on those areas that the staff rated as low in Part $A$ and valued as high in Part $B$. Looking at Part $A$ and $B$ together will help you and your staff appreciate the uniqueness of your setting. Each center must develop its own formula for achieving a healthy organizational climate. There is no one prescription that applies equally to all settings.

\section{Part C. Summary of Overall Commitment to the Qrganization}

This scale provides a summary of the staff's overall commitment to the center. Individuals who feel deeply committed to their jobs tend to put extra effort into their work and take pride in their center. It is not surprising that commitment is strongly correlated with staff turnover.

\section{Part D. Summary of How Current Work Environment Resembles Ideal}

One additional way to understand how workers perceive their present work conditions is to measure their perceptions of how closely their current work situation resembles their ideal work environment. This section summarizes the descrepancy between real and ideal conditions along the ten dimensions of organizational climate. 


\section{Center A.2}

PART E. RANKING OF VARIOUS EDUCATIONAL GOALS AND OBNECTIVES $(N=16)$

\begin{tabular}{|l|c|c|c|c|c|c|}
\hline & \multicolumn{7}{|c|}{ Number of subjocts who rankad ltem as } \\
\hline To holp childron dovelop... & 1 & 2 & 3 & 4 & 6 & 6 \\
\hline language and problem solving skills & 0 & 7 & 2 & 6 & 0 & 1 \\
\hline strong friendships, skills in sharing & 0 & 3 & 10 & 3 & 0 & 0 \\
\hline concepts needed for reading and math & 0 & 0 & 0 & 1 & 6 & 9 \\
\hline independence in caring for themselves & 0 & 6 & 4 & 5 & 1 & 0 \\
\hline physical skill and coordination & 0 & 0 & 0 & 1 & 9 & 6 \\
\hline positive self-concepts and self-esteem & 16 & 0 & 0 & 0 & 0 & 0 \\
\hline
\end{tabular}

PART F. DEGREE OF INFLUENCE OF THE TEACHING STAFF REGARDING VARIOUS ORGANIZATIONAL DECISIONS $(N=17)$

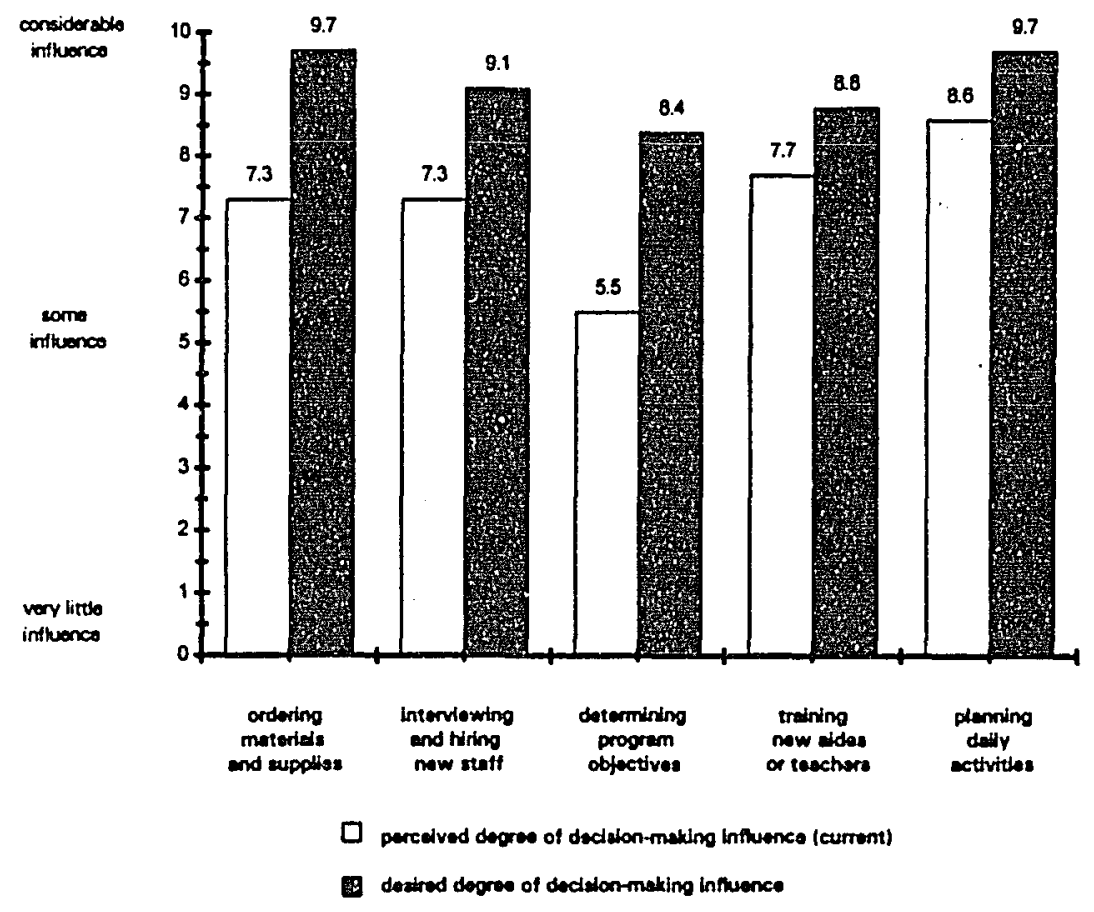


Part E. Ranking of Various Educational Goals and Objectives

There are many educational goals and objectives that guide curricular policies and procedures in our early childhood programs. But the priority that individual staff assign to different goals may vary. This section of the Work Environment Profile details the rankings that respondents assigned to six different early childhood educational objectives. If goal consensus is high at your center, the rankings for each objective should cluster. If staff have strong differences in the importance of different objectives, however, you will notice that the rankings will be widely dispersed.

Part F. Degree of Influence of the Teaching Staff Regarding Various Qrganizational Decisions

This section of the Work Environment Profile describes the perceptions of workers regarding the degree of influence of the teaching staff with respect to various organizational decisions. It includes both workers' perceptions of teachers' degree of current decision-making influence as well as their desired degree of influence.

This section of the profile provides a fuller explanation of the decision making dimension of organizational climate as reflected in Part A. It may prove useful in understanding some of the different decisions that are typically made in early childhood programs - both those where centralized decision making may be preferred and those where shared decision making may be possible. The appropriate amount of decision-making influence by the lteaching staff will depend on your unique set of circumstances and will be different from other programs. 


\section{SYMLOG}

Fiold Dlagrain

Your Name Average of All Katers

Diagram of what Group: Center A.2 Present Date Fall 1997

Group met from what date to what date Page_ 1 of 1

Diagram based on whose perceptions Playing whose role

Rating or Scoring Rating If Rating, scale $(0,1,2)$ or $(0,1,2,3,4 / 2)$

Expansion Multiplier 1 . 9 Comment

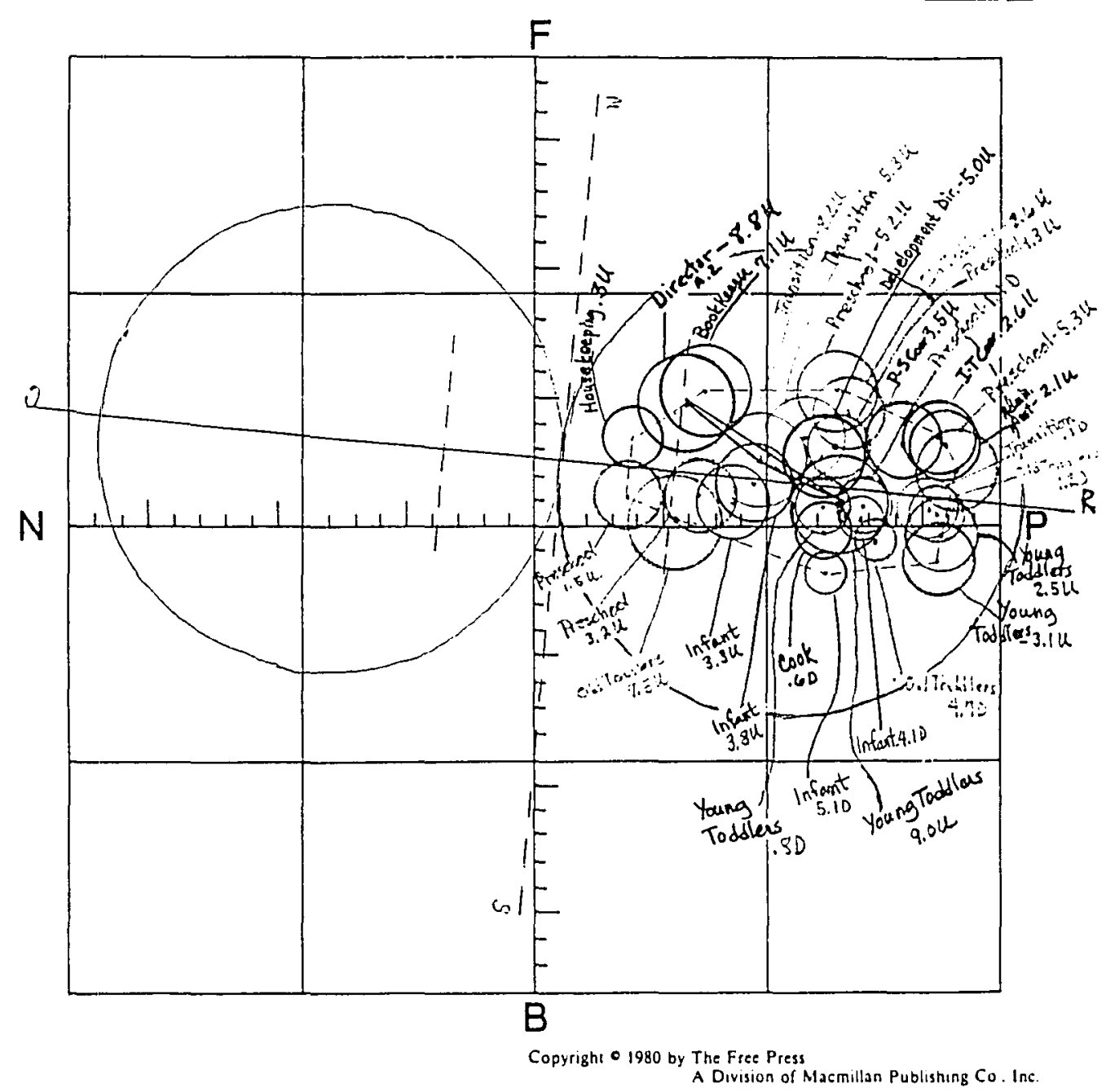




\section{SYMLOG}

DIRECTIONIAL DEFINITIONS

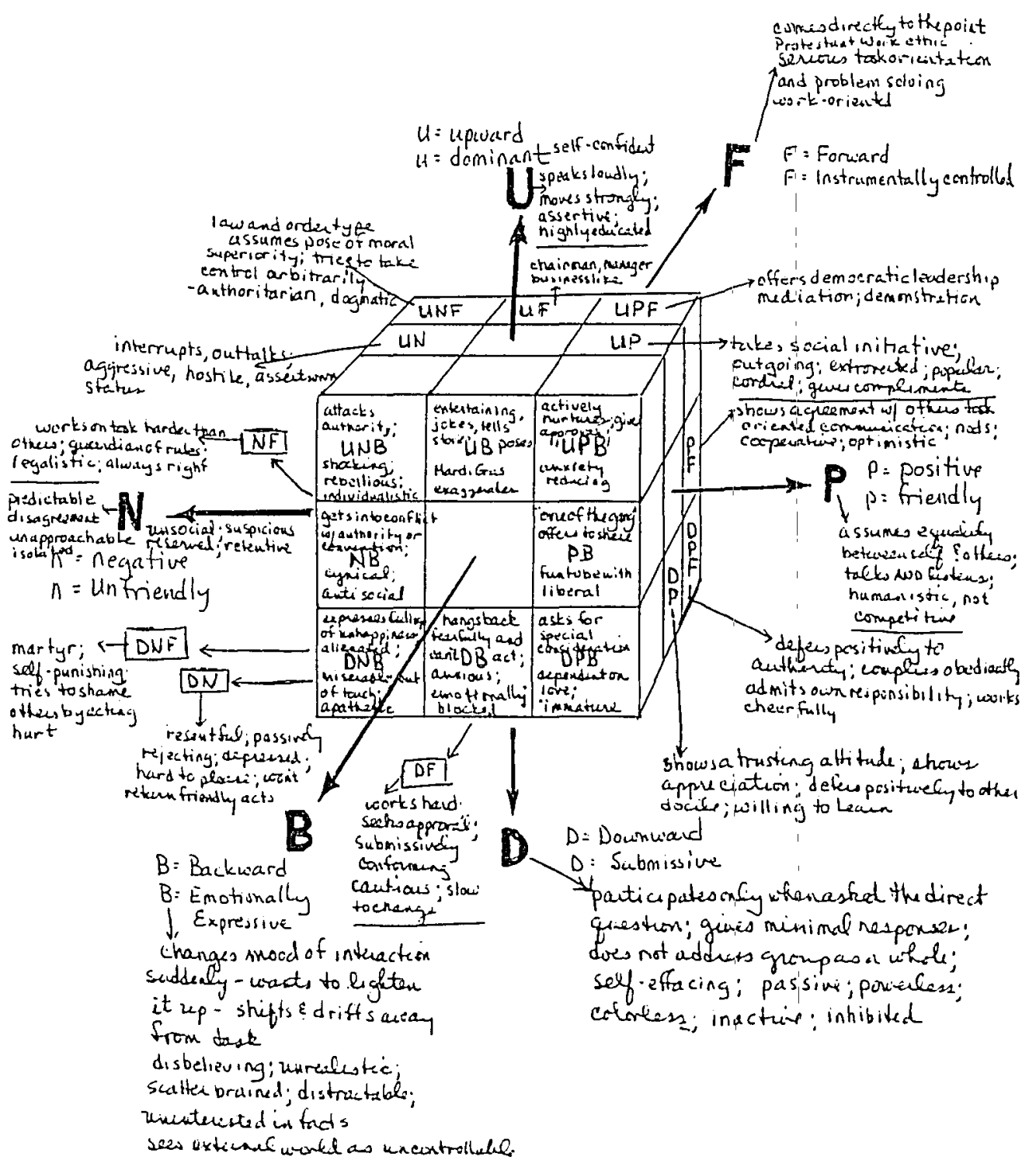


Summary of Leaciership Characteristics of Director A.2. I-T Coordinator, and P-S

Coordinator; and, Center A.2's Organizational Climate

Interviews

All three administrators of Center A.2 employ essentially female styles of leadership. Director A.2 talks about trying to achieve a balance, however, between a "controlling" and a "collaborative" style. As Executive Director of a large child care center with a major fund raising function and a staff that is unionized, Director A.2's job is essentially task oriented. To balance this instrumental orientation, she does several things that I was able to observe. She values relationships and positive communication as components of providing a high quality service to the client. In addition, she employs a cooperative and flexible supervisory relationship with the administrative staff.

The two coordinators described their styles of administration using less formal expressions, such as: "pretty relaxed"; "gives teachers space"; "laid back, but not carefree"; "indirect"; "thoughtful"; and "worries a lot". Their roles are to support the staff who work directly with the children and the parents. In the interviews, both Director A.2 and the P-S Coordinator complained about having problems with time management. The 1-T Coordinator did not comment about this at all and instead described her use of time by telling how she "flows" in and out of the rooms meeting with staff and has a "running todo list". Her description carried with it a feeling that she was comfortable with this style. Does she feel more at-home using a predominantly female style because she is responsible for the care of the youngest children, infants and toddlers? Is it easier to rationalize the 
seeming inefficiencies of direct caregiving when the recipient of the care is a baby? Parents, child care center providers, and the public have historically had a more difficult time accepting group care for infants than for any other age group of children, because group care is frequently interpreted to mean institutionalized or commercialized care, which has a pejorative meaning in the field of child development and family life. Arguments concerning the appropriateness of placing infants in group care have gone on in the child development and early childhood education literature since the 1960s. (See Early Childhood Research Quarterly, Volume 3, Number 3 and Volume 3, Number 4 of September and December 1988, respectively.) As in the example of Center B.1, the Leadership Style Assessment Tool provides some insights on what was reported in the interviews.

Leadership Style Assessment Tool

Staff at Center A.2 rated all three administrators as having a balanced Transactional Style of leadership, with scores that were very close (Director A.2's mean= 3.7; I-T Coordinator's mean $=3.8$; and, P-S Coordinator's mean $=4.1$ ). Each of the three administrators' second strongest style corresponds with their responses to the interview question about how they manage their time. Director A.2 and the P-S Coordinator complained about not having their time organized enough and for both of them their second strongest area was the Task-oriented Style (with means of 2.7 and 2.1 respectively). The I-T Coordinator, who "flows" in and out of rooms had a Peopleoriented Style (with a mean of 1.95) for her second strongest. This would be consistent 
with being more comfortable with the female style of managernent.

Work Environment Profile

Staff rated the Organizational Climate (Part A) as being higher than the norm on five dimensions: Professional Growth, Supervisor Support, Clarity, Reward System, and Physical Setting. They rated the other five dimensions just below but within one point of the norm Collegiality, Decision Making, Goal Consensus, Task Orientation, and Innovativeness. Physical Setting received an average score which was especially high at 9.2 out of a possible 10 points. This dimension also had the narrowest range, that of 3 points, indicating a high degree of consensus on this item. Goal Consensus and Task Orientation both were rated below the norm and had the widest ranges ( 9 points), indicating the greatest lack of agreement among the staff on these dimensions. ${ }^{57}$

As previously mentioned, in using the Work Environment Profile, the areas to work on that are likely to be most successful are those that staff have rated as low on the measure of Organizational Climate and as high on the measure of Values. For Center A.2, Collegiality was rated below average on Organizational Climate and received a 4.1 score out of a possible 5 on Summary of Worker Values, which, for this center, was the second highest ranked value. Center A.2 is a very large child care center when compared to the vast array of formal child care arrangements that exist. When completing the SYMLOG

${ }^{57}$ Only Center A.1 had a dimension with a wider range, which was Task Orientation which had a range of 10 out of 10 . 
rating forms for this project, each staff member was asked to fill out a General Behavior Description list of adjectives for each permanent employee of the center. At Center A.2, very few of the staff members were able to describe all of the permanent staff. Because of their size, the whole staff (which totals 41) rarely meets together as a group. The staff, instead, meet as sub-groups divided by the ages of the children with whom they work, and these sub-groups are supervised by either the I-T Coordinator or the P-S Coordinator. In addition, the buildings's arrangement of classrooms has the Infants downstairs, and the other groups upstairs. Some of the Infant staff "did not know" some members 'of the preschool staff and visa versa. Thus, collegiality appears to be compromised by the structure of the organization, specifically physical organization of the center and size of the staff.

Decision Making and Goal Consensus are also both rated below average on the measure of Organizational Climate, and received Values of 3.8 and 3.3 respectively, out of a range of 3.3 to 4.2 . In terms of Decision Making, the larger size and financial organization of this center have resulted in multiple layers of organization structure. There is a Board, an Executive Director, a Director of Development (fund raiser), an Administrative staff, two Program Coordinators, Head Teachers, and Assistant Teachers. The other three centers have a Director, Administrative Assistant or Program Coordinator, Head Teachers, and Assistant Teachers, and teaching staff work directly with the top administrator of the center in making decisions that impact their daily routines. At Center A.2, staff each work directly with only one administrator, their specific Program Coordinator. Some decisions are made at a level that is not accessible to 
the teaching staff, and working condition issues are addressed at the bargaining table. Thus, direct involvement of individual staff members in decision making is shaped by the organizational structure. In Part F, which compares the perceived and desired degrees of influence in decision making, the staff at Center A.2 indicate that they actually do have a significant amount of influence in decision-making, but would like more, especially in the area of Determining Program Objectives. It appears that the staff, in fact, have considerable influence on decisions being made in regard to the operation of their classrooms, but would like more programmatic influence.

Goal Consensus may not be achievable in such a large staff due to the diversity of roles and responsibilities that people have in that organization. However, in Part E where staff do a Ranking of Various Educational Goals and Objectives, $100 \%$ of the respondents ranked Positive Self-concepts and Self-esteem as number one, indicating a high level of Goal Consensus among the staff, at least in their goals for the children. The staff of Center A.2 are unionized, which is not common in child care. The perceived lack of goal consensus may be reflective of employee-management bargaining issues and how different staff members feel about them. Goal Consensus as a Value, was rated the lowest of all the values.

Overall Commitment to the organization is rated at 7.1 which is almost halfway between Committed at 5.5 and Highly Committed at 10. Center A.2's rating was the lowest averaged rating for this item of the four centers, yet it still indicates a strong degree of commitment on the part of the staff. 
SYMLOG Field Diagram

Considering the size of Center A.2, the Field Diagram is startling by the fact that all of the images representing the group average location of each member are contained within the Reference Circle. The Reference Circle

represents the presumed tendency of the individual to cluster images around the self-image or to move the self-image toward association with some subgroup of images [seen as] relatively accepted or acceptable. The Opposite Circle represents the presumed tendency to cluster images around other images [that are] dissociated from the self-image as relatively unacceptable, or rejected" (Bales and Cohen 1979, 43).

Considering that the staff members of this center do not know all other members equally well and that they engage in collective bargaining which frequently divides groups, one would think that there would be some polarization occurring. SYMLOG theory assumes that:

in an individual perceptual evaluative field, so far as the total potential field of images is concerned, polarization is likely and unification is typically a matter of unification of images at one pole or the other, or both. Thus, polarization of the total field (figure and ground) into two clusters of images and unification of images within each polar cluster is the most general expected pattern (Bales and Cohen 1979, 43).

Center A.2 defies that pattern by each staff member (through the average of their ratings) locating all of the other members "close" to themselves in the Reference Circle, with no polarization occurring. In a similar pattern to Center B.1, all of the images in Center A.2's Field Diagram have "P" (or Positive) as one of the three dimensions, indicating a very Friendly staff. Bales and Cohen (1979) have reported a tendency for group members to crowd people into the Positive side of the Field Diagram when doing ratings (as were 
done in this study) as compared to non-group-member observers doing observations of a group and scoring ${ }^{58}$. Their findings suggest that there may be a Positive rating bias occurring, which may not operate to the same extent when observers are scoring. "These differences between rating and scoring occur despite the fact that, overall, there is a high correlation between rating and scoring, especially in the P-N dimension" (Bales and Cohen $1979,284-5)$.

Director A.2's location in the space is clearly UPF (purposeful, democratic leader), but in addition, she is in a position called Mediator. When there is member on the Perimeter ${ }^{59}$ and far out in the direction marked M (Mediator Direction) on the Line of Balance $^{60}$, this member "...has the potential of attracting simultaneously the members at both end of the Line of Polarization ${ }^{61} . . ., "$ if there is polarization, and neutralizing the conflict and hostility between the two polarized groups (Bales 1980,13). This person may be able to get the polarized groups to replace the negative feelings with positive ones "toward a common object [person] of acceptance or attraction" (Bales 1980, 13).

\footnotetext{
${ }^{58}$ Scoring is a use of SYMLOG whereby observers watch a group in action and observe and score both their verbal and non-verbal behavior as well as the intent of the content of their behaviors.

${ }^{59}$ The Perimeter is the dotted line connecting the center dots of the outermost circles (Bales 1980, 13).

${ }^{60}$ The Line of Balance is the dotted line between the two circles with the Mediation Direction on one end (M) and the Scapegoat Direction on the other end (S).

${ }^{61}$ Line of Polarization is the solid line that intersects the two circles with the Reference Direction (R) on one end and the Opposite Direction (O) at the other end.
} 
As the Executive Director who negotiates the contract with the non-administrative staff, Director A.2 is in the ideal position to bring polarized factions together, namely the Board of Directors and the staff union. Director A.2 is clearly in charge, though, as she has the largest circle, denoting the $\mathrm{U}$ (Upward/Dominant) direction.

The two Program Coordinators are also found in the UPF section of the space, however they are located in a more Positive/Friendly direction than Director A.2. In addition, the Coordinators are very near each other, indicating that the staff see them in similar ways, and differentiate them clearly from Director A.2. Neither of the Coordinators is extremely Dominant nor Instrumentally Controlled, which when combined with the strong Positive factor, provides a picture of a supportive facilitator. Finally, none of the staff members, no matter what position they hold, is far out in either the F (Instrumentally Controlled) or B (Emotionally Expressive) directions indicating a balance of styles among the staff as a whole. 


\section{Center A.1: Qbservation, Interview, and Findings}

The observation of the center and interview with the director (Director A.1) took place on October 19, 1994.

\section{The Setting}

Center A.1 serves staff and students of a local university. It is housed in an older building in a highly urban location on the edge of the campus. The building has lots of windows providing ample natural light and has two floors with classrooms on both levels. The center serves toddler and preschool aged children from 7:30 a.m. to 5:30 p.m. five days a week in four classrooms, with a post-kindergarten program in the summer only. The front door of the center opens into a breezeway of sorts with the assistant's office having a window that opens out onto it. For security reasons in their downtown location, the second door is locked and all people entering the center must announce themselves to whoever is in the assistant's office and be "buzzed" in through the second door. One comes into an open entry area where one sees large bulletin boards covered with children"s art work of all varieties. The director and administrative assistant's offices are directly to the right of this entryway. The classrooms the "homey" feeling of a comfortable, well used room that invites a person inside.

Center A.1 is a tax supported, nonprofit child care center licensed for 95 children, with a total of 109 families enrolled. The parent population in comprised of $2 / 3$ student parents and $1 / 3$ parents who are faculty, staff, or community members (of which there are 
very few). There are 10 full time staff members: 2 administrative; 7 teaching; and 1 cook. There are also six part-time "regular" staff: 2 administrative and 4 teaching. In addition there are about 40 individuals working from 5-35 hours per week on a short term basis because they are students at the college. These positions together are equivalent to 10 full time positions. Upon walking through the center, it is clear that both the staff and families are diverse by ethnicity, sex, age, and lifestyle. Values of inclusion, multiculturalism, diversity and anti-bias were implied by the people who populate the center. The center is currently NAECP accredited.

\section{Interview with Director A.1}

At the time of the interview, Director A.1 had been in the position for almost 4 years. She had initially been the acting director while the former director was on leave, but for the last 5 months she had been the permanent director. Prior to becoming acting director, Director A.1 had been head teacher of the 3 and 4 year olds for $7 \frac{1}{2}$ years. She has an M.A. degree in early childhood education from a west coast college.

\section{Describe your style of administration:}

Director A.1 described her style of administration as being "relaxed, personal, 
laissez-faire, humanistic." ${ }^{.62}$ She is "permissive to a fault."

\section{Tell me how decisions are made, regarding:}

Staffing and scheduling. There are three shifts to fill with permanent staff and one part-time position that is set. Two permanent people must be there until 5:30. Within those parameters, staff determine their schedules by seniority and mutual agreement. ${ }^{64}$

Budgeting. To begin with, Center A.1 has a "pretty good budget" so decisions aren't too hard. Director A.1 takes requests (wish lists) from the teachers and she finds that there are "few outrageous requests." As the budget allows, the staff are able to get these things. Director A.1 just orders the basics such as supplies and other consumables.

Children's program. The teachers get a "significant amount of freedom" in this area. They set the daily schedule and do all the planning. Director A.1 buys resource

\footnotetext{
${ }^{62}$ Helgesen (1990) found that women leaders "saw their identities as complex and multifaceted" and were process oriented and emphasized relationships with people (29).

${ }^{63}$ In a discussion on perceptions of power, Gilligan (1982) states that "while men represent powerful activity as assertion and aggression, women in contrast portray acts of nurturance as acts of strength" (167-8). Lunnebiorg found that the women in her study had "an attraction to managing others using power differently than men did" (1990, xviii).

${ }^{64}$ Kanter and Fassel (1977) found that women who were most successful and effective were "interested in empowering subordinates (sharing power with them)" (302).

${ }^{65}$ In Belenky et al. (1986), the authors describe the teacher as one "who would help [the students] articulate and expand their latent knowledge" (217).
} 
materials, training materials, and classroom materials. ${ }^{66}$

Physical facility. In terms of the physical facility, Director A.1 says there are not many aptions. They have no room for expansion, so the only possibilities are to redesign the space they have. They are designing a new space in the center, a "constructivist" play room. A number of the staff have formed a task group to help design it. The teachers also designed an "all center day" where all the rooms are open for the children to use, thus providing the children with a new experience within limited options. ${ }^{67}$

\section{How do you organize your time and responsibilities? What are your priorities?}

Director A.1 stated that her number one priority is "responding to crises." She went on to say, "I don't know how time will be spent until it hits me!"68 Beyond crises, she sees her primary responsibility as being "to support the teachers." She gives supervisory support, provides supplies and resources, does observations, and gives other day-to-day support.. Her second responsibility is "to support the parents."

${ }^{66}$ This again demonstrates an interest in "empowering subordinates" (Kanter and Fassel 1977, 302).

${ }^{67}$ Heffron (1989) cites Weick stating that the people in effective organizations avoid "over reliance on past experiences and the knowledge derived from it, which is not necessarily valid in changed circumstances" (339), i.e., change is welcomed and old ways are not presierved simply because change is hard.

68 "When women construct the adult domain, the world of relationships emerges and becomes the focus of attention and concern" (Gilligan 1982, 167) Women "find order where others saw chaos" (Gilligan 182, 169).

Helgesen found that successful women in leadership "did not view unscheduled tasks and encounters as interruptions"(1990,19). 
4. How do you maintain quality caregiving by the staff?

Director A.1 uses an "indirect approach" by "establishing a climate that respects individual differences and sees people's strengths." This approach is similar to how she ran her room as a teacher. She treats the staff (as she did the children in her room) as she would like to be treated. She believes in "empowerment" as an approach to maintaining quality. Director A.1 stated that teachers need to feel good about themselves to do a good job..$^{69}$

On a more systematic level, she maintains quality caregiving by having on-site staff trainings throughout the year. Also, each staff member gets 2 professional development days per year as one of their benefits and they each decide how he or she will use the days.

\section{How do you balance your job here in the child care center and your life outside?}

Director A.1 answered this question right away with "better than I used to!" She works nine hour days, with some flexibility -- " 45 ish hours per week." She has a Program Coordinator who does student hiring (of the 40 or more students hired each school term), training, and payroll, thus taking these responsibilities over for her. She has friends who are support people for her ${ }^{70}$ and she runs. She is a serious runner and runs competitively.

\footnotetext{
69 "Reality and fairness indicate that a new set of criteria for measuring treatment of employees be derived [especially] for organizations experiencing decline [of resources compared to need]" (Heffron 1989, 342).

${ }^{70}$ Helgesen (1990) found that the women she interviewed "maintained a complex network of relationships with people outside their organizations" (24).
} 
She "processes stuff when she runs." She said that she needs to balance the "lack of control" she feels over things she "cannot fix."71

6. What about the personal lives of staff members -- what are your expectations for how much of the personal can come into the workplace or into your awareness?

Director A.1 said that people do bring their personal lives into the center and she "frets about it!" She talks to them and tries to support them. They all acknowledge that people do have other things going on. They "cry with each other."72

\section{How do you work with parents? How do you expect staff members to work/interact} with parents?

Parent involvement at Center A.1 ranges from informal to formal. Teachers have daily, informal contact with parents and periodic conferences. Director A.1 doesn't get as close to the parents due to the size of the center. However, they have "parent coffees" where they set a table in the entry hall and put out coffee, tea, and cake and Direct A.1 interacts with the parents at these events as well as at the planned ice cream socials and parent picnics.

\footnotetext{
${ }^{71}$ Insistence on a balanced life-style and taking care of oneself (in the midst of caring for others) were cited as important to successful and healthy women (Lunneborg 1990, xviii; Gilligan 1982, 173).

${ }^{72}$ Key themes for women in leadership and not are nurturance, intimacy, attachment and care (Gilligan 1982, 169; Lunneborg 1990, xviii).
} 
Director A. 1 opens the center 2 days a week so she can greet parents. In addition there are spontaneous, informal, and one-on-one contact. According to Director A.1, ninety percent of this contact is parent initiated and ten percent initiated by herself. Finally, the center has a formal Parent Advisory Board that is made up parents, faculty members from the university, and an early childhood professional from the community. ${ }^{73}$

Director A.1 described some of the other activities that the center has organized for parents. They have had several support groups, one for parents of children of color and one for fathers and male caregivers. There is an open house each year for parents that is organized around an anti-bias theme. The center has organized a lending library with books on child development, parenting, and hard-to-find books for children with special focuses such as: books with a multicultural theme or diverse characters; or, books that deal with special issues like death, toilet training, and divorce. The staff video tape activities of the children to show at events sponsored by individual classes. Director A.1 described how they refer all or any parents to the Student Parent Center for parenting classes and, in particular, to a single parent support group. ${ }^{74}$

\footnotetext{
${ }^{73}$ One of the four themes that Lunneborg (1990) found about women was that they had a "service orientation to clients" (xviii).

${ }^{74}$ Gilligan points out that women use an "ethic of responsibility" which "relies on the concept of equity [and] the recognition of differences in need" $(1982,164)$.
} 


$$
\text { CEnTER A.1 - Director A.I }
$$

SCORING SHEET FOR LEADERSHIP STYLE ASSESSMENT TOOL

To score Part I, tally the fesponses by noting with a mark each time staff checked a particular response:

1.

2 .

3.

4.

5 .

6 .

7 .

8.

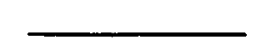

9.

10.

11.

12.

13.

14.

15.

16.
17.

18.

19.

20.

21.

22 ,

23.

24.

Now total the marks for the following responses:

Task-oriented: $1,6,8,10,14,17,19,22$

T"otal $=\bar{x}=1.5$

Achieving center goals is most important in this leadership style. Strong concern for high performance and accomplishing tasks. Emphasis is on planning, directing, following procedures, and applying uniform standards and expectations for all. This director may be viewed as too structured, bureaucratic, and inflexible.

People-oriented: $2,4,7,11,15,18,20,24 \quad$ Total $=\bar{x}=2.5$

Achieving harmonious group relations is foremost in this leadership style. Strong emphasis on maintaining comfortable, friendly, and satisfying working conditions. Allows staff to exercise control and be self-directed with minimal intrusion of center-wide policies and procedures. Staff working in centers with this style of leadership may complain about the lack of order and coordination.

Transactional: $3,5,9,12,13,16,21,23$ Total $=\underline{\bar{x}}=3.75$

Achieving both center goals and maintaining high morale is important in this leadership style. This director is flexible and fair, recogniziny that different situations may require a different emphasis on centef-wide needs or individual needs. 


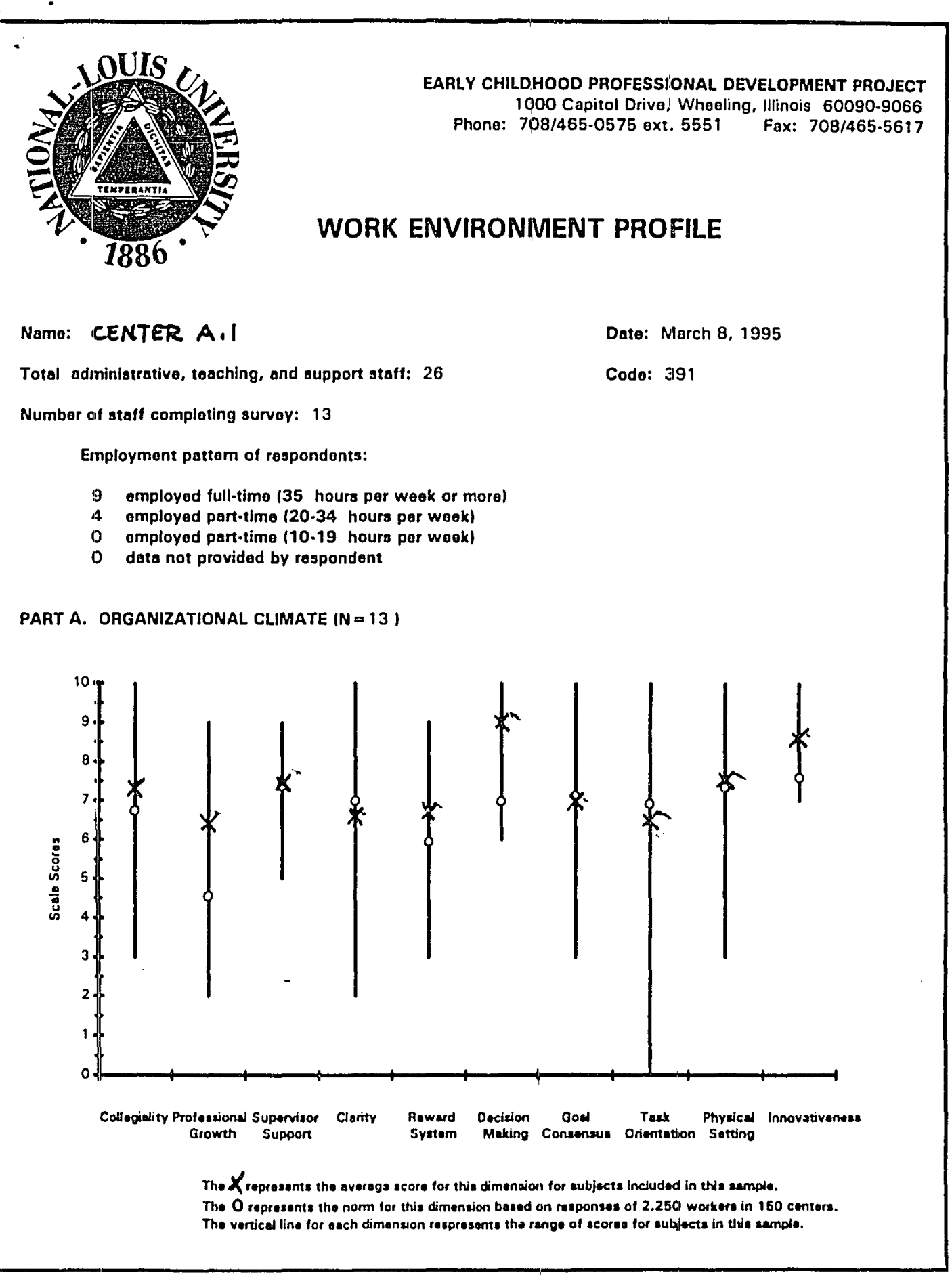




\section{Part A. Qrganizational Climate}

This profile provides a summary of the respondents' answers to questions pertaining to the ten dimensions of organizational climate. The vertical axis indicates that the lowest possible score for each dimension is 0 and the highest possible score is 10. The vertical line for each dimension indicates the range of scores (high and low) for your school. The circle represents the mean score on this dimension for 2,250 early childhood workers who have completed the Work Environment Survey. The $X$ shows the average rating of the respondents from your center with respect to each dimension.

The number of respondents' surveys used for Part A of your Work Environment Profile is indicated by the notation $\mathrm{N}=$. If this number differs from the total number of staff who completed surveys, it is because some surveys were incomplete or filled out incorrectly. incomplete surveys were not used in the data analysis.

The following provides a fuller explanation of how to interpret the ratings for each dimension.

Collegiality: This dimension measures the extent to which staff are friendly, supportive, and trust one another. A high score indicates that staff feel free to express their feelings. They believe communication is generally frank and candid. Individuals working at centers with a high rating on the collegiality dimension usually feel that morale is high and that a strong sense of team spirit characterizes their work relationships.

Professiona/ Growth: This category measures the extent to which professional growth opportunities are available for the staff. Centers that score high on this dimension provide regular staff development workshops, encourage staff to share resources with each other, provide released time for teachers to attend conferences and visit other schools, and provide financial support and guidance for professional advancement.

Supervisor Support: The collective perceptions of workers at centers scoring high on this dimension is that the supervision they receive is both supportive and helpful. Individuals who rank supervisor support positively feel that high but reasonable standards are set and that staff are helped to develop their skills. A low rating on this dimension may indicate that the supervisor does not provide enough feedback or that he/she is too critical and hard to please.

Clarity: This dimension refers to the way in which policies, procedures, and responsibilities are defined and carried out. Early childhood workers at centers scoring high on this dimension generally feel that communication is good and that work schedules, job descriptions, and rules are clear and well-defined. Low ratings on this dimension indicate that 
people are often confused about policies and procedures and that conflicting demands are often placed on workers.

Reward System: This dimension measures the extent to which individuals in the setting feel that pay and fringe benefits are fair and equitably distributed. Centers scoring high in this category provide good job security for their workers and handle promotions and raises fairly. Workers in these settings feel that their pay is fair compared to what other early childhood centers pay. A low score in this dimension indicates that people feel that some individuals are paid more than they are worth, that raises are based on favoritism, and that people are taken advantage of.

Decision-Making: This dimension refers to the extent to which autonomy is valued and staff are encouraged to make decisions about those things which directly affect them. Centers that score high in this category are those where staff are also encouraged to provide input on schoolwide policies. A low rating on this dimension indicates that the overall perception of workers is that the center values conformity and individuals do not feel free to express their opinions on important issues.

Goal Consensus: The dimension of goal consensus refers to the degree to which staff agree on school philosophy, are unified in their approach, and are committed to program goals and objectives. A high score in this area reflects the ability of staff to appreciate differing points of view and to be able to compromise and agree on important programmatic issues.

Task Orientation: This dimension measures the degree of emphasis placed on good planning, efficiency, and getting the job done. Workers who rate their centers high in this area believe that they work hard but still have time to relax, that program procedures are efficient, and that meetings are productive. Low ratings generally indicate that time is often wasted, things get put off, and people often procrastinate.

Physical Setting: This dimension measures the extent to which staff feel that their work environment is well-arranged, organized, and provides sufficient supplies and equipment for them to do their job. A low score in this category indicates that the center may appear drab or need major repairs, that the temperature may be too hot or too cold, that parking may be inadequate, or that classroom space is cramped and crowded.

Innovativeness: This final dimension measures the extent to which the center encourages staff to be creative and innovative in their work. Individuals rating their setting high in this area believe that they are encouraged to try out new ideas to solve problems and then are supported in implementing needed changes. Programs rating low in this dimension are characterized by a traditional approach that avoids risk and allows many problems to go unsolved. 
'PART B. SUMMARY OF WORKER VALUES $(N=13)$

CENTER A.I

How important is...

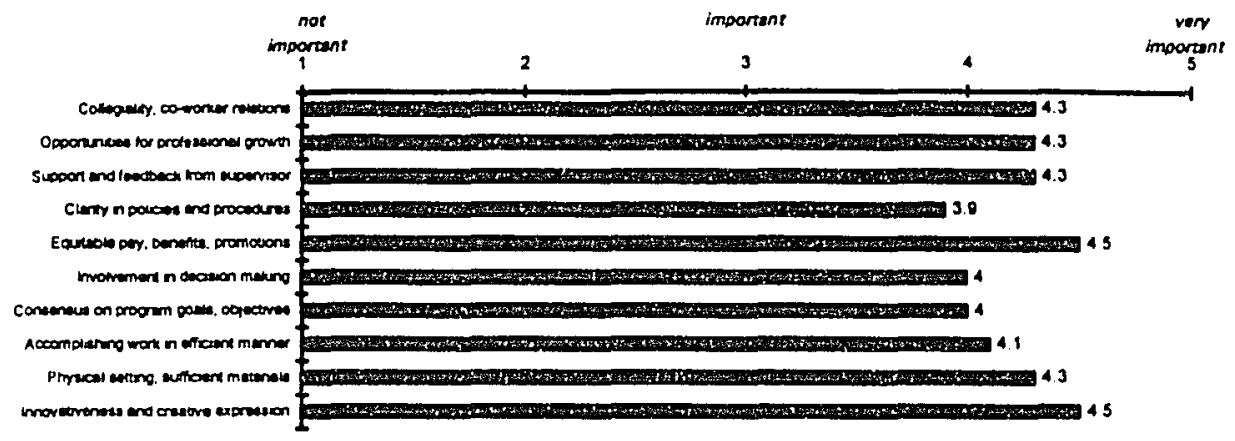

PART C. SUMMARY OF OVERALL COMMITMENT TO THE ORGANIZATION (N= 13 )

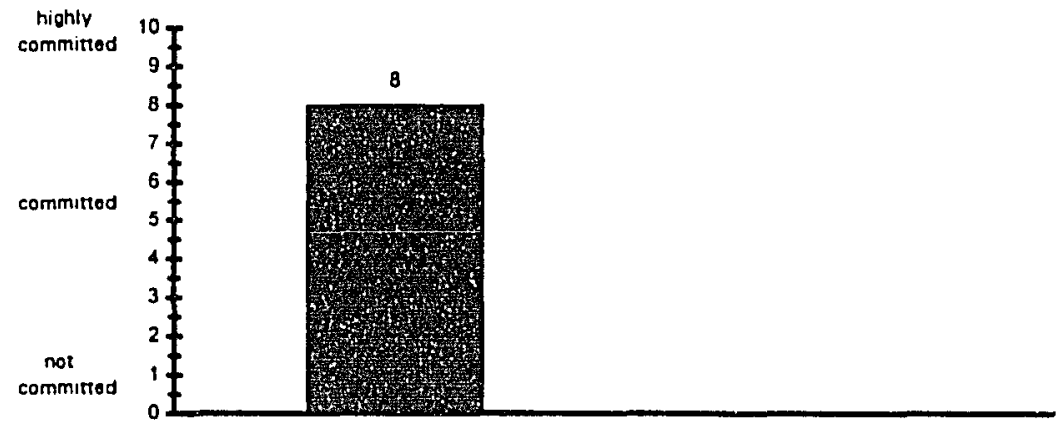

PART D. SUMMARY OF HOW CURRENT WORK ENVIRONMENT RESEMBLES IDEAL $(N=13)$

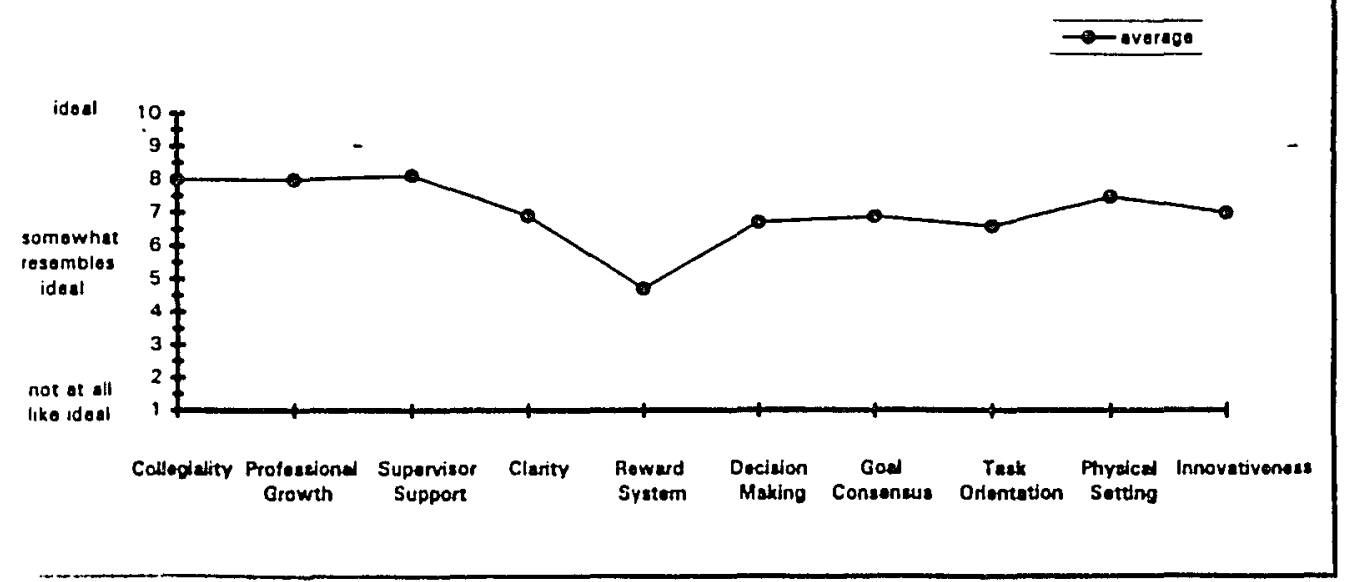


People do not all want or value the same things from their work. For some individuals, a sense of collegiality may be important and essential for job satisfaction. For others who prefer to work alone, the need for affiliation may be less. Likewise, for some people the comfort level of the physical setting and the availability of materials and supplies may be of considerable importance. For others, however, the physical setting may be minimally important.

This profile will help you assess the importance or value that your staff attaches to each of the dimensions of organizational climate. The profile provides a summary of the importance they assign to each dimension. Each score thus represents a composite evaluation of how important that dimension is to them in their work setting.

This profile can guide you in knowing which dimensions should be given high priority. In other words, you will probably achieve more lasting results in your school improvement efforts if you focus on those areas that the staff rated as low in Part $A$ and valued as high in Part $B$. Looking at Part $A$ and $B$ together will help you and your staff appreciate the uniqueness of your setting. Each center must develop its own formula for achieving a healthy organizational climate. There is no one prescription that applies equally to all settings.

\section{Part C. Summary of Qverall Commitment to the Organization}

This scale provides a summary of the staff's overall commitment to the center. Individuals who feel deeply committed to their jobs tend to put extra effort into their work and take pride in their center. It is not surprising that commitment is strongly correlated with staff turnover.

\section{Part D. Summary of How Current Work Environment Resembles Ideal}

One additional way to understand how workers perceive their present work conditions is to measure their perceptions of how closely their current work situation resembles their ideal work environment. This section summarizes the descrepancy between real and ideal conditions along the ten dimensions of organizational climate. 
CENTER A.I

PART E. RANKING OF VARIOUS EDUCATIONAL GOALS AND OBJECTIVES $(N=9$ )

\begin{tabular}{|l|c|c|c|c|c|c|}
\hline \multicolumn{1}{|c|}{} & \multicolumn{3}{|c|}{ Number of subjocts who ranked item as } \\
\hline To halp childron develop... & 1 & 2 & 3 & $\mathbf{6}$ & $\mathbf{6}$ & $\mathbf{6}$ \\
\hline language and problem solving skills & 0 & 1 & 3 & 3 & 2 & 0 \\
\hline strong friendships, skills in sharing & 0 & 3 & 2 & 3 & 0 & 1 \\
\hline concepts needed for reading and math & 0 & 0 & 0 & 0 & 3 & 6 \\
\hline independence in caring for themselves & 0 & 5 & 4 & 0 & 0 & 0 \\
\hline physical skill and coordination & 0 & 0 & 0 & 3 & 4 & 2 \\
\hline positive self-concepts and self-esteem & 9 & 0 & 0 & 0 & 0 & 0 \\
\hline
\end{tabular}

PART F. DEGREE OF INFLUENCE OF THE TEACHING STAFF REGARDING VARIOUS ORGANIZATIONAL DECISIONS $(N=13$ )

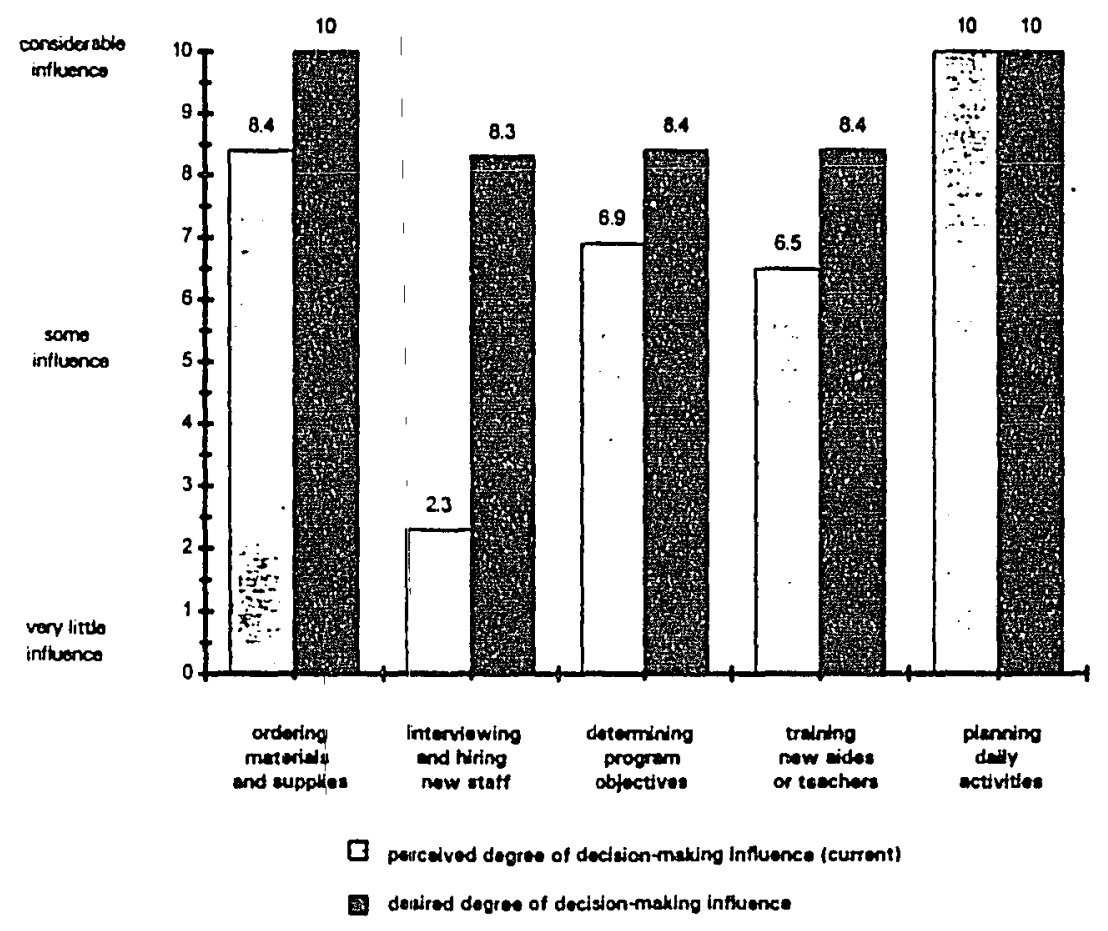




\section{Part E. Ranking of Various Educational Goals and Objectives}

There are many educational goals and objectives that guide curricular policies and procedures in our early childhood programs. But the priority that individual staff assign to different goals may vary. This section of the Work Environment Profile details the rankings that respondents assigned to six different early childhood educational objectives. If goal consensus is high at your center, the rankings for each objective should cluster. If staff have strong differences in the importance of different objectives, however, you will notice that the rankings will be widely dispersed.

\section{Part F. Degree of Influence of the Teaching Staff Regarding Various Organizational Decisions}

This section of the Work Environment Profile describes the perceptions of workers regarding the degree of influence of the teaching staff with respect to various organizational decisions. It includes both workers' perceptions of teachers' degree of current decision-making influence as well as their desired degree of influence.

This section of the profile provides a fuller explanation of the decision making dimension of organizational climate as reflected in Part A. It may prove useful in understanding some of the different decisions that are typically made in early childhood programs - both those where centralized decision making may be preferred and those where shared decision making may be possible. The appropriate amount of decision-making influence by the teaching staff will depend on your unique set of circumstances and will be different from other programs. 


\section{SYMLOG}

Field Diagram

Diagram of what Group: CENTER A.I

Group met from what date

Diagram based on whose perceptions

Rating or Scoring Rating

Expansion Multiplier_1.24 Comment
Your Name Averabe of All Baters Present Date_Spring 1995 to what date Page__ 1 of 11 Playing whose role If Rating, scale $(0,1,2)$ or $(0,1,2,3,4 / 2)$

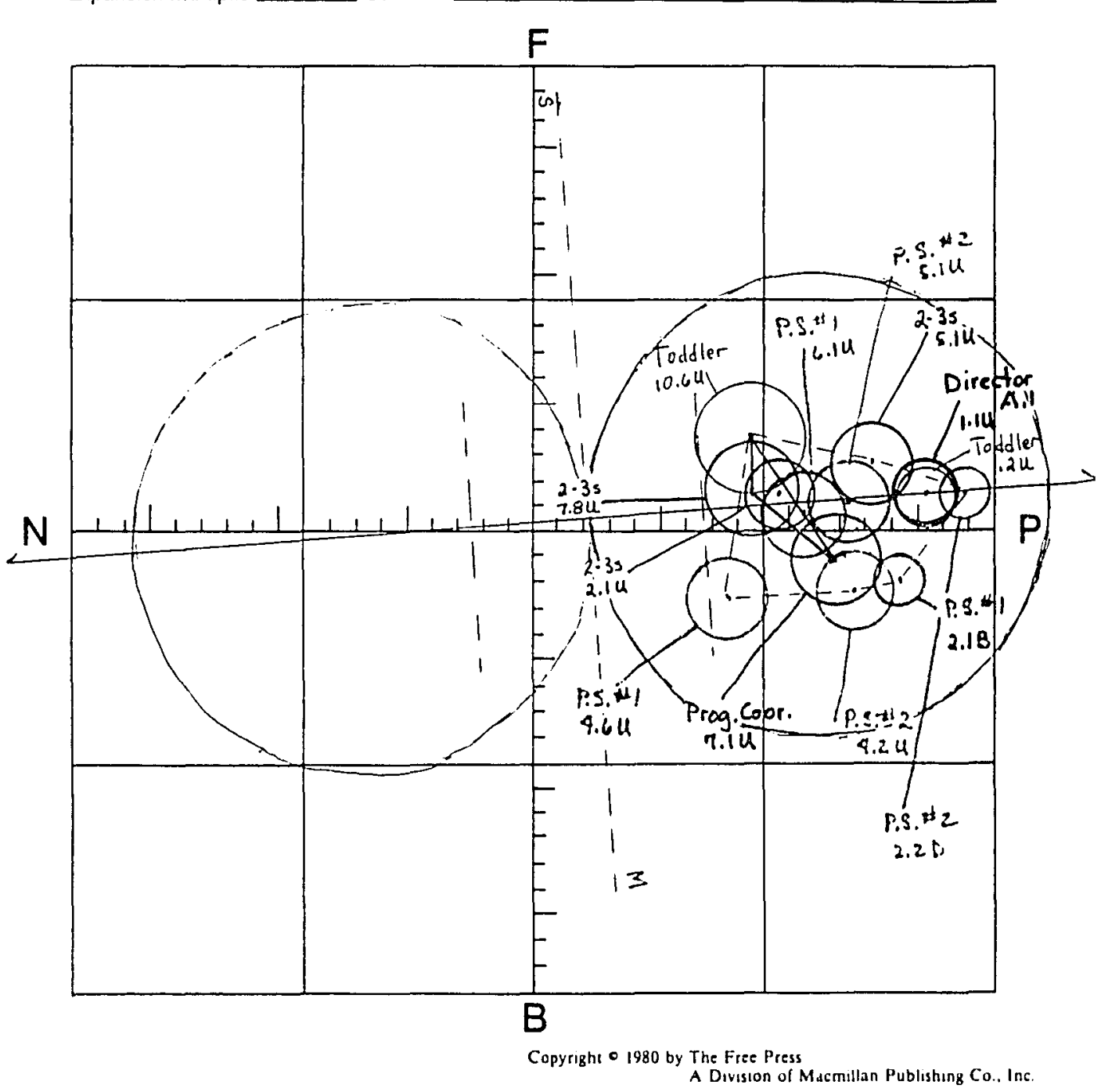


SYMLOG

DIRECTONAL DEFINITIONS

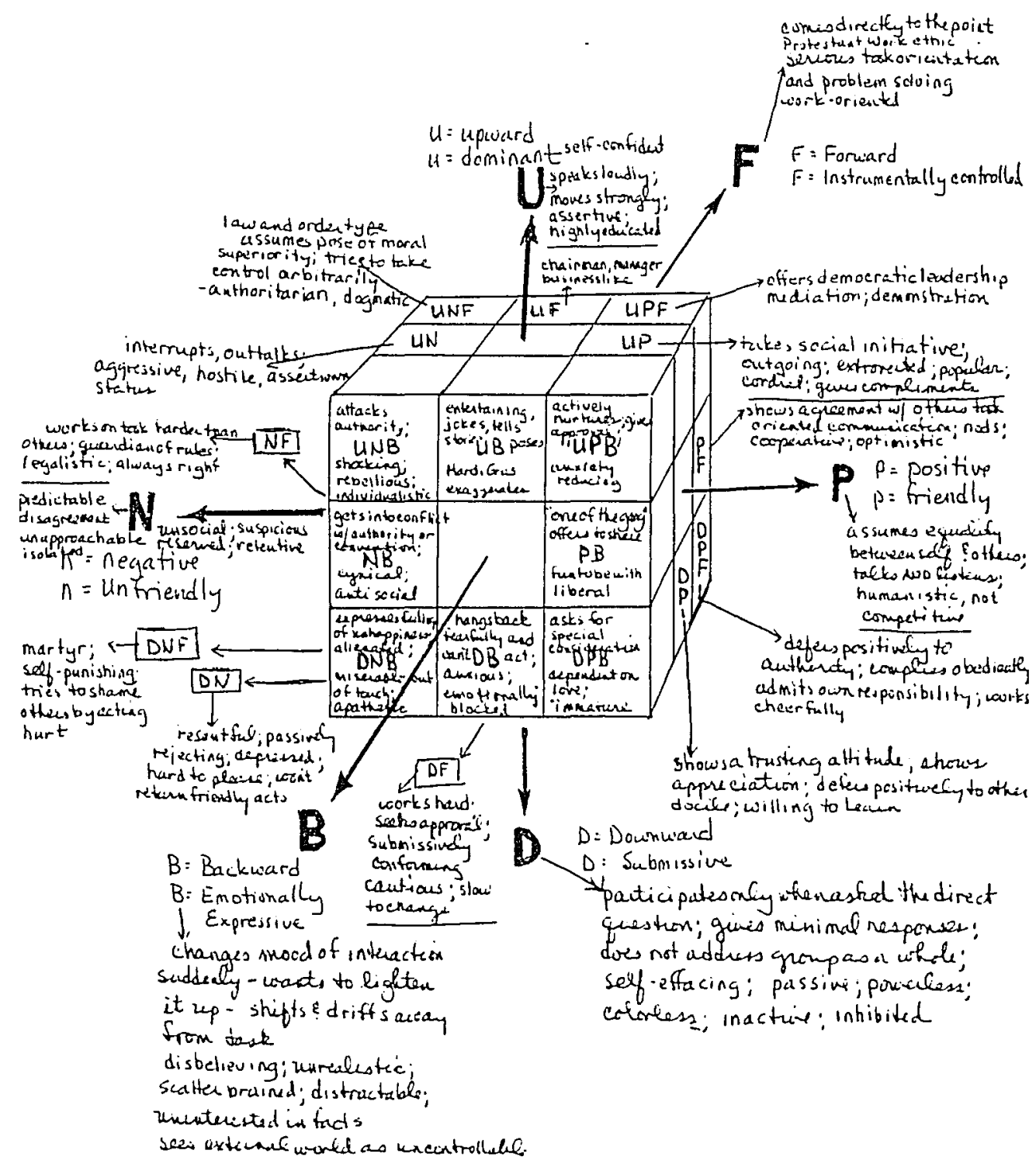


Summary of Director A.1's Leadership Characteristics and Center A.l's Organizational

Climate

Interview

The interview with Director A.1 revealed that she, like the other directors in Centers B.1 and A.2, displayed a female style of leadership. She seems well aware of the indirect and personal approach she takes, as well as her responsive style of leading ("I don't know how time will be spent until it hits me!'). She sees one of her primary responsibilities as being a "support" to the staff and parents. She demonstrated some concern over the leadership style she employs when she described her style as being "relaxed, personal, laissez-faire, humanistic, and permissive to a fault."

Leadership Style Assessment Tool

Director A.1, like all of the others previously cited, was rated by the staff has having a Transactional Style of leadership (mean $=3.75)$. Her second strongest style was that of being People-oriented (mean $=2.5$ ). This style features many of the concepts Director A.1 described in her interview. The People-oriented Style is described as follows:

Achieving harmonious group relation is foremost in this leadership style. Strong emphasis on maintaining comfortable, friendly, and satisfying working conditions. Allows staff to exercise control and be self-directed with minimall intrusion of center-wide policies and procedures (JordeBloom et al.1991, 15)

Director A.l's emphasis on empowering employees to be self-directed shows up in the 
Organizational Climate ratings in the Work Environment Profile.

\section{Work Environment Profile}

Staff at Center A.1 rated seven of the dimensions in Part A, Organizational Climate, as being higher than the norm, Collegiality, Professional Growth, Supervisor Support, Reward System, Decision Making, Physical Setting, and Innovativeness. The dimensions of Decision Making ${ }^{75}$ and Innovativeness were rated significantly higher than the norm (9 and 8.5 respectively); and, these correspond well to Director A.1's second strongest style, People-orientation, which stresses the empowerment of subordinates to be self-directive. In addition, Innovativeness had the narrowest range of all ten dimensions, indicating a high degree of consensus among staff members on this dimension. Decision Making and Supervisor Support also had narrow ranges just slightly wider than that for Innovativeness.

Three dimensions were rated as being just below the norm: Clarity, Goal Consensus, and Task Orientation. The range of Task Orientation was as wide as possible at $10 / 10$ and was the widest range for any measurement in this study. The variation in ranges for Task Orientation, Innovativeness, and Decision Making give an impression of an organizational climate that encourages creativity and minimizes conformity to only necessary areas (licensing issues and developmentally appropriate practices). Visual

\footnotetext{
${ }^{75}$ Galinsky found that job autonomy or the ability to make decisions about one's work was related to less staff turnover $(1989,3)$.
} 
observation of Center A.1 on a walk-through confirms this analysis. The rooms are clearly child-centered with evidence of a value on children's individuality and creativity everywhere, from the decorations on the walls and bulletin boards to choices made in selecting toys, equipment, books and furniture. Values of diversity, inclusion, and antibias were observable in these choices also.

When compared with the above ratings, Part B, the Summary of Workers Values can give direction for areas on which to work (those areas low in Part A and high in Part B). In general, for Center A.1 those dimensions in the Organizational Climate that are rated low are also rated low in terms of Worker Values and visa versa. The dimensions that are rated below the norm in Organizational Climate are Clarity, Goal Consensus, and Task Orientation. All three of these of these, plus Decision Making, were given the lowest ratings in the Summary of Worker Values (3.9 to 4.1). The other six dimensions were rated between 4.3 and 4.5. The two dimensions receiving the highest value ratings (4.5) were Reward System and Innovativeness. Concerning Innovativeness with its narrow range and high value rating, the message is clear: the staff think Innovativeness is important; they have it; and, they want to keep it. The Reward System at Center A.1 is rated as being above the norm (they are State Government workers) and is very important to them. However, when looking at Part D, one sees that the staff feel that in spite of the relatively good Reward System that they have, it only "somewhat resembles the ideal". The salary range at this center is between $\$ 11-23,000$ per year, with the most frequent salary for teaching staff being between $\$ 11-14,000$.

Decision Making is a dimension that the staff feel is a strong component of the 
Organizational Climate, giving it the highest average score. In terms of values, it is among the lower scoring ones, yet in Part F, the staff indicate that they would like a greater degree of influence in decision-making, particularly in the area of Interviewing and Hiring New Staff. Staff also perceive that they have full control over Planning Daily Activities and they want to keep it that way, supporting the importance they place on Innovativeness.

Although Goal Consensus was rated as being just below the norm, the staff demonstrated consensus in Part E where $100 \%$ of the respondents ranked Positive Selfconcept and Self-esteem as the number one Educational Goal and Objective. Finally, the Overall Commitment to the Organization was rated at 8 , more than halfway between Committed and Highly Committed.

\section{SYMLOG Field Diagram}

Director A.1 is, like the other directors in this study, located in the UPF direction, representing a purposeful democratic task leader. The size of her circle represents her degree of $U$, Upward/Dominant direction. Her $U$ rating is low at 1.1 as is her $F$ at slightly over 1 . Her $\mathrm{P}$ rating is very high at $15+$. This configuration fits her relaxed or (self-described) laissez-faire style of leadership very positive, neither very dominant nor submissive, with a mix of task orientation, and emotional expression. The Program Coordinator, when compared to the Director, is more dominant, more emotionally expressive, and not as friendly. The two seem to balance each other's strengths and weaknesses well, making for a strong administrative team. Both administrators are 
located within the cluster and are not on the Perimeter. Members located far from each other and on the Perimeter have the potential to come in conflict with each other.

The group as a whole are all located close to one another in the Reference Circle, indicating a relatively homogeneous, friendly group. Homogeneous, in this sense, refers to values and orientations, not backgrounds or group memberships. The staff at Center A.l are the most diverse by ethnicity, sex, age, and apparent life-style. One member of the P.S. \#1 staff has been located close to the Mediator position and could be seen as a person who could negotiate conflicts within the organization. 


\section{Center B.2: Observation, Interview, and Findings}

The observation of the center and interview with the director (Director B.2) occurred on February 2, 1995.

\section{The Setting}

Center B.2 is located on a community college campus. It provides child care for students and staff at the college as well as for families in the community not affiliated with the college. It is also the laboratory school for the college's Early Childhood Education department. The building is relatively new, and was designed as a child care facility. The program had formerly been located in a student housing project off campus, dating from 1973. There is a well designed outdoor play space that was developed through a grant and was designed to provide children with a meaningful, developmentally appropriate interaction with the outdoor environment. The design was based on the collective memories of many adults (staff, parents, and students) about their most meaningful experiences outside.

Center B.2 is a single story building with lots of windows bringing ample natural light into the four preschool classrooms which house groups of 18 children each ranging in age from $2 \frac{1}{2}$ to 6 years. There are comfortable chairs in the entry way for sitting. On a small table are magazines related to child development and parenting and some photo albums of the children and some of their activities. On the wall are photographs of all the permanent staff. Next to each classroom door is a bulletin board where teachers post 
curriculum materials. Children's art work (individual and group) decorates the walls along with posters of children and adults of diverse ethnicities, ages and abilities. On either side of the front entry way, the director and the administrative assistant have their respective offices, with windows facing the entry for visual observation.

There are 105 different children enrolled in the center, with a total licenced capacity of 80 . The permanent, full-time staff include the director, an administrative assistant, and three teacherș. In addition to one part-time office assistant and 5 part-time teachers, there are around 40 students employed between 1-16 hours per week as teacher assistants. The three full-time teachers have the highest salaries in the study which range between \$23-26,000 plus per year. The state of B enacted comparable worth legislation in the late 1980 s and as a result state child care workers received the largest increases in pay.

Finally, students in early childhood classes do practicum experiences in the classrooms under the supervision of the teachers and the faculty teaching the classes. The center is a non-profit, state supported center that offers full and part-time care from 7:30 a.m. to 5:30 p.m., five days a week, $11 \frac{1}{2}$ months a year. When the college is not in session, there are fewer children, so the four rooms are combined into two or one as the numbers dictate. The center was NAECP accredited at its former site, and is in the process of preparing for re-accreditation.

\section{Interview with Director B,2}

Director B. 2 had been the director of the center for 4 years at the time of the interview. Prior to being appointed director, she had been a parent educator in another 
department at the college. She has an M.A. degree in Early Childhood Administration from a west coast college.

\section{Describe your style of administration:}

Director B.2 described her style as being participatory and group focused. ${ }^{76}$ She sets the framework that allows or sets safe practices; she is the "overseer of safe practices." Teachers have autonomy and voice in the program. ${ }^{77}$ Director B.2 does a lot informally and teachers generate most of the issues that are addressed.

\section{Tell me how decisions are made, regarding:}

Staffing and scheduling. This has "been evolving" according to Director B.2. She and the administrative assistant track "glitches" in the scheduling of staff and work to solve these problem right away. They used to be saved up for addressing at their weekly

\footnotetext{
${ }^{76}$ Belenky et al. (1986) comment that the role of being a "connected" teacher [or leader] "does not entail power over the students [employees]; however it does carry authority, an authority based not on subordination but on cooperation" (227).

Women leaders, according to Helgesen were process oriented and emphasized relationships with people (Helgesen 1990, 29).

77 To be healthy, "the concept that every person has a leadership role and responsibility (the ability and necessity to respond) would be integral to the structure and process of the organization" (Schaef and Fassel 1988, 221).
} 
staff meeting, but not anymore..$^{78}$

Budgeting. Center B.2 currently receives financial support from various departments of the college, in addition to parent tuitions. The program gets a monthly report from the college accounting office and they see their financial status each month. Earlier in her tenure as director, Director B.2 had severe budgetary problems. With a more stable budget now, there is some flexibility in the budget. Teachers write down equipment needs by priority and give it to Director B.2. In staff meetings they collectively decide on a focus and the equipment needed to support it. There is a petty cash fund and teachers can purchase small items that they need for their rooms. In addition, Director B.2 "invests" in individual projects when teachers show initiative. ${ }^{79}$

Children's program. Within the guidelines of Developmentally Appropriate Practices and the Early Childhood Education Code of Ethics, teachers have autonomy in their classrooms. Staff do curriculum planning together through "webbing" when addressing specific program challenges. "Webbing" is a method of brainstorming ideas

\footnotetext{
${ }^{78}$ Gilligan states that "women... are ideally situated to observe the potenitial in human connection both for care and for oppression.... In relationships of temporary inequality, such as parent and child or teacher and student [or employer and employee], power ideally is used to foster the development that removes the initial disparity" $(1982,168)$.

${ }^{79}$ Kanter and Fassel (1977) found that women who were most successful and effective were "interested in empowering subordinates (sharing power with them)" and were the "most collaborative and humane" (302). "They have political connections in the wider system, and they know how to make subordinates feel powerful in their own right" (Kanter and Fassel 1977, 303).
} 
related to a particular conceptual theme. ${ }^{80}$

Physical facility. Issues involving the physical facility are emergent, meaning that any person can observe a concern and bring it up in staff meetings to discuss it as a group and make a decision. The center has good support from the college's custodial and plant services staff. ${ }^{81}$

\section{How do you organize your time and responsibilities? What are your priorities?}

In terms of organization of time and responsibilities, Director B.2 said that they did not "feel very organized." She wants to be "available when the need arises" as much as possible. People dynamics are her first priority, but she manages how much time she spends "listening." She does believe in prevention, as indicated by her saying that "putting out sparks that start fires, saves time." Thus, people problems come first, so they don't

${ }^{80}$ In their discussion of the teacher as a "midwife" to her students, Belenky et al. (1986) describe the teacher as the one "who would help [the students] articulate and expand their latent knowledge" (217).

${ }^{81}$ Women who are successful and effective share power with subordinates. In addition, they "have political connections in the wider system, and they know how to make subordinates feel powerful in their own right" (Kanter and Fassel 1977, 303).

${ }^{82}$ This is the fourth example of an administrator saying that she could or should be more organized or businesslike. In her next statement though, Director B.2 says she wants to be available, or as Helgesen puts it in regard to successful women in leadership, she does "not view unscheduled tasks and encounters as interruptions" (1990, 19). 
build into larger problems, and, "non-people problems get pushed to the back burner."

\section{How do you maintain quality caregiving by the staff?}

Director B.2 does not see herself as maintaining quality, but that the staff do. She supports the staff by meeting their needs. ${ }^{84}$ And this, she feels, leads to quality. She observes and supervises and then relays concerns and observations back to the staff. ${ }^{85}$ She has created an atmosphere wherein staff feel they are "able to question" without getting into trouble or being judged. ${ }^{86}$

5. How do you balance your job here in the child care center and your life outside?

Director B.2 "doesn't always distinguish the difference" between the two but she is getting clearer about what is "work" and what is not work. ${ }^{87}$ She also has had to divide

\footnotetext{
${ }^{83}$ Gilligan (1982) states that "when women construct the adult domain, the world of relationships emerges and becomes the focus of attention and concern, women find order where others saw chaos" (167-9).

${ }^{84}$ Heffron (1989) speaks of the need for a "new set of criteria for measuring treatment of employees" especially in organizations with restricted budgets and expanding needs (342).

85 "A service/information economy does not lend itself to massive bureaucratic organization" (Lenz and Myerhoff 1985, 82). There are but two levels of organization: the administration and the caregiving staff and they relate directly to each other.

${ }^{86}$ A healthy organization welcomes complaints, questioning and constructive criticism (Heffron 1989, 340).

${ }^{87}$ Lenz and Myerhoff (1985) point to "women's deeply rooted need to integrate love and work. The work-home division grates against the feminine sensibility" (81).
} 
off time to prepare for her college teaching during the day (she is a tenured faculty member). On weekends she has designated one day and two nights that are non-work time, as she is past the "survival stage" of her job as director of the center. ${ }^{88}$ The difference between work and non-work get a little indistinct, though, because she and the rest of the staff spend social time together outside of work hours. ${ }^{89}$

6. What about the personal lives of staff members -- what are your expectations for how much of the personal can come into the workplace or into your awareness?

Director B.2 stated that they are a "family support place" for both the parents and the staff. They promote caring and support and are willing to adapt to situations that arise. She tries to achieve a balance, though. If some problem outside of work causes a behavior that becomes a pattern which takes time and energy away from the children and the other staff, then Director B.2 works with the individual and they do some problem solving together. ${ }^{90}$

\footnotetext{
${ }^{88}$ One of the four major themes of successful women was "an insistence upon a balanced life-style" (Lunneborg 1990, xviii).

${ }^{89}$ Gilligan notes that women "define their identity through relationships of intimacy and care..., attachment is supported by an ethic of care" $(1982,169)$.

${ }^{90}$ Lunneborg (1990) found that one of the major theme of successful women in leadership was "a nurturant approach to coworkers" (xviii).

Schaef and Fassel (1988) state that in a healthy organization such as child care, the people who give care but also feel cared for by the organization (219).
} 
7. How do you work with parents? How do you expect staff members to work/interact with parents?

Director B.2 tries to respond to parent needs immediately and respectfully in a manner that is non-judgmental of life styles, situations, or skills. ${ }^{91}$ She reported that the staff are starting to change their philosophy about working with parents toward this approach. Director B.2 feels that parents need to be comfortable at the center as well as the child. She stated that the staff try to respect parent views as being real and valid and to work in an open way with parents to get to know and to build a relationship with them. Director B.2 and the staff will not "turn families out on the street" especially with a challenging child. They will problem solve with parents. ${ }^{92}$ They will not, however, compromise their philosophy, developmentally appropriate practices, or other fundamental principles of child centered early childhood education.

\footnotetext{
${ }^{91}$ Women use an "ethic of responsibility" which "relies on the concept of equity, the recognition of differences in need" (Gilligan 1982, 164).

${ }^{92}$ One of the themes Lunneborg found was that of having a "service orientation to clients" (1990, xviii).
} 


\section{Center B.2 - DiREctor B.2}

\section{SCORING SHEET FOR LEADERSHIP STYLE ASSESSMENT TOOL}

To score part I, tally the responses by noting with a mark each time staff checked a particular response:
1 .
9.
17.
2 .
10.
18.
3 .
11.
19.
4.
12.
20.
5.
13.
21.
6.
14.
22.
7.
15.
23.
8.
16.
24.

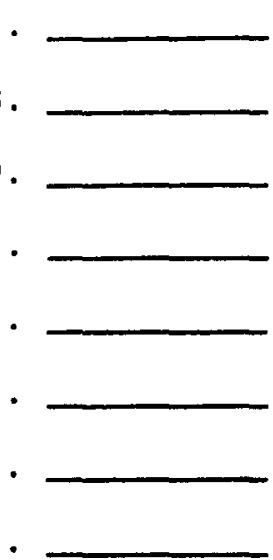

Now total the marks for the following responses:

Task-oriented: $1,6,8,10,14,17,19,22$

Total $=\bar{x}=0.56$

Achieving center goals is most important in this leadership style. Strong concern for high performance and accomplishing tasks. Emphasis is on planning, directing, following procedures, and applying uniform standards and expectations for all. This director may be viewed as too structured, bureaucratic, and inflexible.

People-oriented: $2,4,7,11,15,18,20,24$ Total $=\underline{x}=2.22$

Achieving harmonious group relations is foremost in this leadership style. Strong emphasis on maintaining comfortable, friendly, and satisfying working conditions. Allows staff to exercise control and be self-directed with minimal intrusion of center-wide policies and procedures. Staff working in centers with this style of leadership may complain about the lack of order and coordination.

Transactional: $3,5,9,12,13,16,21,23$

Total $=\bar{x}=5.22$

Achieving both center goals and maintaining high morale is important in this leadership style. This director is flexible and fair, recognizing that different situations may require a different emphasis on center-wide needs or individual needs. 


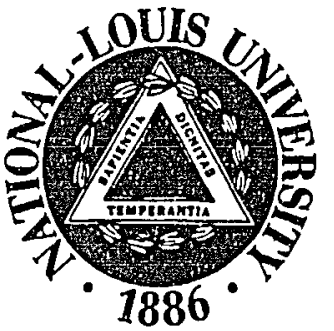

Namo:

CENTER B.R

Total adminlstrativo, toaching, and support staff: 11

Number of staff comploting aurvoy: 9

Employment pattern of respondents:

5 employad full-time (35 hours per weak or more)

0 employed part-time (20-34 hours per weak)

4 employed part-time (10-19 hours per wook)

0 dato not provided by raspondent

PART A. ORGANIZATIONAL CLIMATE IN $=9$ !
Date: August 17, 1995

Code: 399

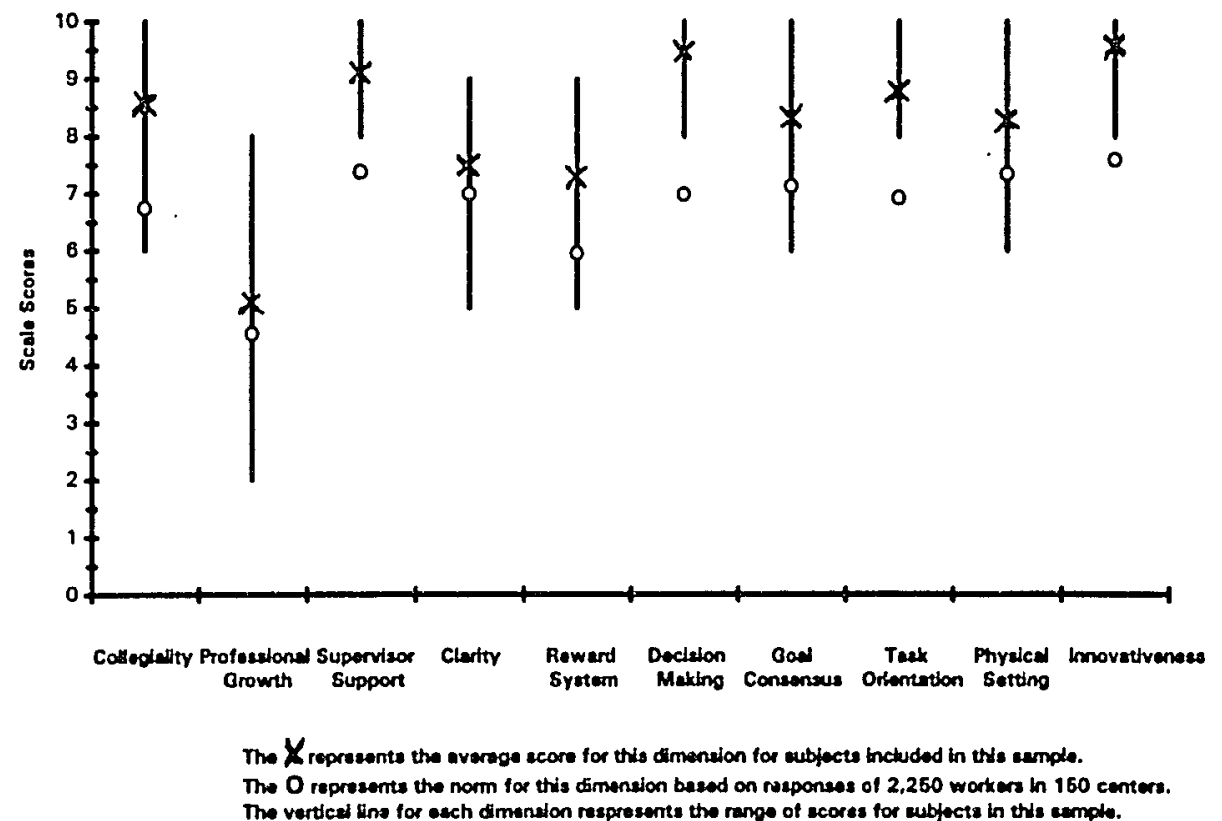




\section{INTERPRETING THE WORK ENVIRONMENT PROFILE}

\section{Part A. Organizational Climate}

This profile provides a summary of the respondents' answers to questions pertaining to the ten dimensions of organizational climate. The vertical axis indicates that the lowest possible score for each dimension is 0 and the highest possible score is 10 . The vertical line for each dimension indicates the range of scores (high and low) for your school. The circle represents the mean score on this dimension for 2,250 early childhood workers who have completed the Work Environment Survey. The $X$ shows the average rating of the respondents from your center with respect to each dimension.

The number of respondents' surveys used for Part A of your Work Environment Profile is indicated by the notation $N=$. If this number differs from the total number of staff who completed surveys, it is because some surveys were incomplete or filled out incorrectly. incomplete surveys were not used in the data analysis.

The following provides a fuller explanation of how to interpret the ratings for each dimension.

Collegiality: This dimension measures the extent to which staff are friendly, supportive, and trust one another. A high score indicates that staff feel free to express their feelings. They believe communication is generally frank and candid. Individuals working at centers with a high rating on the collegiality dimension usually feel that morale is high and that a strong serise of team spirit characterizes their work relationships.

Professional Growth: This category measures the extent to which professional growth opportunities are available for the staff. Centers that score high on this dimension provide regular staff development workshops, encourage staff to share resources with each other, provide released time for teachers to attend conferences and visit other schools, and provide financial support and guidance for professional advancement.

Supervisor Support: The collective perceptions of workers at centers scoring high on this dimension is that the supervision they receive is both supportive and helpful. Individuals who rank supervisor support positively feel that high but reasonable standards are set and that staff are helped to develop their skills. A low rating on this dimension may indicate that the supervisor does not provide enough feedback or that he/she is too critical and hard to please.

Clarity: This dimension refers to the way in which policies, procedures, and responsibilities are defined and carried out. Early childhood workers at centers scoring high on this dimension generally feel that communication is good and that work schedules. job descriptionsi, and rules are clear and well-defined. Low ratings on this dimension indicate that 
people are often confused about policies and procedures and that conflicting demands are often placed on workers.

Roward System: This dimension measures the extent to which individuals in the setting feel that pay and fringe benefits are fair and equitably distributed. Centers scoring high in this category provide good job security for their workers and handle promotions and raises fairly. Workers in these settings feel that their pay is fair compared to what other early childhood centers pay. A low score in this dimension indicates that people feel that some individuals are paid more than they are worth, that raises are based on favoritism, and that people are taken advantage of.

Decision-Making: This dimension refers to the extent to which autonomy is valued and staff are encouraged to make decisions about those things which directly affect them. Centers that score high in this category are those where staff are also encouraged to provide input on schoolwide policies. A low rating on this dimension indicates that the overall perception of workers is that the center values conformity and individuals do not feel free to express their opinions on important issues.

Gos/ Consensus: The dimension of goal consensus refers to the degree to which staff agree on school philosophy, are unified in their approach, and are committed to program goals and objectives. A high score in this area reflects the ability of staff to appreciate differing points of view and to be able to compromise and agree on important programmatic issues.

Task Orientation: This dimension measures the degree lof emphasis placed on good planning, efficiency, and getting the job done. Workers who rate their centers high in this area believe that they work hard but still have time to relax, that program procedures are efficient, and that meetings are productive. Low ratings generally indicate that time is often wasted, things get put off, and people often procrastinate.

Physical Setting: This dimension measures the extent to which staff feel that their work environment is well-arranged, organized, and provides sufficient supplies and equipment for them to do their job. A low score in this category indicates that the center may appear drab or need major repairs, that the temperature may be too hot or too cold, that parking may be inadequate, or that classroom space is cramped and crowded.

Innovativeness: This final dimension measures the extent to which the center encourages staff to be creative and innovative in their work. Individuals rating their setting high in this area believe that they are encouraged to try out new ideas to solve problems and then are supported in implementing needed changes. Programs rating low in this dimension are characterized by a traditional approach that avoids risk and allows many problems to go unsolved. 
PART B. SUMMARY OF WORKER VALUES $(N \neq 8)$

CENTER B.2

How important is...

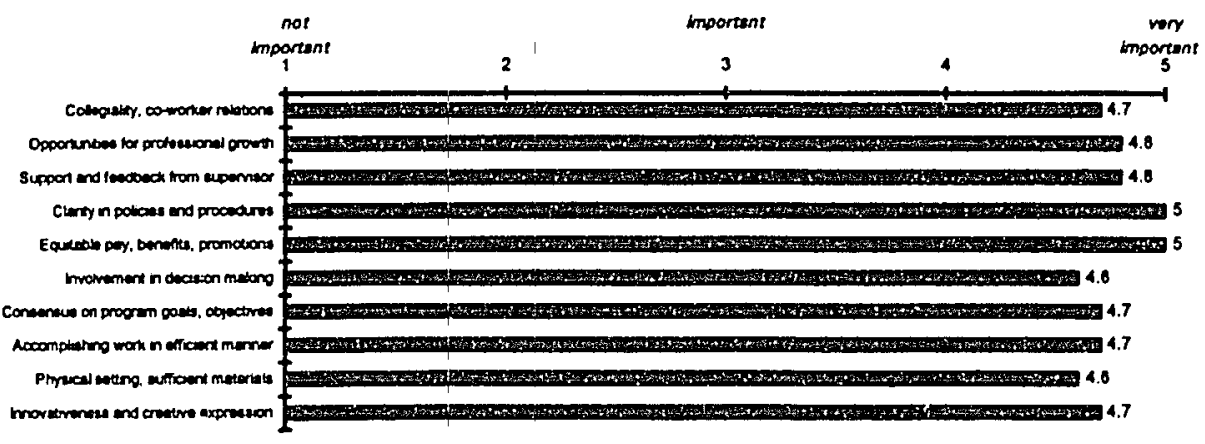

PART C. SUMMARY OF OVERALL COMMITMENT TO THE ORGANIZATION ( 9 )

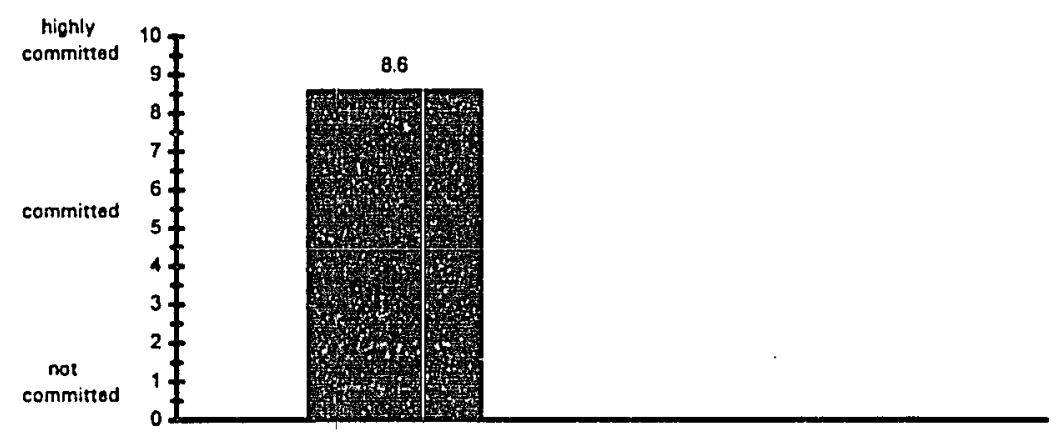

PART D. SUMMARY OF HOW CURRENT WORK ENVIRONMENT RESEMBLES IDEAL $(N=8)$

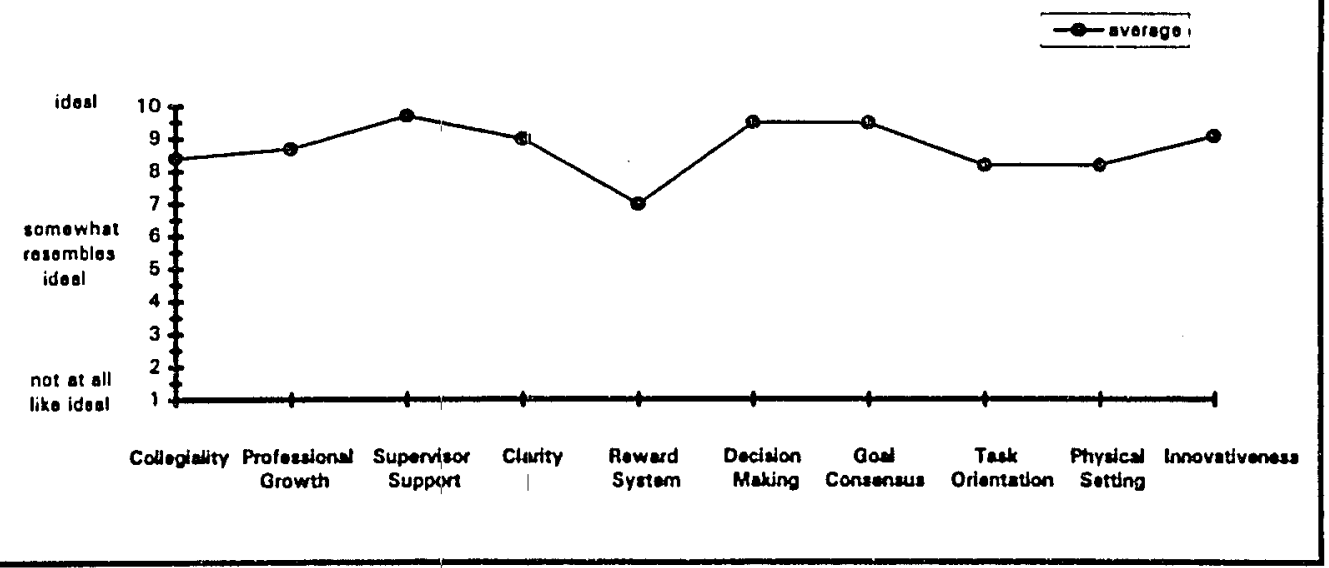


People do not all want or value the same things from their work. For some individuals, a sense of collegiality may be important and essential for job satisfaction. For others who prefer to work alone, the need for affiliation may be less. Likewise, for some people the comfort level of the physical setting and the availability of materials and supplies may be of considerable importance. For others, however, the physical setting may be minimally important.

This profile will help you assess the importance or value that your staff attaches to each of the dimensions of organizational climate. The profile provides a summary of the importance they assign to each dimension. Each score thus represents a composite evaluation of how important that dimension is to them in their work setting.

This profile can guide you in knowing which dimensions should be given high priority. In other words, you will probably achieve more lasting results in your school improvement efforts if you focus on those areas that the staff rated as low in Part $A$ and valued as high in Part $B$. Looking at Part $A$ and $B$ together will help you and your staff appreciate the uniqueness of your setting. Each center must develop its own formula for achieving a healthy organizational climate. There is no one prescription that applies equally to all settings.

\section{Part C. Summary of Qverall Commitment to the Organization}

This scale provides a summary of the staff's overall commitment to the center. Individuals who feel deeply committed to their jobs tend to put extra effort into their work and take pride in their center. It is not surprising that commitment is strongly correlated with staff turnover.

\section{Part D. Summary of How Current Work Environment Resembles Ideal}

One additional way to understand how workers perceive their present work conditions is to measure their perceptions of how closely their current work situation resembles their ideal work environment. This section surnmarizes the descrepancy between real and ideal conditions along the ten dimensions of organizational climate. 
CENTE B.2

PART E. RANKING OF VARIOUS EDUCATIONAL GOALS AND OBJECTIVES (N $=9$ )

\begin{tabular}{|l|c|c|c|c|c|c|}
\hline & \multicolumn{7}{|c|}{ Numbor of aubjects who rankod ltom as } \\
\hline To halp childran dovelop... & $\mathbf{1}$ & $\mathbf{2}$ & $\mathbf{3}$ & $\mathbf{4}$ & $\mathbf{6}$ & $\mathbf{6}$ \\
\hline language ond problem solving skills & 0 & 4 & 2 & 2 & 1 & 0 \\
\hline strong friendships, skills in sharing & 0 & 2 & 4 & 1 & 1 & 1 \\
\hline concepts needed for reading and miath & 0 & 0 & 0 & 0 & 3 & 6 \\
\hline independence in caring for themseives & 1 & 2 & 3 & 3 & 0 & 0 \\
\hline physical skill and coordination & 0 & 0 & 0 & 3 & 4 & 2 \\
\hline positive self-concepts and self-estgem & 8 & 1 & 0 & 0 & 0 & 0 \\
\hline
\end{tabular}

PART F. DEGREE OF INFLUENCE OF THE TEACHING STAFF REGARDING VARIOUS ORGANIZATIONAL DECISIONS I $N=9$ )।

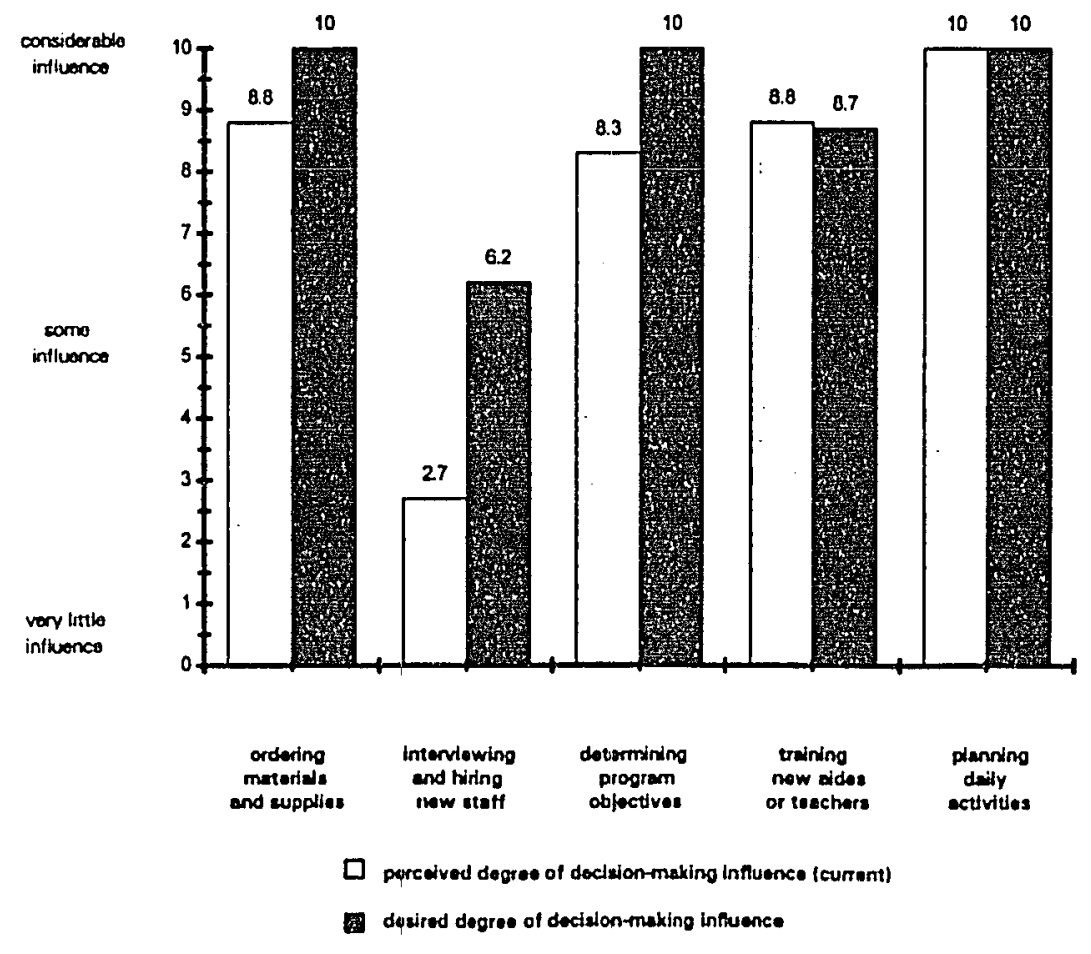


Part E. Ranking of Various Educational Goals and Objectives

There are many educational goals and objectives that guide curricular policies and procedures in our early childhood programs. But the priority that individual staff assign to different goals may vary. This section of the Work Environment Profile details the rankings that respondents assigned to six different early childhood educational objectives. If goal consensus is high at your center, the rankings for each objective should cluster. If staff have strong differences in the importance of different objectives, however, you will notice that the rankings will be widely dispersed.

\section{Part F. Degree of Influence of the Teaching Staff Regarding Various Organizational Decisions}

This section of the Work Environment Profile describes the perceptions of workers regarding the degree of influence of the teaching staff with respect to various organizational decisions. It includes both workers' perceptions of teachers' degree of current decision-making influence as well as their desired degree of influence.

This section of the profile provides a fuller explanation of the decision making dimension of organizational climate as reflected in Part A. It may prove useful in understanding some of the different decisions that are typically made in early childhood programs - both those where centralized decision making may be preferred and those where shared decision making may be possible. The appropriate amount of decision-making influence by the teaching staff will depend on your unique set of circumstances and will be different from other programs. 


\section{SYMLOC}

Field Diagram

Your Name Average of All Ralers

Diagram of what Group: _ C C ENTER B.L Present Date_Fall 95

Group met from what date to what date Page_ 1 of 1

Diagram based on whose perceptions Playing whose role

Rating or Scoring Rating If Rating, scale $(0,1,2)$ or $(0,1,2,3,4 / 2)$

Expansion Multiplier 1.182 Comment

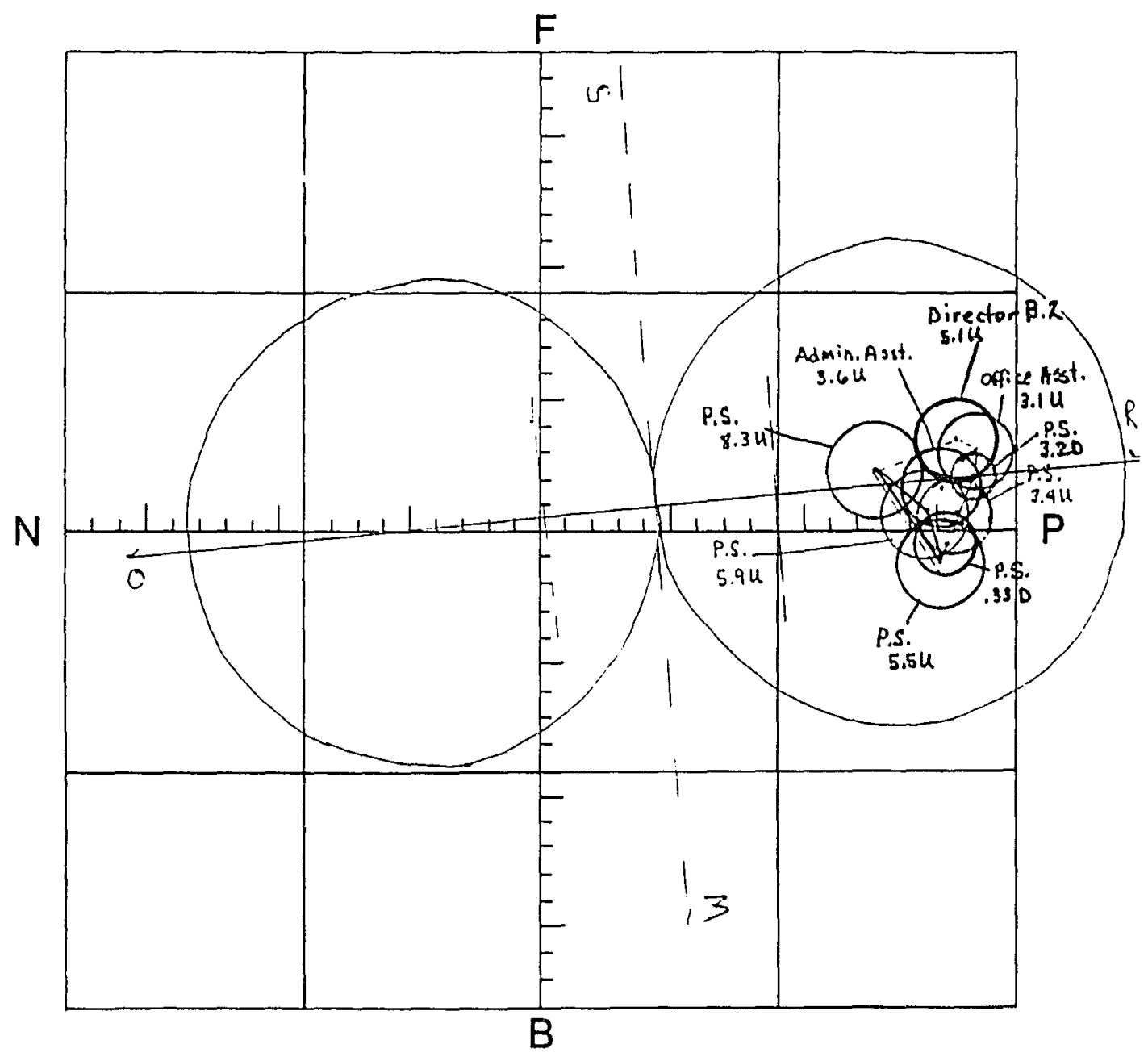

Copyright $\odot 1980$ by The Free Press

A Division of Macmillan Publishing Co.. Inc. 


\section{SYMLOG}

DIRECTONIAL DEFINITIONS

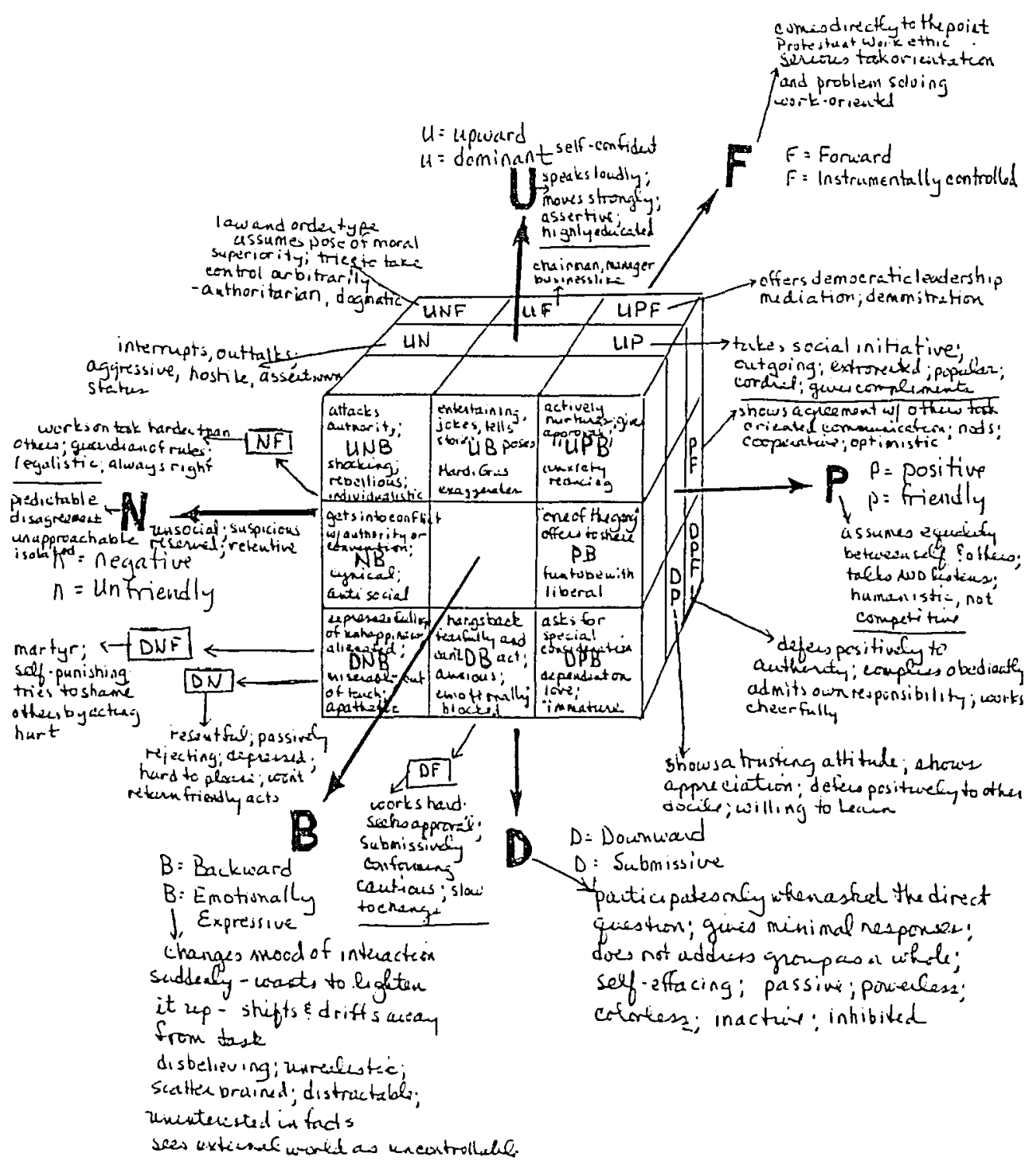


Summary of Director B.2's Leadership Characteristics and Center B.2's Organizational

Climate

Interview

Director B.2 clearly describes her leadership style using female style descriptors. The interview indicates that she values process and puts a lot of energy into decision making and problem solving. Non-linear processes are employed, such as brainstorming or what she calls "webbing" for program challenges. She addresses problems as they arise so as to prevent them from becoming larger issues.

Like many of the other Directors, Director B.2 stated that she did not "feel very organized". She also stated that she wants to be available to people "when the need arises" indicating that she is most comfortable being flexible and spontaneous, but also feels a need to be more organized, or in control. Like Director A.1, she sees herself as being a support person to the staff and parents.

Leadership Style Assessment Tool

Staff rated Director B.2 as having a strong Transactional Style (mean $=5.22$ out of a possible 8) indicating a well balanced approach to leadership. Her rating on the Task Oriented Style is very low, with a mean of 0.56 . Her evaluation that she needs to get more organized is reflected in this low score and may thus be a reflection of reality in this case rather than a reflection of a feeling of discomfort with using a predominantly "female" style. The second strongest area for Director B.2 was the People-oriented style (mean $=$ 
2.22), similar to Director A.1. Interestingly, these two directors with somewhat similar philosophical approaches are both directing campus child care centers.

\section{Work Environment Profile}

When examining the Organizational Climate section of this Profile, one is at first struck by the fact that the ranges for four of the dimensions begin and end above the norm for that dimension. Each of these dimensions (Supervisor Support, Decision Making, Task Orientation, and Innovativeness) has a very short range of 2 points, which turn out to be the 4 narrowest ranges of the whole study.

All ten of the dimensions were rated above the norms. Only two of the dimensions were less than 1 point above the norm. Professional Growth had the lowest overall rating at 5.0 and the widest range. It was a clear outlier, with 7.3 being the next lowest score. On three dimensions, the center average scores were between 9 and 10: Supervisor Support, Decision Making; and Innovativeness. This center displays a value for creativity by allowing people to come up with their own ideas to try out or experiment with, and the supervisor actively supports this.

In Part B, Summary of Worker Values, Professional Growth, which was rated lowest, was valued highly, though not as the highest. The two areas most highly valued (both at 5.0) were Clarity in Policies and Procedures and Equitable Pay, Benefits, and Promotions. These were among the 3 lowest ratings on Part A, so these could be looked at as areas for further development. In the area of pay, however, this center was clearly the highest in the study. 
Overall Commitment was rated at 8.6, well above halfway between Committed and Highly Committed. Similar to Center A.1, all but Reward System were rated as being between Somewhat Resembles Ideal and Ideal. For Center B.2, all but Reward System were between 8 and 10 on How Current Work Environment Resembles the Ideal.

The staff were mostly in agreement (8/9) on the Education Goals and Objectives that they ranked as number one, Positive Self-concepts and Self-Esteem. In terms of Degree of Influence of the Teaching Staff Regarding Various Organizational Decisions, the area of greatest disparity between perceived degree of influence and desired degree of influence was in the area of Interviewing and Hiring New Staff. Staff in three of the four centers wanted more influence in this area. In two areas, Training New Aides or Teachers and Planning Daily Activities, the staff had the degree of influence that they wanted.

\section{SYMLOG Field Diagram}

The Group Average Field Diagram of Center B.2 shows a tight cluster of circles far in the Positive/Friendly direction. Clusters can form in groups for "when individuals work together in an alliance they may develop more mutuality of perception, and they may come to perceive greater similarity among the individuals in a given cluster," and "may experience reward in working together" (Bales and Cohen 1979, 45). It should be noted that when makling a Group Average Diagram, there is a tendency for extreme scores to cancel each other out and for there to be a tendency for the ratings to "regress toward the zero point of the diagram" (Bales and Cohen 1979, 25). To compensate for this tendency, the authors have devised a formula for expanding the diagram so all diagrams can be 
comparable. This is called the Expansion Multiplier, which was 1.182 for Center B.2. All average ratings are multiplied by the Expansion Multiplier in order to make the circle of the most Positive image touch the edge of the Field Diagram (Bales and Cohen 1979, 434). Thus, by using this techrique, one can be relatively assured that the Group Average Diagrams reflect the ratings of the group in a way that allows comparison from group to group.

Director B. 2 is in the UPF position, with a strong Positive/Friendly direction. She is moderately Dominant (U) and even less Forward (F) or Instrumentally Controlled. This placement corresponds well with her low Task-oriented Style score and her high rating on Supervisor Support. She is a friendly, sensitive, and strong leader. In relation to the other people in the Diagram, Director B.2 is on the Perimeter and the Administrative Assistant is in the middle of the cluster. Director B.2 has a half-time appointment as Coordinator of the child care center and is half-time teaching as a Tenured Faculty member. The Administrative Assistant is full time and on-site all day. She frequently helps in the classrooms and works a lot with the staff and family scheduling. Her office is the "hub" of the center as it serves as the center office and the staff lounge for breaks. It is a very small office but is clearly at the heart of the organization.

This program has a lot of staff members who are Dominant/Upward which works well with a leadership style of support and empowerment. Center B.2 is staffed by a very friendly, homogeneous group that work cooperatively as well as independently. 


\section{Analysis of the Findings}

\section{Interviews}

All of the administrators in this study employed a leadership style that can be characterized as female as indicated by their self-descriptions in the interview questions. Some of the directors indicated a level of discomfort at using this female style at what they perceive to be the expense of a more task-oriented male approach. In reality they all employed balanced styles that contained elements of both "so called" female and male styles.

\section{Leadership Style Assessment Tool}

The Directors of the four high quality child care centers included in this study displayed some clear characteristics in common in terms of their styles of leadership. All four Directors and the two Program Coordinators were rated by staff as employing a Transactional Style as determined by the Leadership Style Assessment Tool. This is a balanced style that stresses both achieving center goals and maintaining a high level of morale. The directors were all oriented to applying different approaches as the situations require, either a center-wide point of view or attention to individual needs.

The administrators split evenly on their second strongest area, with three scoring highest on a People-oriented Style and three highest on a Task-oriented Style. Of those who favored a Task-oriented Style as their second highest, one was the Director of the center that is a part of a larger corporation and is organized as a for-profit corporation. 
This organizational factor might directly and indirectly place more emphasis on uniformity and standardization than might be expected to be found in an independent center. The Executive Director of the very large child care center was another who received her second highest rating on Task-orientation. She does not directly supervise the teaching staff, but is in charge of keeping the facility licensed, managing it as a business, negotiating a contract with the staff, and participating in major fundraising every year. Her job duties demand an attention to achieving goals and maintaining standards. The third person whose second highest rating was Task-orientation was the Preschool Coordinator for the large child care center. In comparison with working with infants and toddlers, staff working with preschool aged children find that at this developmental level curriculum planning (for example, more organized time schedules and goal directed activities, like field trips) becomes possible and developmentally appropriate. Parents of children at this age are beginning to be concerned now with what their child is "learning" and thus are more interested in the curricular program and philosophy of the child care center. This characteristic of the children's developmental level may influence the Preschool Coordinator to emphasize a Task Oriented Style.

The three administrators whose second highest score on the Leadership Style Assessment Tool was People-orientation included the two directors of campus child care centers and the Infant-Toddler Coordinator of the large child care center. In terms of infant-toddler care, anecdotal evidence suggests that both staff and parents need a lot of social, emotional, and physical support. Infant-toddler care is emotionally and physically exhausting on many days. The children must all be approached as individuals most of the 
time, removing most all possibilities of group activities and economies of scale. Parents whose infants and toddlers are in child care have strong emotions concerning this arrangement due to the highly dependent status of the child at this developmental level. Parents often feel guilty about leaving the child. They can become hypercritical of the care the child is receiving. Teacher-caregivers become a part of their family as they are extensively involved in the raising of the children. This creates new social relationships that involve establishing high degrees of trust and strong communication skills. Thus, it is not surprising that the Infant-Toddler Coordinator of an excellent child care center would have a tendency to be somewhat People-oriented in her more balanced, Transactional Style.

The two campus child care center directors were rated as having a stronger orientation toward people in their Transactional Style. One unique characteristic of campus child care centers is that they depend on students for a great deal of their part-time and casual help. Because Federal Financial Aid limits the number of hours students can be employed on the Work-Study program and State rules limit the number of hours part-time employees may work before becoming eligible for benefits, campus child care centers employ a lot of different people per total licensed capacity compared to centers that are not affiliated with a college or university. In addition to the sheer numbers employed at any given time, those who are students are necessarily employed for a limited period of time (they eventually graduate or leave school), and their available hours for work change each term as their class schedules change. Staff scheduling in campus child care is a major task, requiring a lot of accommodating to individual people's needs. Similar scheduling 
problems arise in campus child care around the scheduling of children's times each term which change with their student parent's schedules. Both of these situations necessitate a high degree of interpersonal interaction, tolerance for change, and periods of "chaos". Maybe a highly task oriented person would not be attracted to work in campus child care!

\section{Work Environment Profile}

All centers were rated by staff as having organizational climates that were higher than the norm on three dimensions, Supervisor Support, Professional Growth, and Physical Setting. All three of these dimensions are directly accessible to influence by the director or coordinator. Supervisor Support is given by the supervisor directly to the staff member, either in face to face contact or in supplies and services. Professional Growth can be achieved in many ways, trainings, resource materials, time to plan and meet, etc. Administrators can directly supply these or can arrange for them to be supplied by someone else, as she or hel controls how the financial resources of the center are utilized. Physical Setting is amenable to manipulation for relatively little actual cost if staff members are given the time and freedom to develop their environments and change them periodically. As child care is a labor-intensive industry, the majority of child care center monetary resources are invested in staff costs (anywhere from $60-85 \%$ has been reported). Supplies and materials can be purchased, made, or gathered from discarded or recycled materials. Young children do not require (nor do they necessarily prefer) new, commercially produced materials and supplies. Safety concerns dictate the investment of substantial monetary resources in some equipment, but considerable savings can be 
achieved in areas without these requirements. Thus the three dimensions that all leaders in this study had in common are ones that can be manipulated if the administrator chooses to do so.

The centers varied from being near (but just below) to very much higher than the norm on all seven of the other dimensions of Organizational Climate. No ratings were significantly below the norms. Staff described their centers as being strong in areas that they also value very highly, including Reward System which has industry wide constraints.

Overall commitment to the organizations, as measured on a scale from 0 to 10 , ranged between 7.1 and 8.6. A score of 5.5 was equated with being Committed to the organization; whereas, a score of 10 was equated with being Highly Committed and a score of 0 was equated with being Not Committed.

In terms of Educational Goals and Objectives for the children, $94 \%$ of the respondents chose Positive Self-concept and Self-esteem. Staff in these high quality centers have a strong level of agreement on their primary goal for children in their care.

All staff want more influence in decision-making than they perceive that they have currently. This is especially true in the areas of Hiring New Staff and Determining Program Objectives. These two areas (staff and program philosophy) are known to be strong indicators of quality in early childhood education. Staff training in Early Childhood Education is correlated strongly with the use of Developmentally Appropriate Practices. Program objectives and philosophy have been correlated with long-term outcomes for the children. Staff in these high quality centers seem to be aware of what factors are most significant and they want involvement in these. 
Three of the four centers were rated by staff as being farthest from the ideal in the dimension Reward System. The one center that did not was the large center that has its own contract for the non-administrative staff which is negotiated locally through collective bargaining by their union. The for-profit center has the lowest wages of all the centers, with their highest teacher salary being in the range of the lowest salaries for two centers and almost $\$ 10,000$ below the range for the third. The staff at the two campus centers also have a union representation available through the State's classified employees unions, but they do not actually negotiate a local contract with the college or university. They are governed and protected by State rules, but have no direct control or influence, for example on their rates of pay or benefits. These are all determined at the state level and apply to all classified employees. Thus the state employees unions are not able to "finetune" the child care working conditions separate from other classified employees in the state. At the large center that is not State affiliated, the contract bargained is for their center only.

When comparing actual rates of pay at the different centers, one campus center had the highest rate of pay, the other campus center and the large not-for-profit were next, and the corporate affiliated center was lowest. However, those who have more control over their wages, benefits, and working conditions seem more satisfied with their center's Reward System.

\section{SYMLQG Field Diagram}

The Field Diagrams of the four centers were strikingly similar, with all members 
clustered close together in the Reference Circle and tending toward a Positive direction. The images were well balanced along the line between the dimensions of Forward/Instrumentally Controlled and Backward/Emotionally Expressive, with no members being located far out in either direction. Members varied in terms of levels of Dominance/Submission. Directors were not uniformly the most Dominant member of the group. These findings characterize the centers as being extremely friendly places with staff who have similar values and goals. All the Directors were characterized as purposeful, democratic leaders. Literature on leadership had indicated that this style is most effective in the majority of group situations.

\section{Summary}

From this study, the leadership characteristics that the administrators of high quality child care centers shared in common were that they employed a balanced leadership style that utilized different approaches depending on the situation. The administrators in this study chose a mostly female approach to their job which seemed to create very healthy, responsive, and supportive work environments for the teachercaregivers. The work environments that these leaders have created tend to unify the staff members who work there in a positive direction. These high quality child care centers are, in one word, friendly. The leaders of these centers provide their staff with strong supervisor support, opportunities for professional growth, and an appropriate physical setting in which to do their work. These factors are strongly related to high quality early childhood education in the research, and this study has provided additional support for 
these findings. 


\section{CHAPTER VI}

\section{IMPORTANCE OF THIS STUDY}

Child care as a service industry is in its infancy, Efforts to establish and maintain quality caregiving may fail if the focus is on only one or two of the specific quality issues, such as staff compensation, fringe benefits, training requirements, or the physical environment. The likelihood of the whole child care industry being fully supported and adequately funded by either parent fees or government/business subsidies in the near future is very slim, given other national economic priorities, such as universal or national health care. Even if significant dollars began to flow into child care, quality of care would not be assured. In an article on "burnout," Townley et al. state that it "hits hardest those professions which involve a great deal of contact with people" $(1986,31)$ and in child care, the teacher-caregiver's work is by its very nature intense contact with people, mostly young children. The factors that contribute to burnout in child care are ones that are in the hands of the administrator to find ways to change, including high staff-child ratio, long working hours, little vacation time, few breaks, lack of space, and little input in designing policies and structure of the program, as well as, low staff pay and few or insufficient benefits. This research is attempting to find out what administrators do to create a work environment that fosters quality caregiving. 


\section{Context for this Research}

As the investigator, I came to this topic as an experienced observer of early childhood programs. My work in the field began with my first teaching position in child care in 1967. Through the years I have been a teacher-caregiver for children aged birth through six years in a variety of settings including: full and half-day programs; programs located in small towns, rural areas, and urban centers; and, both full and half-day programs that were parent cooperatives. I, myself, have been an administrator twice, in a college laboratory preschool and in a parent cooperative preschool, and a parent educator in a federally funded program targeting children aged birth to three. In addition, I worked as a federal child care center field specialist who validated state licensing requirements and enforced the Federal Interagency Day Care Requirements in centers receiving federal funding for low income families. Currently, I am an instructor of early childhood education and psychology, and I coordinate the Early Childhood Education department at a community college.

Having these multiple perspectives of early childhood programs has given me first hand knowledge of the unique stressors involved in work with each age group under six years and the impact of both the physical and social-psychological environments on the quality of teacher-caregiving. This heightened my ability to formulate the question and the approach to answering it, as well as my ability to do an analysis of the findings. 


\section{Reflections on the Findings in Context}

Child care, like other direct service organizations, is a complex and dynamic organization. This study looked at leadership style and the consequent work environment for insight into what makes child care high quality, but leadership style and work environment alone are not enough. Research in the field of early childhood education has uncovered multiple factors and characteristics that are correlated with high quality child care. It is my contention that leadership style is the "glue" that brings the other quality indicators together.

In looking at the four centers, the one that received ratings indicating the highest quality in terms of leadership style, group interaction, and work environment was Center B.2. It is significant to note that Director B.2 recently completed a Masters Degree program in early childhood administration. She has consciously and consistently applied the processes that she learned and developed in this program and in a subsequent class that she taught on the topic of leadership for the same college. She articulated her approach well in the interview. Thus, leadership style is something she purposefully applies. In addition to Director B.2's leadership style, though, Center B.2 is very strong in two other significant quality indicators, staff training in early childhood education and staff wages. Specific training in early childhood education has been correlated with quality of caregiving. All permanent staff members at Center B.2 have at least an Associate degree in Early Childhood Education. Appropriate practices in teaching are constantly on the minds of teaching staff as they are involved in teacher training and Center B.2 is the laboratory 
school for the Early Childhood Education department. When solving problems, Director B.2 first guides the staff in analyzing the problem in terms of Developmentally Appropriate Practices and the Early Childhood Education Code of Ethics thus reinforcing the concepts central to the field. Finally, staff wages and benefits have been correlated with quality of caregiving. The staff at Center B.2 receive the highest wages, on average, of the four centers, and being state workers they receive relatively comprehensive benefits.

The lesson learned from this research is that the highest quality child care is an outcome of the interaction of all the quality indicators within an appropriate and supportive work environment, under the guidance of an administrator who utilizes a style of leadership appropriate for each situation encountered. As each of these elements is strengthened and developed, quality of care increases. Weak elements detract from quality.

\section{Implications of Quality Child Care on Worker Productivity}

The issue of U.S. competitiveness in the global economic market is a cause of great concern to many people. One specific target of this concern, the productivity of the American worker, has become a topic that has heightened tensions in union-management relations and international trade as well. The American work force is becoming increasingly gender balanced, and more and more families are characterized by dual wage earners. Due to these developments, the provision of quality child care for the children of working parents is emerging as a key factor in worker productivity, akin to the provision 
of health benefits, (i.e. healthy workers are more productive workers).

\section{Child Care, Stress, and Worker Productivity}

Child care is an example of the ever-expanding U.S. service industry. This implies, then, that it provides a service to people, in other words, it helps them. Child care arrangements, however, can equally be a source of stress for working parents, particularly for women who become caught in what Kelly and Voydanoff (1985) describe as work/family role strain. Their review of the research in this area indicates that of all groups, work/family role strain is most prevalent among adults who have children at home. Role strain is characterized by "cumulative demands of multiple roles" which can result in either overload (more than one can handle) or interference (when roles are in conflict and demand that two things be done at the same time) (Kelly and Voydanoff 1985,368 ). Time shortage as one type of work/family role strain appears to be related to the following variables:

being a female working parent, the presence of preschool and school age children, experiencing at least three significant family changes, a wife with higher occupational status than her husband, and work hours and scheduling (Kelly and Voydanoff 1985, 369).

Specifically, Kelly and Voydanoff found that preschool-aged children (approximately 2-5 years) placed the heaviest time and energy demands on employed parents; and their presence is one of the strongest predictors of work/family role strain in the authors' model. Another very strong predictor of role strain is that of being a single parent with sole responsibility for financially supporting and caring for children. This multiple role 
situation is characterized by both time shortage and job tension. Kelly and Voydanoff make a strong case that "work/family role strain may be viewed as a type of stress" and that it is, therefore, likely to result in some of the following, "increased health risks for employed parents, poorer performance of the parenting role, decreased productivity at work and reduced individual life satisfaction (Kelly and Voydanoff 1985, 369).

The Bureau of Labor Statistics has reported recently that women with children miss the greatest number of work days due to illness; and, significantly, when considering men (who typically take fewer sick days than the national average), those who are single fathers take one-and-a-half as many sick days as the national average (Garreau 1993). In a study of the daily schedules of dual career couples, Nock and Kinston (1984) report that work and family lives are not easily balanced, and the scheduling of time becomes even more complex when there are children in the household, especially preschoolers. In an examination of the "spillover" effect from family to work, Crouter (1984) notes in her discussion that as long as society sees women's gender role as including primary responsibility for the care of dependent family members (children, elderly, disabled, etc.), many women with children, in particular, are likely to experience "spillover from family to work in the form of absenteeism, tardiness, energy deficit, preoccupation with familyrelated matters, and reluctance to accept work-related responsibilities that conflict with family time and activities" (437)

When parents, typically mothers, are employed outside of the home, they must struggle with how they will care for their children while they are at work. The form of the child care arrangement depends on a number of factors, of which cost and convenience are 
only two (Lein 1979, 14). In fact, according to Lein, studies that focus on cost and convenience issues "tend to oversimplify the complex decision-making strategy that many parents enter into and the important role of parental philosophy about early childhood" (12). Parents are trying to find an equivalent substitute for the love, attachment, and care they would give their children if they were at home. As the children grow older, parents begin to want more than they could give their children at home, such as peer group and educational experiences. In a study on the supply and demand of child care in the U.S., Hofferth (1989) found that for parents who are choosing child care, "all the top issues (except care for a sick child) can be considered quality and quality-of-life related" (32). For the parents in Lein's study, the following criteria were important in how they evaluated care: reliability of the caregiver(s), continuity of caregivers, cognitive development of the child, protection of the child in terms of physical care, protection of the child from alien values, provision of warmth and love, and shared concepts of discipline and control (1989, 12-15).

The vast majority of infants, (birth to twenty-four months) are cared for by relatives, with alternatives of babysitters or family day care homes being preferred over centers by most parents (Floge 1985; Neugebauer 1992). As children become preschoolers (two to five years), parents begin to want more than a warm and loving caregiver. It is at this point that parents begin to add some kind of group care to their child care puzzle, which is typically one of multiple caregivers. Parents also tend to change their child care arrangements rather frequently during the child's preschool years (Floge 1985, 151), usually by replacing some of the care given by relatives with more 
social or educational group care. Parents, however, also change care arrangements due to dissatisfaction. Endsley and Bradbard (1987) report that in their study of parental dissatisfaction with child care, $80 \%$ of it could be grouped into five categories: "lack of" educational stimulation, caregiver undependability, lack of peer stimulation, caregiver neglect, and discrepant caregiver-parent values" (249).

Lein concludes that when parents make child care arrangements, the "choices among alternatives are the result of a complicated decision-making process, representing compromise among a number of factors" $(1979,15)$. The act of choosing child care arrangements is likely to be stressful due to conflicting priorities and reality factors. Emlen (1971) supports this in the following statement:

Perhaps the most persistently articulated problem in family day care is what the working mother refers to as "finding a new babysitter." Having to make a decision about whether or not to go to work or to continue working, having to decide what kind of child care arrangements to make, having to find a new caregiver and to work out understandings with her are hardly easy tasks at best, and they may come at a time of stressful changes in family life, such as separation or divorce, illness or unemployment, first entry into the labor market or a new job situation (13).

If a successful compromise in arrangements can be achieved, then child care becomes supportive because most of the needs of both parent and child have been met. As Atkinson (1987) states:

Child care, provided by caregivers with expectations for programs that are similar to parents, should mean that children will have fewer adjustments to make between care in the home and care in the center. It may also mean that parents and providers will be more likely to have a positive and supportive relationship (45).

If a poor fit is made when child care is arranged and parents are dissatisfied enough 
to make new arrangements, parents tend to subsequently choose care that is aboveaverage in quality (Endsley and Bradbard 1987, 261). Moving to better quality care (which should reduce changing again) is a fortunate trend, because frequent changes in child care arrangements are among the contributing factors to later insecurity in children (Bronfenbrenner, xv). Thus, state Endsley and Bradbard,

Whether or not a parent is aware of the impact of undependable caregivers on their children, they will be mobilized to secure more dependable arrangements which, fortunately for the children, turn out to be higher quality programs as well $(1987,261)$.

Higher quality child care can have a long term benefit on children's development, socially and intellectually (Cotton and Conklin 1989); and the delivery of higher quality care has been correlated with better working conditions, including pay, for the child care staff (Feeney and Chun 1985; Galinsky 1988; Howes et al. 1987; NAEYC 1993; Whitebook et al. 1989).

Quality of Child Care and Parents' Productivity

Linking quality of care and worker productivity, Whitebook (1984) used data from the National Employer Supported Child Care Project to examine the financial advantages to companies when they offer employer supported child care as a benefit to their employees. Employers support child care in a number of ways, by providing on-site child care, contracted care, information and referral, and/or co-payment of child care tuition. With on-site child care (which is becoming more common with large companies), child care provider wages and benefits are usually higher than are found in independent 
(proprietary) centers. Whitebook's study (1984)found that child care staff who are relatively well paid "experience greater satisfaction, have lower rates of turnover and have greater opportunity to create stable and creative environments for children" (17-18).

More important for employers, though, was her finding that:

greater productivity and reduced turnover and absenteeism among employees receiving child care as a benefit were correlated with higher wages and benefits for child care staff. Additionally, higher morale and more successful recruitment among employees were also correlated with better benefit packages for child care staff $(1984,18)$.

In summary, when child care providers (for whatever reason) deliver higher quality care, the parents (whose children are being cared for) experience reduced work-family role strain and, in turn, are more productive employees. Therefore, one of the ways to attack the problem of worker productivity is to ensure that workers with children have high quality child care services available to them. Since quality of care is so dependent on the behavior of the teacher-caregivers, improving their level of compensation would surely be one way to attract and retain quality staff with field specific training. However, as Sheerer and Jorde-Bloom (1990) point out "there is no 'quick fix' to the staffing crisis. Barring a sudden infusion of federal dollars that would allow us to double salaries, we are left with implementing some fundamental changes in the way we conduct business" (12), which brings one back to the issue of leadership.

\section{Implications for Further Research}

The findings of this study point to several other areas for future research. An in- 
depth analysis of the interaction of leadership style, work environment, administrator and staff education and training history (in detail), and staff wages might yield a more detailed picture of the extent to which each of the factors relates to quality. In addition, having teacher-caregivers do SYMLOG ratings on the children in their classes could show a relationship between work environment and the functioning of the groups of children. Numerous studies have been done looking at relatively large numbers of centers. This data yields information about quality factors in general, but not in detail. As each child care center is unique in its organization and staff composition, it seems important to do some in-depth analyses of a few centers that are achieving high quality in caregiving. 


\section{CHAPTER VII}

\section{WORKS CITED}

Atkinson, Alice M. "A Comparison of Mothers' and Providers' Preferences and Evaluations of Day Care Center Services." Child \& Youth Care Quarterly 16 (Spring 1987): 35-47.

Bales, Robert F. SYMLOG: Case Study Kit with Instructions for A Group Self Study. New York: The Free Press, 1980.

Bales, Robert F. and Stephen P. Cohen. SYMLOG: A System for the Multiple Level Qbservation of Groups. New York: The Free Press, 1979.

Belenky, Mary Field, Blythe McVicker Clinchy, Nancy Rule Goldberger, and Jill Mattuck Tarule. Women's Ways of Knowing: The Development of Self, Voice, and Mind. n.p.: Basic Books, 1986.

Berns, Roberta M. Child, Family, Community; Socialization and Support, 3rd ed. Fort Worth, TX: Harcourt Brace Jovanovich College Publishers, 1993.

Blake, R., and Mouton, J. Building a dynamic corporation through grid organization development. Reading, MA: Addison-Wesley, 1969.

Bredekamp, Sue, Ed. Developmentally Appropriate Practice in Early Childhood Programs Serving Children From Birth Through Age 8: Expanded Edition. Washington, DC: NAEYC, 1987.

Bredekamp, Sue and Judith Berby. "Maintaining Quality: Accredited Programs One Year Later." Young Children 43 (November 1987): 13-15.

Bronfenbrenner, Urie. "Forward - Family Support: The Quiet Revolution." in Family Support Programs: Perspectives and Prospects. ed. Sharon L.. Kagan, Douglas R. Powell, Bernice Weissbourd, and Edward F. Zigler. New Haven: Yale University Press, 1987, xi-xvii.

- The Ecology of Human Development: Experiments by Nature and Design. Cambridge, MA: Harvard University Press, 1979.

Burts, Diane C., Craig H. Hart, Rosalind Charlesworth, and Lisa Kirk. "A Comparison of Frequencies of Stress Behaviors Observed in Kindergarten Children in Classrooms with Developmentally Appropriate Versus Developmentally Inappropriate Instructional Practices." Early Childhood Research Quarterly 5 (1990): 407-423. 
Children's Defense Fund. The State of America's Children. Washington, DC:Children's Defense Fund, 1996.

Cost, Quality, and Outcomes Study Team. Cost, Quality and Child Qutcomes in Child Care Centers: Executive Summary. Denver: Economic Department, University of Colorado at Denver, April 1995.

Cost, Quality, and Outcomes Study Team. "Cost, Quality, and Child Outcomes in Child Care Centers: Key Findings and Recommendations." Young Children 50 (May 1995): 40-44.

Cotton Kathleen, and Nancy Faires Conklin. Research on Early Childhood Education: Topical Synthesis \#3. Portland, Oregon: Northwest Regional Educational Laboratory, 1989.

Crouter, Ann C. "Spillover from Family to Work: The Neglected Side of the Work-Family Interface." Human Relations 37 (1984): 425-442.

Drucker, Peter F. The New Realities. New York: Harper and Row, Publishers, 1989.

Emlen, Arthur, C. and Eunice L. Watson. Matchmaking In Neighborhood Day Care: A Descriptive Study of the Day Care Neighbor Service. Corvallis, OR: Oregon State University, 1971.

Endsley, Richard C. and Marilyn R. Bradbard. "Dissatisfaction with Previous Child Care Among Current Users of Proprietary Center Care." Child \& Youth Care Quarterly 16 (Winter 1987): 249-262.

Fagot, Beverly I. "Variations in Density: Effect on Task and Social Behaviors of Preschool Children." Developmental Psychology 13 (March 1977): 166-167.

Feeney, Stephanie and Robyn Chun. "Effective Teachers of Young Children." Young Children 41 (November 1985): 47-52.

Floge, Liliane. "The Dynamics of Child-care Use and Some Implications for Women's Employment." Journal of Marriage and the Family 47 (February 1985): 143-154.

Francis, Dave and Don Young. Improving Work Groups: A Practical Manual for Team Building. San Diego: University Associates, Inc., 1979.

Galinsky, Ellen. "Parents and Teacher-Caregivers: Sources of Tension, Sources of Support." Young Children 43 (March 1988): 4-12. 
. "The Staffing Crisis." Young Children 44 (January 1989): 2-4.

"Why Are Some Parent/Teacher Partnerships Clouded With Difficulties?" Young Children 45 (July 1990): 2-3; 38-39.

Garreau, Joel. "Sneezin, wheezin, fevers and flu - that's why SICK DAYS are made for you!" The Qregonian, 19 April 1993, sec. C: 1-2.

Getzels, J., and Guba, E.G. "Social behavior as an administrative process." The Scheol Review 65 (11957): 423-441.

Giammatteo, M.C. Training package for a model city staff. Field paper no. 15. Portland, OR: Northwest Regional Educational Laboratory, 1975.

Gifford, Robert, Environmental Psychology: Principles and Practice. Boston: Allyn and Bacon, Inc., 1987.

Gilligan, Carol. In A Different Voice: Psychological Theory and Women's Development. Cambridge, MA: Harvard University Press, 1982.

Glossop, Robert G. "Bronfenbrenner's Ecology of Human Development: A Reappreciation." in Ecological Research with Children and Families: From Concepts to Methodology, ed. Alan R. Pence, 1-15, New York: Teachers College Press, 1988.

Goetz, Elizabeth M., Ann P. Turnbull, and Marion O'Brian. "Helping Parents Work and Raise Children." Day Care \& Early Education 11 (Summer 1984): 31-36.

Gould, Nora Palmer. "Caregivers in Day Care: Who Are They?" Day Care and Early Education 10 (Summer 1983): 17-21.

Halpern, Robert. "Major Social and Demographic Trends Affecting Young Families: Implications for Early Childhood Care and Education." Young Children 42 (September 1987): 34-40.

Harms, Thelma, and Richard M. Clifford. Early Childhood Environment Rating Scale. New York: Teacher's College Press, 1980.

Heffron, Florence. Qrganization Theory and Public Organizations: The Political Connection. Englewood Cliffs, N.J.: Prentice Hall, 1989.

Helgesen, Sally. The Female Advantage: Women's Ways of Leadership. New York: Doubleday, 1990. 
Hersey, P., and Blanchard, K. Management of organizational behavior. Englewood Cliffs, NJ: Prentice Hall, 1982.

Hillner, Kenneth P. History and Systems of Modern Psychology: A Conceptual Approach. New York: Gardner Press, Inc., 1984.

Hofferth, Sandra L. "What is the Demand for and Supply of Child Care in the United States?" Young Children 44 (July 1989): 28-33.

Howes, Carollee, Willa Pettygrove and March Whitebook. "Cost and Quality in Child Care: Reality and Myth." Child Care Information Exchange (November 1987): 4042.

Hymes, James L., Jr. Early Childhood Education Living History Interviews. Carmel, CA: Hacienda Press, 1978-79.

Book 1: Beginnings, 1978.

Book 2: Care of the Children of Working Mothers, 1978.

Book 3: Reaching Large Numbers of Children, 1979.

Hyson, Marion C., Kathy Hirsh-Pasek, and Leslie Rescorla. "The Classroom Practices Inventory: An Observation Instrument Based on NAEYC's Guidelines for Developmentally Appropriate Practices for 4- and 5-Year-Old Children." Early Childhood Research Quarterly 5 (1990): 475-494.

Jorde-Bloom, Paula. A Great Place To Work: Improving Conditions for Staff in Young Children's Programs. Washington, D.C.: National Association for the Education of Young Children, 1988.

- Measuring Work Attitudes in the Early Childhood Setting. Evanston, Illinois: National-Louis University, 1989.

. "Organizational Climate in Child Care Settings." In Educational Environments, ed. B.J. Fraser and H. Walberg, 161-175, New York: Pergamon Press, 1991.

Jorde-Bloom, Paula and Marilyn Sheerer. "The Effect of LeadershipTraining on Child Care Program Quality." Early Childhood Research Quarterly 7 (1992): 579-594.

Jorde-Bloom, Paula; Marilyn Sheerer, and Joan Britz. "Leadership Style Assessment Tool." Child Care Information Exchange (October 1991): 12-15. 
Jones, Elizabeth. "Introduction: Growing Teachers." In Growing Teachers: Partnerships in Staff Development. ed. Elizabeth Jones, xii-xxiii. Washington, D.C.: National Association for the Education of Young Children, 1993.

Jones, Elizabeth, and Elizabeth Prescott. Dimensions of Teaching-Learning Environments II: Focus on Day Care. Pasadena, CA: Pacific Oaks College, 1978 .

Kagan, Sharon Lynn, and James W. Newton. "For-Profit and Nonprofit Child Care: Similarities and Differences." Young Children 45 (November 1989): 4-10.

Kanter, Rosabeth Moss and Diane Fassel. "Appendix II: Some Observations of Women's Leadership in Organizations." In Men and Women of the Corporation. ed. Rosabeth Moss Kanter, 299-303. New York: Basic Books, Inc., 1977.

Katz, Lillian G., Demetra Evangelou, and Jeanette Allison Hartman. The Case for Mixed Age Grouping in Early Childhood Education. Washington, D.C.: National Association for the Education of Young Children, 1990.

Kelly, Robert F. and Patricia Voydanoff. "Work/Family Role Strain Among Employed Parents." Family Relations 34 (July 1985): 367-374.

Keyton, Joann and Jeff Springston. "Redefining Cohesiveness in Groups." Small Group Research 21 (May 1990): 234-254.

Krupp, Steven. "The Quality Circle Phenomenon." In The Lewin Legacy: Field Theory in Current Practice. ed. Eugene Stivers and Susan Wheelan, 147-157. Berlin: Springer-Verlag, 1986.

Larson, Carl E. and Frank M. J. LaFasto. Teamwork: What must ge right/What can ge wrong. Newbury Park: Sage Publications, 1989.

Lein, Laura. "Parental Evaluation of Child Care Alternatives." The Urban and Social Change Review 12 (Winter 1979): 11-16.

Lenz, Elinor and Barbara Myerhoff. The Feminization of America: How Women's Values Are Changing Our Public and Private Lives. Los Angeles: Jeremy P. Tarcher, Inc., 1985.

Lewin, Kurt. Field Theory in Social Science, ed. Dorwin Cartwright. New York: Harper and Row, Publishers, 1951.

Lipsky, Michael. Street-Level Bureaucracy: Dilemmas of the Individual in Public Services. New York: Russell Sage Foundation, 1980. 
Lunneborg, Patricia. Women Changing Work. New York: Bergin and Garvey, Pub., 1990.

Marshall, Catherine and Gretchen B. Rossman. Designing Qualitative Research. Newbury Park: Sage Publications, 1989.

Maus, Heinz. A Short History of Sociology. London: Routledge \& Kegan Paul, 1971.

Maxcy, Spencer J. Educational Leadership: A Critical Pragmatic Perspective Critical Studies in Education and Culture Series, ed. Henry A. Giroux and Paulo Freire. New York: Bergin and Garvey, 1991.

NAEYC (National Association for the Education of Young Children). Accreditation Criteria and Procedures: Revised Edition - 1991. Washington, D.C.: NAEYC, 1991.

NAEYC. "NAEYC Position Statement on Guidelines for Compensation of Early Childhood Professionals." Young Children 46 (November 1990): 30-32

NAEYC. "The Effects of Group Size, Ratios, and Staff Training on Child Care Quality." Young Children 48 (January 1993): 65-67.

Neugebauer, Roger. "An Up-to-Date Look at the Supply of Child Care." Child Care Information Exchange (January/February 1992): 14-18.

Nock, Steven L. and Paul William Kingston. "The Family Work Day." Journal of Marriage and the Family 46 (May 1984): 333-343.

Oregon Child Care Resource and Referral Network. "Child Care Definitions." Chap. in Child Care Works...When We Work Together: Resource Guide. Salem, Oregon: Oregon Child Care Resource and Referral Network, n.d.

Pearman, William A., and Robert Rotz. The Province of Sociology: Selected Profiles. Chicago: Nelson-Hall, 1981.

Pence, Alan R. "Introduction." in Ecological Research with Children and Families: From Concepts to Methodology, ed. Alan R. Pence, xxi-xxvi. New York: Teachers College Press, 1988.

Phyfe-Perkins, Elizabeth. "Children's Behavior in Preschool Settings - A Review of Research Concerning the Influence of the Physical Environment." In Current. Tepics in Early Childheod Education Vol, III. ed. Lillian G. Katz, Norwood, New Jersey: Ablex Publishing Corp, 1980, 91-125. 
Prescott, Elizabeth, and Elizabeth Jones. Day CAre as a Child-Rearing Environment, Vol. II. Washington, D.C.: National Association for the Education of Young Children, 1972.

Reddin, W.J. Managerial Effectiveness New York: McGraw-Hill, 1970.

Rogers, Dwight L., Cathleen Boggs Waller, and Marilyn Sheerer Perrin. "Learning More About What Makes a Good Teacher Good Through Collaborative Research in the Classroom." Young Children 42 (May 1987): 34-39.

Ruddick, Sara. Maternal Thinking: Toward a Politics of Peace. New York: Ballantine Books, 1989.

Ruopp, Richard, Jeffrey Travers, Frederic Glantz, and Craig Coelen. Children at the Center: Summary Findings and Their Implications. Cambridge, MA: Abt Associates, Inc., 1979.

Schaef, Anne Wilson and Diane Fassel. The Addictive Organization. San Francisco, CA: Harper and Row, 1988.

Schon, Donald A. "Leadership as Reflection-in-Action." in Leadership and Organizational Culture: New Perspectives on Administrative Theory and Practice, Thomas J. Sergiovanni and John E. Corbally, ed. Urbana Illinois: University of Illinois Press, 1986, 36-63.

Schweinhart, Lawrence J. and David P. Weikart. "Changed Lives, Significant Benefits: The High/Scope Perry Preschool Project to Date." in Sources: Notable Selections in Early Childhood Education, Karen Menke Paciorek and Joyce Huth Munro, ed. Guilford, Conn.: Dushkin Publishing Group, 1996.

Schweinhart, Lawrence J., David P. Weikart, and Mary B. Larner. "Consequences of Three Preschool Models through Age 15." Early Childhood Research Quarterly 1 (1986): 15-45.

Sheerer, Marilyn and Paula Jorde-Bloom. "The Ongoing Challenge:Attracting and Retaining Quality Staff." Child Care Information Exchange (April 1990): 11-16.

Smith, Allen N. Final Report of the National Day Care Study: Children at the CenterExecutive Summary. Cambridge, MA: Abt Associates, Inc., 1979. 
Snider, Margaret Hardy and Victoria R. Fu. "The Effects of Specialized Education and Job Experience on Early Childhood Teachers' Knowledge of Developmentally Appropriate Practice." Early Childhood Research Quarterly \$ (1990) 69-78.

Stivers, Eugene and Susan Wheeler, ed. "An Overall View." in The Lewin Legacy: Field Theory in Current Practice. Berlin: Springer-Verlag, 1986, xi-xiv.

Tagiuri, Renato. "The Concept of Organizational Climate." in Organizational Climate: Explorations of a Concept, Renato Tagiuri and George H. Litwin, ed. Boston: Harvard University, 1968.

Townley, Kimberly F., Kathy R. Thornburg, and George W. Wise.। "Burnout: Causes, Consequences, and Cures." Child Care Information Exchange (March 1986): 31 34.

Vaill, Peter B. "The Purposing of High-performing Systems." in Leadership and Organizational Culture: New Perspectives on Administrative Theory and Practice, Thomas J. Sergiovanni and John E. Corbally, ed. Urbana Illinois: University of Illinois Press, 1986, 85-104.

WAEYC (Washington Association for the Education of Young Children). "National Child Care Staffing Study." WAEYC News (June 1993): 1,

Weikart, David P. Quality Preschool Programs: A Long-Term Social Investment Occasional Paper Number Five Ford Foundation Project on Social Welfare and the American Future. New York: Ford Foundation, 1989.

Weiten, Wayne. Psychology: Themes and Variations, 3rd ed. Pacific Grove, CA: Brooks/Cole Publishing Co., 1995.

Wheatley, Margaret J. Leadership and the New Science: Iearning About Organization from an Orderly Universe. San Francisco: Berrett-Koehler Publishers, Inc., 1992.

Whitebook, Marcy. "The Teacher Shortage: A Professional Precipice." Young Children 41 (March 1986): 10-11.

. "What Can Employer Supported Programs Do for Child Care Staff?" Day Care and Early Education 11 (Summer 1984): 16-19.

Whitebook, Marcy and Gerri Ginsburg. "Warning: Child Care Work May Be Hazardous to Your Health." Day Care and Early Education 11 (Winter 1983): 22-27. 
Whitebook, Marcy and Robert C. Granger. "Mommy, who's going to be my teacher today?" Young Children 44 (May 1989): 11-14.

Whitebook, Marcy, Carolee Howes, Deborah Phillips, and Caro Pemberton. "Who Cares? Child Care Teachers and Quality of Care in America." Young Children 45 (November 1989): 41.45 .

Willer, Barbara. "Quality or Affordability: Trade-Offs for Early Childhood Programs?" Young Children 42 (September 1987): 41-43.

Willer, Barbara, Sandra L. Hofferth, Ellen Eliason Kisker, Patricia Divine-Hawkins, Elizabeth Farquhar, Frederic B. Glantz. The Demand and Supply of Child Care in 1990: Joint findings from The National Child Care Survey 1990 and A Profile of Child Care Settings. Washington, D.C.: National Association for the Education of Young Children, 1991.

Yanoff, Jay M,. and William E. Bryan. "Utilizing Lewinian Principles for an Institutional Planning Process Within a Medical School." In The Lewin Legacy: Field Theory in Current Practice. ed. Eugene Stivers and Susan Wheeler, 171-178. Berlin: Springer Verlag, 1986. 


\section{CHAPTER VIII}

\section{APPENDIX}

\section{Contents}

Letter to Informants for Center Sample Selection....................208

Rating Form for Center Sample Selection.............................210

Letter of Introduction of the Study to Participants...................211

Informed Consent Forms for Adults.....................................212

Interview Questions for Administrator...................................214

SYMLOG Specific Behavior Descriptions.............................216

Leadership Style Assessment Tool........................................217

Classroom Practices Inventory...........................................220 


\title{
CONFIDENTIAL EVALUATION OF CHILD CARE CENTERS
}

\author{
FOR DISSERTATION RESEARCH
}

BY

KATHY A. BOBULA

DOCTORAL STUDENT

URBAN STUDIES

PORTLAND STATE UNIVERSITY

Dear Early Childhood/Child Care Professional:

I am a doctoral candidate in the Urban Studies graduate program at Portland State University and am doing my dissertation research on the topic: "Characteristics of Administrator's Leadership Style in Quality Child Care Centers." I will be doing case studies of four high quality child care centers in the Portland/Vancouver area in an effort to see what characterizes the way administrators of these centers carry out their role as a leader and creator of a work environment. I am contacting you for assistance in the selection of the centers to be included.

Your role in this study is as an "informant in the field" who is familiar with child care centers in your community. In selecting the centers to be included in this study, all centers must be licensed by their respective state, and accredited by the National Academy of Early Childhood Programs (or in the process of accreditation or reaccreditation) or have been cited for "excellence" by a confidential informant in the Early Childhood field. This however, yields more centers than I need, so I am trying to narrow the list down to the "best" centers - those that are known for excellence in child care. I am asking you for your judgement on what centers represent "excellence" in quality, i.e., which ones are the "top?"

Please evaluate the following centers as indicated. Answer each question to the best of your knowledge. If you do not know an answer, select "don't know" for your answer. I have enclosed one blank form for you to add a center to the list and rate it, if you wish.

Your identity in this study will remain confidential and you will be referred to by a numerical code (ex. Rater \#7). Records that link your name to your answers will be kept 
separate from the actual data collected.

I will average all the ratings I receive and choose the top 4 centers, selecting 2-3 from Multnomah County and 1-2 from Clark County. I will then ask these centers if they will participate in the study. If a center declines, I will go to the next on the list.

A self-addressed, stamped envelope is enclosed for your convenience. I truly appreciate your assistance in this part of my study.

Sincerely,

Kathy A. Bobula, Instructor

Dept. of Early Childhood Education and Psychology

Clark College

1800 E. McLoughlin Blvd.

Vancouver, WA 98663 
SAMPLE SELECTION FOR THE RESEARCH OF KATHY A. BOBULA

Center:

Address:

In terms of your knowledge (both direct and indirect) about this center, HOW WOULD YOU RANK IT in terms of each of the following:

1. PROGRAM FOR THE CHILDREN

$\begin{array}{ccccc}4 & 3 & 2 & 1 & 0 \\ \text { top 5\% } & \text { top 10\% } & \text { top 25\% } & \begin{array}{l}\text { above don't know } \\ \text { average }\end{array}\end{array}$

2. QUALITY AND EFFECTIVENESS OF THE STAFF

$\begin{array}{ccccc}4 & 3 & 2 & 1 & 0 \\ \text { top } 5 \% & \text { top } 10 \% & \text { top 25\% } & \begin{array}{l}\text { above don't know } \\ \text { average }\end{array}\end{array}$

3. LEADERSHIP QUALITIES OF THE ADMINISTRATOR

$\begin{array}{ccccc}4 & 3 & 2 & 1 & 0 \\ \text { top } 5 \% & \text { top } 10 \% & \text { top } 25 \% & \begin{array}{l}\text { above don't know } \\ \text { average }\end{array}\end{array}$

4. PHYSICAL ENVIRONMENT AND EQUIPMENT

$\begin{array}{ccccc}4 & 3 & 2 & 1 & 0 \\ \text { top } 5 \% & \text { top } 10 \% & \text { top 25\% } & \begin{array}{l}\text { above don't know } \\ \text { average }\end{array}\end{array}$

5. PARENT RELATIONS AND INVOLVEMENT

$\begin{array}{ccccc}4 & 3 & 2 & 1 & 0 \\ \text { top 5\% } & \text { top 10\% } & \text { top 25\% } & \begin{array}{l}\text { above don't know } \\ \text { average }\end{array}\end{array}$

6. WORK ENVIRONMENT/ORGANIZATIONAL CLIMATE

$\begin{array}{cccc}4 & 3 & 2 & 1 \\ \text { top } 5 \% & \text { top } 10 \% & \text { top 25\% } & \begin{array}{l}\text { above don't know } \\ \text { average }\end{array}\end{array}$


Dear Child Care Center Employee:

Thank you for agreeing to participate in this study which asks, "What makes great child care so good?" Your center was chosen as one of the best child care centers in the Portland-Vancouver metropolitan area.

Please fill out the questionnaires enclosed in this envelope as completely as you can. Return them in the envelope to the area designated in your center.

However, if there are any questions that you do not wish to answer, you may leave them blank. If at any time you choose not to participate, you may simply return the uncompleted forms in the envelope to area designated in your center.

Should you have any questions on filling out the forms, feel free to call me at my home (503) 282-5472.

Once again, that you for your/participation.

Kathy A. Bobula

Doctoral Candidate

Instructor of Early Childhood

Portland State University

Education

School of Urban Studies

Clark College, Vancouver WA 


\title{
INFORMED CONSENT FORM
}

\author{
FOR ADULTS
}

$\mathrm{I}$, agree to take part in this research project on the role of management style on the quality of care delivered in child care.

I understand that the study involves my filling out several questionnaires and behavior description lists concerning the functioning of people working here in this child care center and one feedback session after the study is completed.

I understand that information about my salary, benefits, length of employment, and education/training will be made available to the researcher. This information and my individual responses on questionnaires will be presented in an aggregate form, and my individual information and responses will remain confidential.

Katherine Bobula has told me that the purpose of the study is to learn how the administrator of a child care center influences the way staff work with the children.

I may receive a direct benefit from taking part in this study during the feedback sessions where a discussion of how my center works will be explored. I also understand that this study may help to increase knowledge that may/help others in the future.

Katherine Bobula has offered to answer any questions I have about the study and what I am expected to do.

She has promised that all information I give will be kept confidential to the extent permitted by law, and that the names of all people and the center names in the study will 
be kept confidential. Names of all participants will not be used, instead a numeric code will be used.

I understand that I do not have to take part in this study, that I may withdraw at any time, that I may refuse to answer any questions, and that not taking part will not affect my relationship with my current employer or with Portland State University.

I have read and understand the above information and agree to take part in this study.

Date: Signature:

If you have concerns or questions about this study, please contact the Chair of the Human Subjects Research Review Committee, Office of Grants and Contracts, 105 Neuberger Hall, Portland State University, 503/725-3417. 


\section{QUESTIONS FOR INTERVIEW OF ADMINISTRATOR}

Name of Administrator:

Center:

Date:

How long in this position?

1. Describe your style of administration.

2. Tell me how decisions are made, regarding:

staffing and scheduling

budgeting

children's program

physical facility

1993

Sex: F M 
3. How do you organize your time and responsibilities? What are your priorities?

4. How do you maintain quality caregiving by the staff?

5. How do you balance your job here in the child care center and your life outside?

6. How would you respond if one of the teachers in the center seemed preoccupied at work, was showing signs of stress, and began arriving late to work frequently?

7. How do you work with parents? How do you expect staff members to work/interact with parents? 


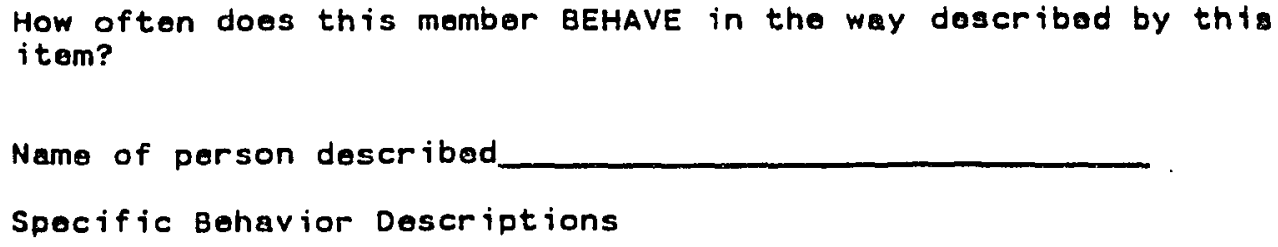

U ... seemed active, dominant, talkative . not otten . . . sometimes ... otten UP . . . seemed extroverted, outgoing, positive ........ not often . . sometimes . . often UPF .. acted as a purposeful democratic leader ........ not otten . . sometimes . . often UF . . acted as an assartive business-like manager . . . . . not often . . sometimes . . often UNF . . seemed authoritarian, controlling, disappreving . . . not often . . . sometimes . . often UN . . . seemed domineering, tough-minded, powertul . . . not often . . sometimes . . otten UNB . . seemed provocative, egocentric, showed off . . . . . not often . . sometimes . . o otten UB ... joked around, seemed expressive, dramatic ..... . not often . . sometimes . . often UPB .. seemed entertaining, sociable, smiling warm . . . . not otten . . sometimes . . often P.... seemed friendly, equalitarian ............ not otten . . sometimes . . often PF ... showed agreement, worked cooperatively. . . . . . not often . . sometimes . . otten F . . . seemed analytical, task-oriented, problem solving . . not often . . sometimes . . otten NF . . seemed legalistic, insistent, had to be right ..... not often . . sometimes . . often N . . . s showed disagreement, seemed to be negativistic. . not often . . sometimes . . often NB . . seemed irritable, cynical, uncooperative . . . . . . . not often . . sometimes . . otten B .... showed feelings and emotions. . . . . . . . . not often . . sometimes . . often PB ... seemed aftectionate, likeable, fun to be with.... . not otten . . sometimes . . often OP ... seemed to look up to others, showed trust ...... not often . . sometimes . . otten OPF .. seemed gentle, willing to accept responsibility ... not often . . sometimes . . otten DF . . s seemed to work submissively . . . . . . . . . not often . . sometimes . . often DNF . . seamed to be self punisning, worked too hard . . . . not often . . . sometimes . . often DN . . seemed depressed, sad, resentful . . . . . . . . not often . . sometimes . . otten DNB .. seemed alienated, withdrew trom task and group . . not often . . sometimes . . otten DB . . seemed atraid to try, doubttul of ability . . . . . . . not often . . sometimes . . often OPB .. seemed quiet but happy just to be with others . . . . not otten . . sometimes . . often D.... seemed passive, introverted, untatkative ....... not often . . sometimes . . otten 


\section{LEADERSHIP STYIF ASSESSMENT ${ }^{\prime}$}

Name of Director:

PART I. Place a check | | in front of the statement that most nearly reflects your director's leadership style in different situations. (Check only one response in each group.)

\section{With respect to planning, my director...}

1. does most of the planning herself by setting goals, objectives, and work schedules for staff to follow. She then works out procedures and responsibilities for stafr to follow.

2. __ does very little planning, either by herself or with the stafl. She tells the staff she has confidence in them to carry out their jobs in a responsible way.

3. gets staff members together to assess center-wide problems and discuss ideas and strategies for improvement. Together they set up goals and objectives and establish individual responsibilities.

With respect to work assignments and the day-to-day operation of the center, my director...

4. checks with staft regularly to see if they are content and if they have the things they need. She does not see the necessity of precise job descriptions, preferring instead to let the staff determine the scope and nature of their jobs.

5. ___ is flexible in adapting job descriptions and changing work assignments as needed. Updates center policies and procedures depending on the needs of the staff, parents, children, and board of directors (if applicable).

6. tends to go by the book. Expects stafl to adhere to written job descriptions. Follows policies and procedures precisely.

With respect to leadership philosophy, my director...

7. ___ tends to emphasize people's well-being, helieving that happy workers will be productive workers.

8. __ tends to emphasize hard work and a job well done. We are a results-oriented progran.

9. ___ tends to emphasize both what we do and what we need as people.

1 Jorde-Bloom, Paula, Marilyn Sheerer, and Joan Britz. "Leadership Style Assessment Tool." Child Care Information Exchange. (September/October 1991): 12-15. 
During meetings, my director...

10. K__ keeps focused on the agenda and the topics that need to be covered.

11. focuses on each individual's feeling and helps people express their emotional reactions to an issue.

12. focuses on differing positions people take and how they deal with each other.

\section{The primary goal of my director is...}

13. ____ to meet the needs of parents and children while providing a healthy work climate for staff.

14. _ to keep the center running efficiently.

15. to help staff find fulfillment.

In evaluating the staff's performance, my director...

16. attempts to assess how each individual's performance has contributed to center-wide achievement of goals.

17. makes an assessment of each person's performance and effectiveness according to predetermined established criteria that are applied equally to all staff.

18. allows people to set their own goals and determine performance standards.

My director believes the best way to motivate someone who is not performing up to his/her ability is to...

19. point out to the individual the importance of the job to be done.

20. _try to get to know the individual better in an attempt to understand why the person is not realizing his/her potential.

21. goals. work with the individual to redefine job responsibilities to more effectively contribute to center-wide

My director believes it is her iole to...

22. ___ make sure that staff members have a solid foundation of knowledge and skill that will help them accomplish center goals.

23. litelp people learn to work effectively in groups to accomplish group goals.

24. help individuals become responsible for their own education and effectiveness, and take the first step toward realizing their potential. 


\section{SCORING SHEET FOR LEADERSHIP STYLE ASSESSMENT TOOL}

To score Part I, tally the responses by noting with a mark each time staff checked a particular response:

1.

2.

3.

4.

5.

6.

7.

8.
9.

10.

11.

12.

13.

14.

15.

16.
17.

18.

19.

20.

21.

22.

23.

24.

Now total the marks for the following responses:

Task-oriented: $1,6,8,10,14,17,19,22$

Total $=$

Achieving center goals is most important in this leadership style. Strong concern for high

perfornance and accomplishing tasks. Emphasis is on planning, directing, following procedures, and applying uniform standards and expectations for all. This director may be viewed as too structured, bureaucratic, and inflexible.

People-oriented: $2,4,7,11,15,18,20,24$ Total $=$

Achieving harmonious group relations is foremost in this leadership style. Strong emphasis on maintaining comfortable, friendly, and satisfying working conditions. Allows staff to exercise control and be self-directed with minimal intrusion of center-wide policies and procedures. Staff working in centers with this style of leadership may complain about the lack of order and coordination.

Transactional: $3,5,9,12,13,16,21,23$

Total $=$

Achieving both center goals and maintaining high morale is important in this leadership style. This director is flexible and fair, recognizing that different situations may require a different emphasis on center-wide needs or individual needs. 


\section{CLASSROOM PRACTICES INVENTORY}

CENTER TEACHER

DATE 19 TIME from to

AGES OF CHILDREN GROUP SIZE

OBSERVER

Rating Scale:

$1=$ not at all like this classroom

2 = very little like this classroom

$3=$ somewhat like this classroom

$4=$ much like this classroom

$S=$ very much like this classroom

\section{$\underline{\text { ITFMS }}$}

\section{Part 1: Program/Activity Focus}

1.Children select their own activities from a variety of learning areas the teacher prepares, including dramatic play, blocks, science, math, games and puzzles, books, recordings, art, and music.

1

2

3

not at all

very little

somewhat

4

much like

very much

2.Large group, teacher directed instruction is used most of the time. Children are doing the same things at the same time.

1

not at all
2

very little
3

somewhat
4

much like
5

very much like 
3.Children are involved in concrete, three-dimensional learning activities, with materials closely related to children's daily life experiences.

$\begin{array}{llllc}1 & 2 & 3 & 4 & 5 \\ \text { not at all } & \text { very little } & \text { somewhat } & \text { much like } & \text { very much like }\end{array}$

4.The teacher tells the children exactly what they will do and when. The teacher expects the children to follow her/his plans.

$\begin{array}{llllc}1 & 2 & 3 & 4 & 5 \\ \text { not at all } & \text { very little } & \text { somewhat } & \text { much like } & \text { very much like }\end{array}$

5. Children are physically active in the classroom, choosing from activities the teacher has set up and spontaneously initiating many of their own activities.

$\begin{array}{llllc}1 & 2 & 3 & 4 & 5 \\ \text { not at all } & \text { very little } & \text { somewhat } & \text { much like } & \text { very much like }\end{array}$

6. Children work individually or in small, child-chosen groups most of the time.

Different children are doing different things.

1

5

not at all
2

very little
3

somewhat much like
4

very much like 
Children use workbooks, ditto sheets, flashcards, and other abstract or two-dimensional learning materials.

$\begin{array}{llllc}1 & 2 & 3 & 4 & 5 \\ \text { not at all } & \text { very little } & \text { somewhat } & \text { much like } & \text { very much like }\end{array}$

8. Teachers ask questions that encourage children to give more than one right answer.

$\begin{array}{llllc}1 & 2 & 3 & 4 & 5 \\ \text { not at all } & \text { very little } & \text { somewhat } & \text { much like } & \text { very much like }\end{array}$

9.Teachers expect children to sit down, watch, be quiet, and listen, or do paper and pencil tasks for major periods of time.

$\begin{array}{llllc}1 & 2 & 3 & 4 & 5 \\ \text { not at all } & \text { very little } & \text { somewhat } & \text { much like } & \text { very much like }\end{array}$

10.Reading and writing instruction emphasizes direct teaching of letter recognition, reciting the alphabet. coloring within the lines, and being instructed in the correct formation of letters.

$\begin{array}{llllc}1 & 2 & 3 & & \\ \text { not at all } & \text { very little } & \text { somewhat } & \text { much like } & 5 \\ \text { very much like }\end{array}$


11.Teachers use activities such as block building, measuring ingredients for cooking, waodworking, and drawing to help children learn concepts in math, science, and social studies.

$\begin{array}{llllc}1 & 2 & 3 & 4 & 5 \\ \text { not at all } & \text { very little } & \text { somewhat } & \text { much like } & \text { very much like }\end{array}$

12.Children have planned lessons in writing with pencils, coloring predrawn forms, tracing, or correct use of scissors.

$\begin{array}{llllc}1 & 2 & 3 & 4 & 5 \\ \text { not at all } & \text { very little } & \text { somewhat } & \text { much like } & \text { very much like }\end{array}$

13.Children use a variety of art media, including easel and finger painting, and clay, in ways of their choosing.

$\begin{array}{llllc}1 & 2 & 3 & 4 & 5 \\ \text { not at all } & \text { very little } & \text { somewhat } & \text { much like } & \text { very much like }\end{array}$


14.Teachers expect children to respond correctly with one right answer. Memorization and drill are emphasized.

$\begin{array}{llllc}1 & 2 & 3 & 4 & 5 \\ \text { not at all } & \text { very little } & \text { somewhat } & \text { much like } & \text { very much like }\end{array}$

15. When teachers try to get children involved in activities, they do so by stimulating children's natural curiosity and interest.
1
2
3
not at all
very little
somewhat
4 much like
5
very much like

16.The classroom environment encourages children to listen to and read stories, dictate stories, notice print in use in the classroom, engage in dramatic play, experiment with writing by drawing, copying, and inventing their own spelling.

$\begin{array}{llllc}1 & 2 & 3 & 4 & 5 \\ \text { not at all } & \text { very little } & \text { somewhat } & \text { much like } & \text { very much like }\end{array}$

17.Art projects involve copying an adult-made model, coloring predrawn forms, finishing a project the teacher has started, or following other adult directions.

$\begin{array}{lllcc}1 & 2 & 3 & 4 & 5 \\ \text { not at all } & \text { very little } & \text { somewhat } & \text { much like } & \text { very much like }\end{array}$


18.Separate times or periods are set aside to learn material in specific content areas such as math, science, or social studies.

$\begin{array}{llllc}1 & 2 & 3 & 4 & 5 \\ \text { not at all } & \text { very little } & \text { somewhat } & \text { much like } & \text { very much like }\end{array}$

19.Children have daily opportunities to use pegboards, puzzles, legos, markers, scissors or other similar materials in ways the children choose.

$\begin{array}{llllc}1 & 2 & 3 & 4 & 5 \\ \text { not at all } & \text { very little } & \text { somewhat } & \text { much like } & \text { very much like }\end{array}$

When teachers try to get children involved in activities, they do so by requiring their participation, giving rewards, disapproving of failure to participate, etc.

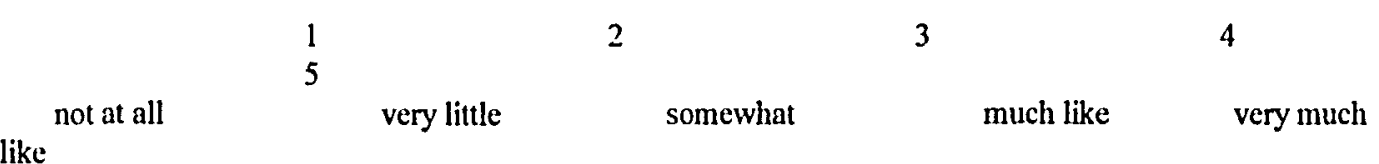

NOTES:

CONTINUE FOR PART 2: EMOTIONAL CLIMATE 


\section{Part 2: Emotional Climate}

1.Teachers show affection by smiling, touching, holding, and speaking to children at their eye level throughout the day, but especially at arrival and departure times.

$\begin{array}{llllc}1 & 2 & 3 & 4 & 5 \\ \text { not at all } & \text { very little } & \text { somewhat } & \text { much like } & \text { very much like }\end{array}$

2.The sound of the environment is marked by pleasant conversation, spontaneous laughter, and exclamations of excitement.

$\begin{array}{llllc}1 & 2 & 3 & 4 & 5 \\ \text { not at all } & \text { very little } & \text { somewhat } & \text { much like } & \text { very much like }\end{array}$

3. Teachers use competition, comparison, or criticism as guidance or discipline techniques.

$\begin{array}{lllcc}1 & 2 & 3 & 4 / & 5 \\ \text { not at all } & \text { very little } & \text { somewhat } & \text { much like } & \text { very much like }\end{array}$

4.Teachers talk about feelings. They encourage children to put their emotions (positive and negative) and ideas into words.

$\begin{array}{llllc}1 & 2 & 3 & 4 & 5 \\ \text { not at all } & \text { very little } & \text { somewhat } & \text { much like } & \text { very much like }\end{array}$


5.The sound of the environment is characterized either by harsh noise or enforced quiet.

$\begin{array}{llllc}1 & 2 & 3 & 4 & 5 \\ \text { not at all } & \text { very little } & \text { somewhat } & \text { much like } & \text { very much like }\end{array}$

6. Teachers use redirection, positive reinforcement, and encouragement as guidance or discipline techniques.

$\begin{array}{llllc}1 & 2 & 3 & 4 & 5 \\ \text { not at all } & \text { very little } & \text { somewhat } & \text { much like } & \text { very much like }\end{array}$

NOTES: 